\title{
Soluble oligomeric Abeta42 affects microglia activation and mitochondrial respiration
}

\author{
Cong Tan
}

Follow this and additional works at: https://researchrepository.wvu.edu/etd

\section{Recommended Citation}

Tan, Cong, "Soluble oligomeric Abeta42 affects microglia activation and mitochondrial respiration" (2015). Graduate Theses, Dissertations, and Problem Reports. 6769.

https://researchrepository.wvu.edu/etd/6769

This Thesis is protected by copyright and/or related rights. It has been brought to you by the The Research Repository @ WVU with permission from the rights-holder(s). You are free to use this Thesis in any way that is permitted by the copyright and related rights legislation that applies to your use. For other uses you must obtain permission from the rights-holder(s) directly, unless additional rights are indicated by a Creative Commons license in the record and/ or on the work itself. This Thesis has been accepted for inclusion in WVU Graduate Theses, Dissertations, and Problem Reports collection by an authorized administrator of The Research Repository @ WVU. For more information, please contact researchrepository@mail.wvu.edu. 


\title{
SOLUBLE OLIGOMERIC ABETA42 AFFECTS MICROGLIA ACTIVATION AND MITOCHONDRIAL RESPIRATION
}

\author{
Cong Tan
}
Thesis / Dissertation submitted to the School of Medicine at West Virginia University

in partial fulfillment of the requirements for the degree of

\author{
Master of Science \\ in \\ Biomedical Sciences
James W. Simpkins, Chair
Jason D. Huber
Paola Pergami
James P. O'Callaghan \\ Department of Physiology and Pharmacology \\ Morgantown, West Virginia \\ 2015
}

Keywords: Alzheimer's disease, Amyloid beta, microglial cell, mitochondrial respiration, glycolysis, microglial polarization, Neuroinflammation, Neuroprotection Copyright 2015 Cong Tan 


\section{Abstract \\ SOLUBLE OLIGOMERIC ABETA42 AFFECTS MICROGLIA ACTIVATION AND MITOCHONDRIAL RESPIRATION}

\section{Cong Tan}

Microglia activation is associated with many neurodegenerative diseases such as Alzheimer's disease (AD). When activated, microglia cells change their morphology and become phagocytic. In the Alzheimer's brain, microglia cells play an important role in scavenging plaquedamaged cells and in clearing $A \beta$ plagues. Soluble oligomeric $A \beta(O A \beta)$ is capable to stimulate microglia activation. In AD brain, microglia cells accumulate around senile plaques as a hallmark of the pathology. Recently, we found that mitochondrial oxidative phosphorylation is affected in a dose-dependent manner in a microglia cell line (C8-B4) and primary rat glia cell. Mitochondrial basal, maximal and spare respiration capacities increase at low concentrations of $\mathrm{OA} \beta$ and then decline at higher concentrations. Flow cytometry for markers of microglial activation (IBA1 upregulation) similarly shows a low dose increase and a high dose decline. In contrast, the oA stimulation does not alter the mitochondrial oxidative phosphorylation in a mouse hippocampal neuronal cell line (HT-22), suggesting a brain cell-specific response to oA 3 .Our experiment results suggest that at low concentrations of $\mathrm{A} A \beta$, which would normally occur in healthy brains, an increased mitochondrial respiration hints that microglia activation responds to mild $\mathrm{OA} \beta$ stimulation. In contract, at higher pathological levels of $\mathrm{OA} \beta$, microglial activation and its associated mitochondrial functions are inhibited which may prevent phagocytosis and allow the accumulation of $A \beta$. 


\section{DEDICATION}

This thesis is dedicated to the best parents in my eyes Yong Tan and Junhua Yu. It is their unconditional love that motivates me to challenge every new task. They have been always with me on each and every stop of my life, providing me never-ending love and strong support whenever I need. 


\section{ACKNOWLEDGMENTS}

The author wishes to give the sincere gratitude to professor Dr. James W. Simpkins who directed this research project, for his invaluable guidance and continuous encouragement.

I wish to express my sincere thanks to Dr. Xuefang Ren, my co-mentor. I am extremely thankful and indebted to her for sharing expertise, and sincere and valuable guidance and encouragement extended to me.

I would like to thank Dr. Sarkar for his help with experience and discussion which inspired me.

I am also grateful to Dr. Liz Engler-Chiurazzi, for providing me with all the necessary suggestions for the research.

I would like to thank Dr. Sujung Jun for her patient help and encouragement.

I take this opportunity to express gratitude to all of the lab members for their help and support.

I also place on record, my sense of gratitude to one and all, who directly or indirectly, have lent their hand during my research.

I wish to acknowledge West Virginia University for providing me such a precious opportunity. 


\section{Table of Contents}

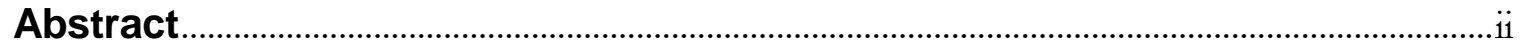

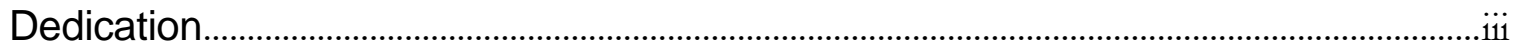

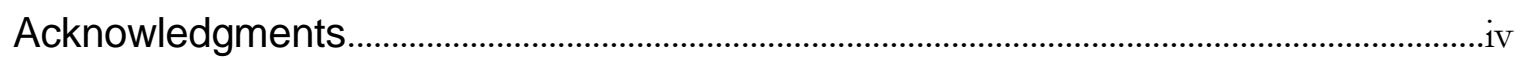

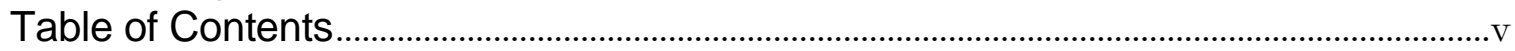

LIST OF FIGURES ...................................................................................................................vii

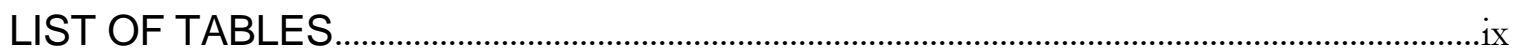

LIST OF SYMBOLS / NOMENCLATURE.................................................................................

1. $\quad \mathrm{OA} \beta$, oligomeric Amyloid-beta ……………………………………………………......

2. $\quad \mathrm{AD}$, Alzheimer's disease .................................................................................

3. BBB, blood brain barrier...........................................................................................

4. CNS, central nervous system......................................................................................

5. ETC, electron transport chain .........................................................................................

6. ROS, reactive oxygen species ..................................................................................

7. PET, positron emission tomography ………………………………………………..

8. OCR, oxygen consumption rate ...................................................................................

9. ECAR, extracellular acidification rate............................................................................

10. PI, propidium iodide .......................................................................................................

11. 2-DG, 2-Deoxy-D-glucose ……………………………………………………….....

12. SEM, standard error of means ....................................................................................

13. DMSO, dimethyl sulfoxide...........................................................................................

14. IBA-1, lonized calcium binding adaptor molecule 1 …….....................................

15. iNOS, Inducible nitric oxide synthase …………………………………………........

16. CCL2, The chemokine (C-C motif) ligand 2 …………………………………….....

17. IL-1 $\beta$, Interleukin 1 Beta ......................................................................................................

18. TNFa, Tumor necrosis factor ......................................................................................

19. Arg1, Arginase 1 (catalyzes the hydrolysis of arginine to ornithine and urea) $\mathrm{x}$

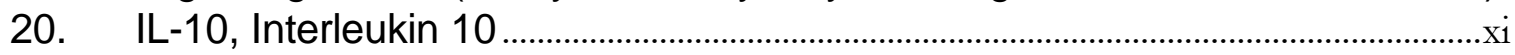

21. TGF- $\beta$, Transforming growth factor beta...................................................................

22. Drp1, Dynamin-related protein 1 ................................................................................xi

23. MAPK, Mitogen-Activated Protein Kinase ................................................................xi

CHAPTER 1: INTRODUCTION ………………………….................................................

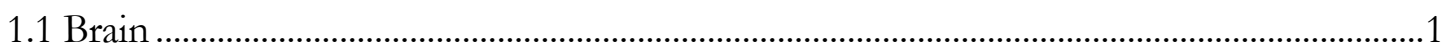

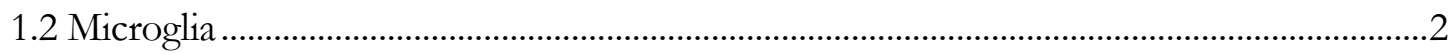

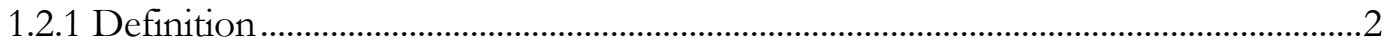

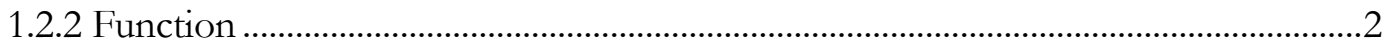

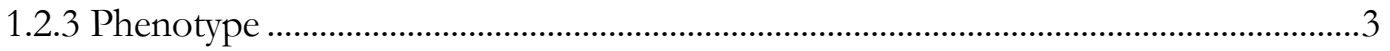

1.3 Alzheimer's disease .................................................................................................................... 


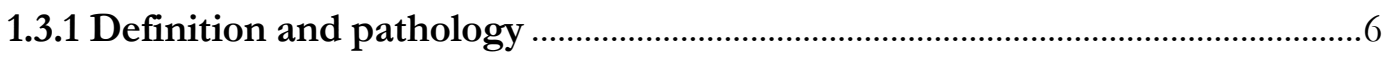

1.3.2 AD and microglia ................................................................................................

1.3.3 Hypothesized microglial activation, neuronal death and the therapeutic

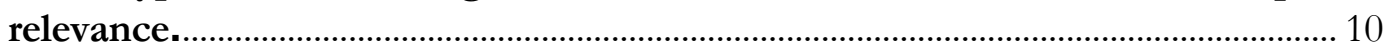

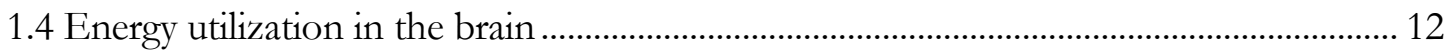

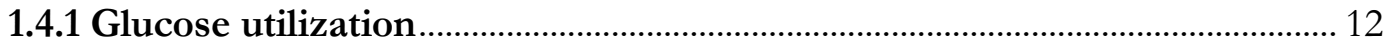

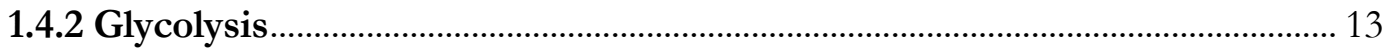

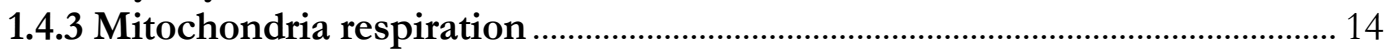

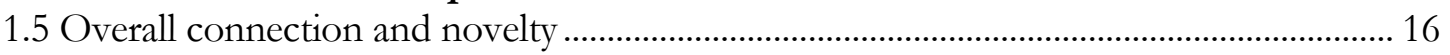

CHAPTER 2: OLIGOMERIC ABETA INDUCED MITOCHONDRIAL

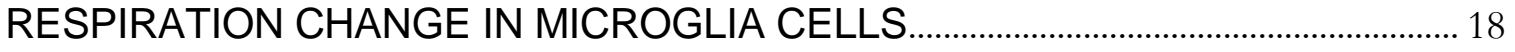

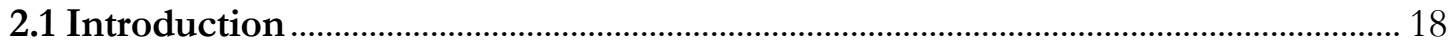

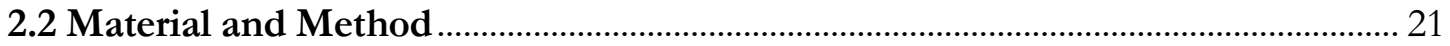

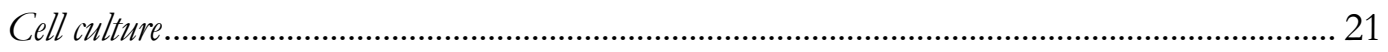

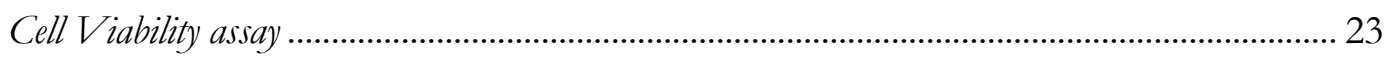

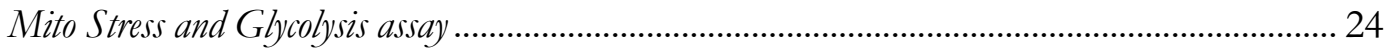

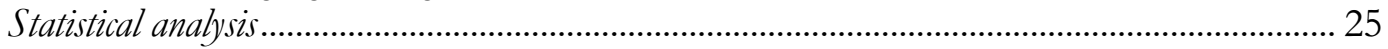

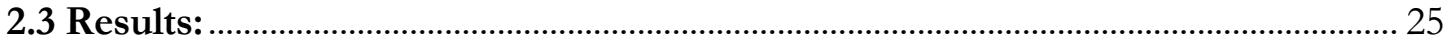

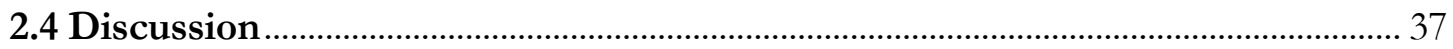

CHAPTER 3: OLIGOMERIC ABETA INDUCED MICROGLIA ACTIVATION AND

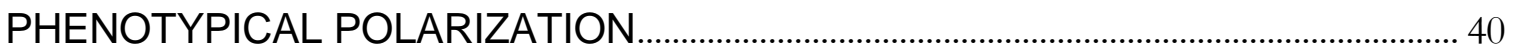

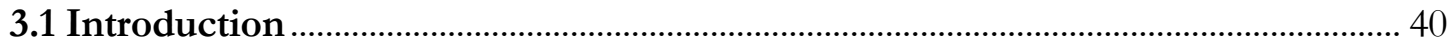

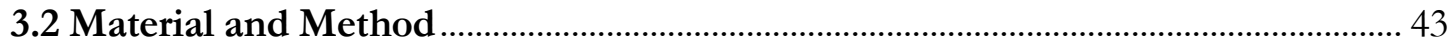

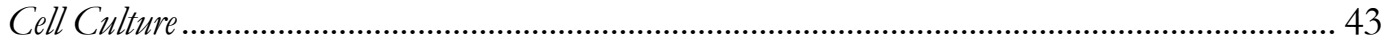

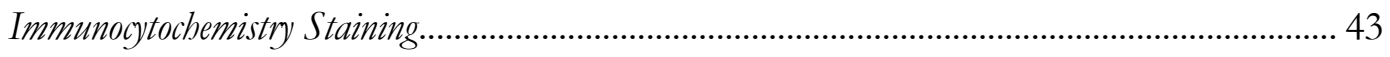

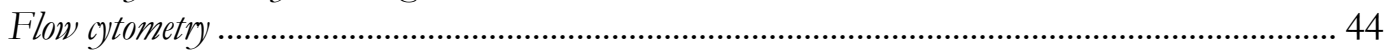

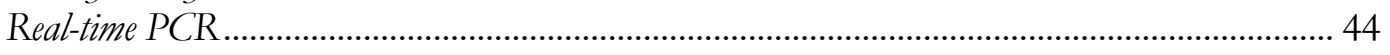

Phagocytosis assay ............................................................................................................. 46

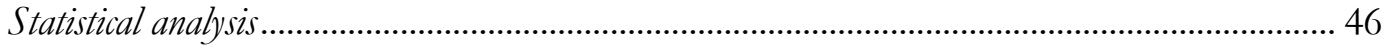

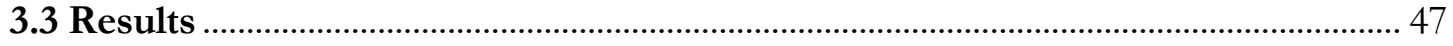

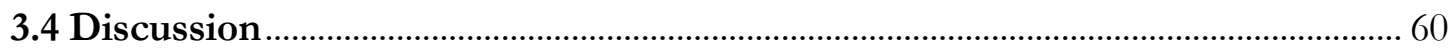

CHAPTER 4: MITOCHONDRIAL RESPIRATION VS. MICROGLIAL

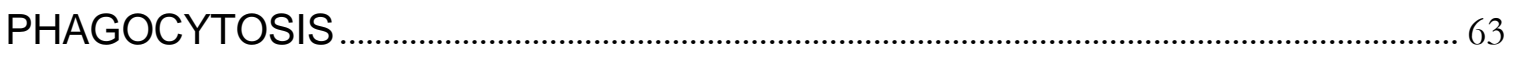

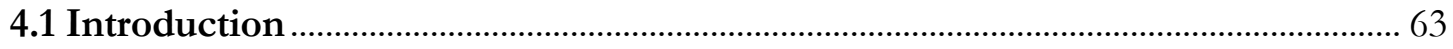

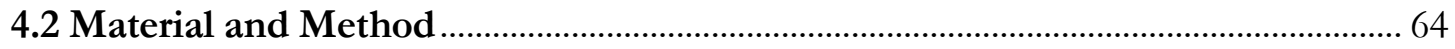

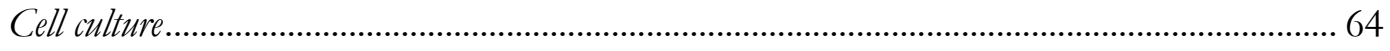

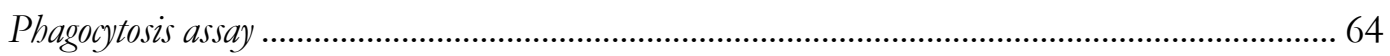

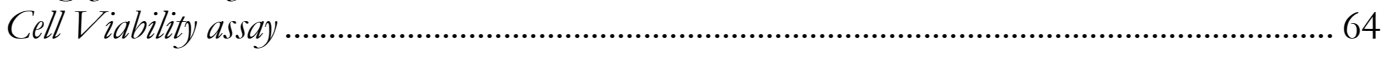

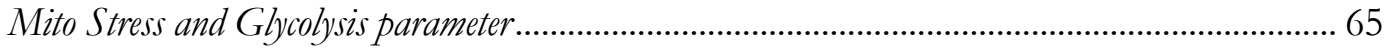

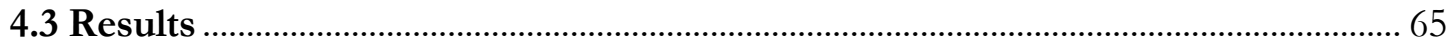

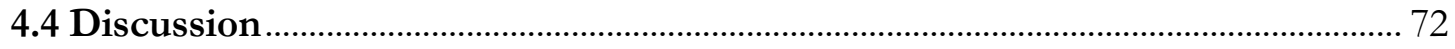

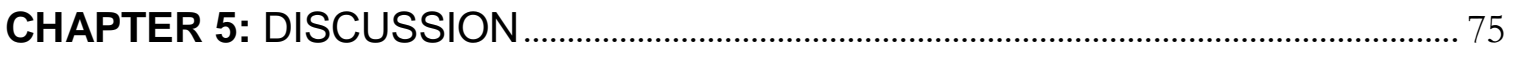

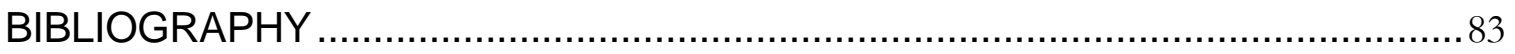




\section{LIST OF FIGURES}

Figure 1.1 Illustration of Microglia State and phenotypical change.

Figure 1.2 Microglia accumulate around $A \beta$ plaque in transgenic mouse models of Alzheimer's

disease

Figure 1.3 PET imaging show microglia overactivation in the brain of AD patient....... 9

Figure 1.4 Microglial activation, neuronal death and the therapeutic relevance. 11

Figure 1.5 Glycolysis and Post-glycolysis process flow chart..................................................... 14

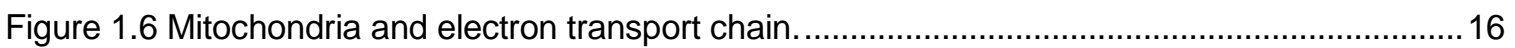

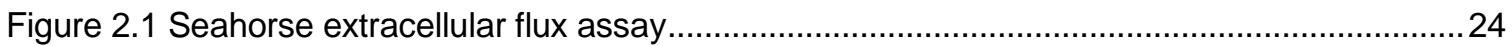

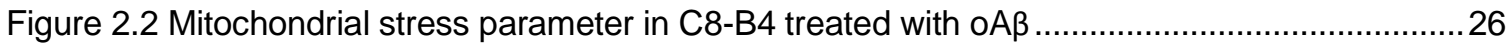

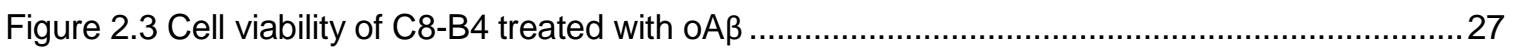

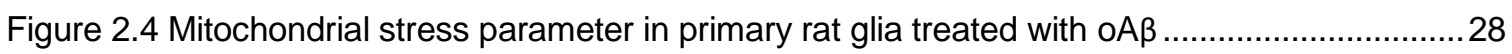

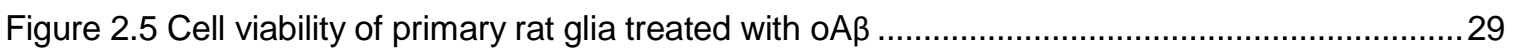

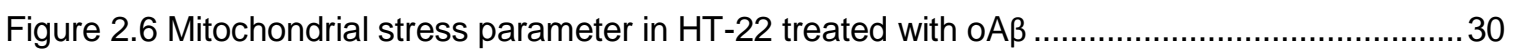

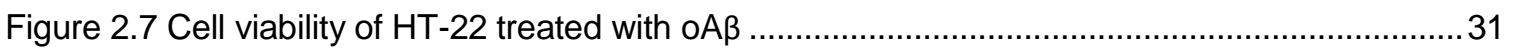

Figure 2.8 Mitochondrial stress parameter in Primary WT mouse neurons treated with oA $\beta$...........32

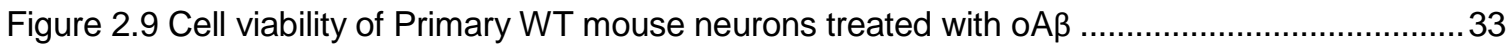

Figure 2.10 Glycolysis Assay measured glycolysis parameters in WT primary neurons ..................34

Figure 2.11 Mitochondrial stress parameter in Primary HAD mouse neurons treated with oA $\beta$.......35

Figure 2.12 Glycolysis Assay measured glycolysis parameters in HAD primary neurons ................36

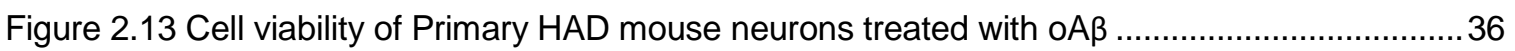

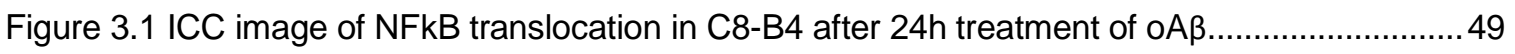

Figure 3.2 Flow cytometry assay of M1 (CD40) and M2 (CD206) marker in C8-B4 cells .................50

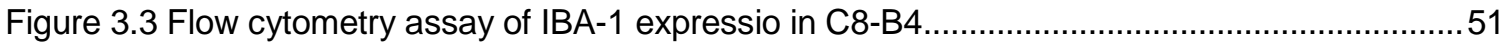

Figure 3.4 Immunofluorescent imaging of C8-B4 cells trated with oAb.......................................... 54 
Figure 3.5 mRNA expression of microglial M1 and M2 activation markers after $24 \mathrm{~h}$ treatment ........55

Figure 3.6 Fluorescent Confocal Imaging of microglia cell C8-B4 phagocytosis assay ...................57

Figure 3.7 Flow Cytometry phagocytosis assay using Nile-red fluorescent microsphere ................58

Figure 4.1 Phagocytosis assay measured by flow cytometry in C8-B4 cells treated with Rotenone

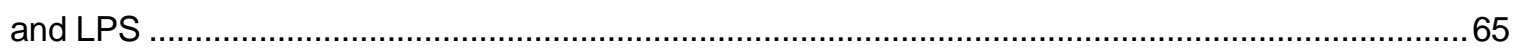

Figure 4.2 Mitochondrial Stress parameter assessment in C8-B4 cells treated with Rotenone and LPS. 67

Figure 4.3 Glycolysis Assay in C8-B4 cells treated with Rotenone and LPS ................................68

Figure 4.4 Viability of C8-B4 cells treated with rotenone 5uM and 10uM......................................69

Figure 4.5 flow cytometry phagocytosis assay in C8-B4 cells treated with LPS and

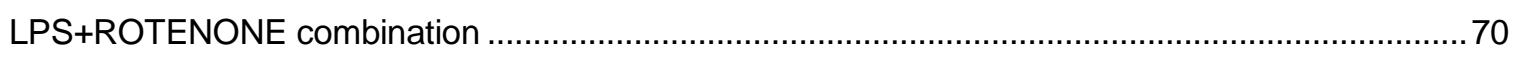




\section{LIST OF TABLES}

Table 3.1 Sequence of forward and reverse primers of microglial activation marker RNA transcripts

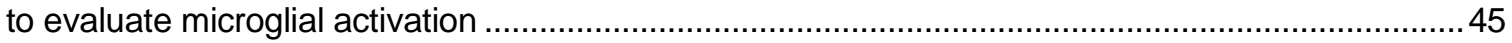

Table 5.1 Inflammatory mediators released by microglia corresponding to microglial surface

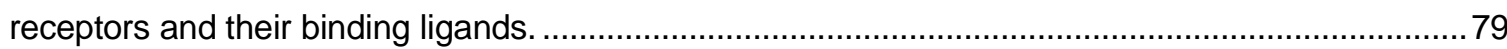




\section{LIST OF SYMBOLS / NOMENCLATURE}

1. $\mathrm{oA} \beta$, oligomeric Amyloid-beta

2. $A D$, Alzheimer's disease

3. BBB, blood brain barrier

4. CNS, central nervous system

5. ETC, electron transport chain

6. ROS, reactive oxygen species

7. PET, positron emission tomography

8. OCR, oxygen consumption rate

9. ECAR, extracellular acidification rate

10. PI, propidium iodide

11. 2-DG, 2-Deoxy-D-glucose

12. SEM, standard error of means

13. DMSO, dimethyl sulfoxide

14. IBA-1, lonized calcium binding adaptor molecule 1

15. iNOS, Inducible nitric oxide synthase

16. CCL2, The chemokine (C-C motif) ligand 2

17. IL-1 $\beta$, Interleukin 1 Beta

18. TNFa, Tumor necrosis factor

19. Arg1, Arginase 1 (catalyzes the hydrolysis of arginine to ornithine and urea) 
20. IL-10, Interleukin 10

21. TGF- $\beta$, Transforming growth factor beta

22. Drp1, Dynamin-related protein 1

23. MAPK, Mitogen-Activated Protein Kinase 
CHAPTER 1: INTRODUCTION

\subsection{Brain}

Brain, the most complex organ, only weighs $2 \%$ of total body weight of human but consumes $20 \%$ of total energy. It takes control of the other part of body by processing enormous amount of information generated from brain and other organs (Raichle \& Gusnard, 2002) (Raichle \& Gusnard, 2002). Unlike other cells, neurons do not undergo cell division. Due to the nature of the neurons and the heavy load of information, brain has its unique vasculature to protect all of the vulnerable nervous tissue. In the brain, a blood-brain barrier (BBB) is formed by brain endothelial cells to selective permeable to certain molecules (e.g. water, glucose, amino acid) separate the peripheral blood from brain. Blood-brain barrier is a natural protection barrier to protect central nervous system (CNS), including brain and spinal cord, effectively from many infections (Giudetti, Romano, Lavecchia, \& Gaetani, 2015). Thus the infections are rare in the CNS, and also hard to treat if there is one due to the delivery difficulty usually also exists for the treating drugs (e.g. antibiotics). Although the blood-brain barrier becomes more permeable during inflammation, the antibiotics and phagocytes still have a hard time passing the BBB. 


\subsection{Microglia}

\subsubsection{Definition}

Microglial cells are a type of brain glial cell that function very similarly to peripheral macrophages. They compose only $10-20 \%$ of brain cell population, but play an important role in "immune privileged" central nervous system. Microglia cell has very active processes, and through microglia the brain has a capacity for an active innate immune response (ElAli \& Rivest, 2015). Microglia cell can play versatile function under different conditions. Microglia helps with neural development as well as adult neurogenesis. They facilitate synaptic interaction: including surveilling surrounding environment, pruning synaptic neurons, phagocytizing damaged cells and plaques, mediating dynamic synaptic plasticity.

\subsubsection{Function}

Microglia cells are sensitive to their microenvironment. Their primary roles are the maintenance of normal CNS functions (Elkabes, DiCicco-Bloom, \& Black, 1996; Sierra et al., 2010; Tremblay et al., 2011; Wake, Moorhouse, Jinno, Kohsaka, \& Nabekura, 2009). Under normal conditions, they are thought to be in a resting state, keep surveying surrounding area using their highly dynamic and plastic ramified processes before get activated upon environmental alterations and homeostasis change (Kettenmann, Hanisch, Noda, \& Verkhratsky, 2011; Nimmerjahn, Kirchhoff, \& Helmchen, 2005). Microglia cells constantly communicate with neighbor astrocytes and neurons, and transmit neurotrophic or 
neurotoxic factors as well as inflammatory mediators. Under pathological conditions, microglial functions are largely dependent on their activation stimuli; whereas moderate CNS damage evokes protection by microglia (Kettenmann et al., 2011), intensive acute activation (for example in spinal cord injury, optic nerve crush, or stroke) and chronic activation, which characterizes neurodegenerative diseases, render these cells neurotoxic, potentially impairing neuronal activity (Hanisch \& Kettenmann, 2007; Perry, Nicoll, \& Holmes, 2010; Scheffel et al., 2012) Such a phenotype not only prohibits microglia from resolving inflammatory damage but rather contributes to the vicious cycle of toxicity and calls for additional assistance to terminate the local inflammation.

Microglia can transform between different morphological phenotypes under different stimuli, and play different roles under different activation status(Morris, Clark, Zinn, \& Vissel, 2013) Based on typical functional categories, it is usually differentiated into: ramified surveillance resting state, classical/pro-inflammatory (M1) state and alternative/Anti-inflammatory (M2) state.

\subsubsection{Phenotype}

Altered microglial function can trigger pathological conditions including cognitive disorders (Dibaj et al., 2012). Microglia activation is profound in CNS pathological conditions, especially $A D$ in which it is believed to be one of the contribution factors in the disease progression. 
Inflammatory processes are believed to play an important role in a number of neurodegenerative diseases including Alzheimer's disease, Parkinson's disease, Prion disease, multiple sclerosis etc (Dheen, Kaur, \& Ling, 2007). The inflammatory response is mediated by the activated microglia, which responds to inflammatory stimuli such as neuronal damage and infection. However it remains unclear whether microglial cells activation is beneficial or detrimental in neuropathological conditions. Figure 1.1 shows the proposed relationship of microglia phenotypical activation states with different functionality. Under normal conditions, microglia exists in a resting state with ramified morphology. Upon different immunological stimuli they polarize into M1 or M2 phenotype. The M1 dominant polarization contributes to extensive microglia-mediated neurotoxicity, increased pro-inflammatory cytokine release and aggravates neurodegeneration. The M2 dominant polarization contributes to tissue repair, resolution of inflammation, phagocytosis and angiogenesis. 


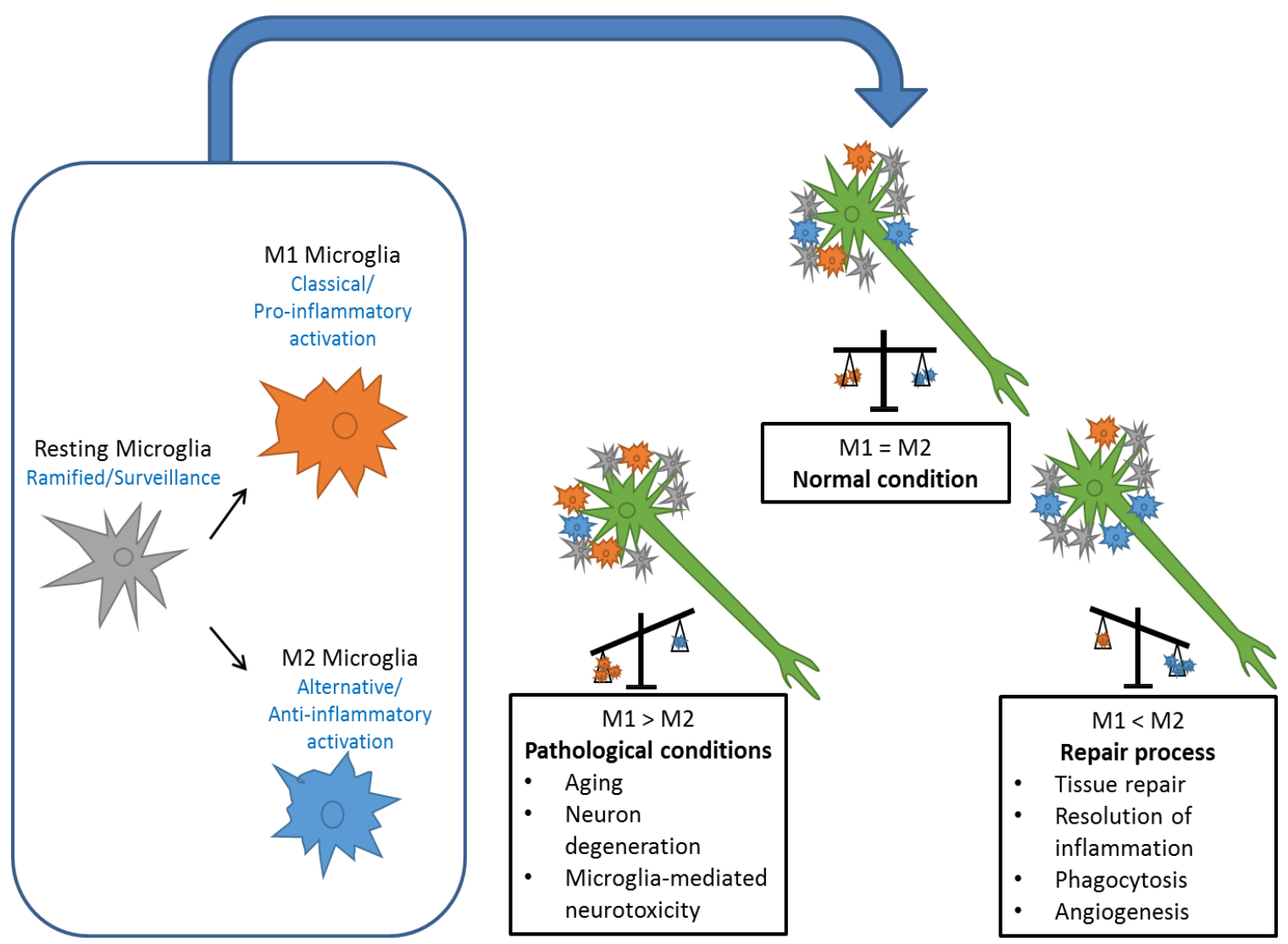

Fig 1.1 - State of Microglia and phenotypical change. Microglial cells maintain resting state under normal physiological conditions (grey), and upon stimuli polarize to classical/pro-inflammatory M1 (orange) and alternative/ anti-inflammatory M2 (blue) states. When M1 and M2 states are balanced in the system with neuron (green), the overall functions of microglia are balanced (middle panel). But when M1 state possessed dominant position, altogether microglia cells contribute to neuron degeneration, accelerated aging, and increase pro-inflammatory cytokine release (bottom left). When M2 state overweigh M1 state, microglia cells tend to resolve inflammation, repair damaged tissue, help homeostasis by phagocytosis and promote angiogenesis to bring more nutrition and oxygen to facilitate local tissue healing. 


\subsection{Alzheimer's disease}

\subsubsection{Definition and pathology}

Alzheimer's disease (AD) is a chronic neurodegenerative disease and is the 6th leading cause of death in the United State (ALZ org website). AD clinically characterized by progressive cognitive decline and impaired function of daily activities (McKhann et al., 1984). The pathology of $A D$ is the production and deposition of the $\beta$-Amyloid peptide $(A \beta)$ extracellularly, and accumulation neurofibrillary tangles of phosphorylated protein tau. $A \beta$ peptides are formed by cleavage at certain positions of the amyloid precursor protein (APP) and results in different length $A \beta$ peptides. $A \beta$ peptides aggregate to form multiple flexible soluble oligomers and insoluble fibril. It is believed that oligomeric $A \beta s$, especially the 1-42 peptide form is the most toxic and may be the causative agents in AD.

$A \beta$ can cause toxicity to neurons directly and also cause neuronal damage by activating surrounding microglia cells (Yankner, Duffy, \& Kirschner, 1990). Recent findings show that the most potent form of oligomeric amyloid- $\beta$ (oA $\beta_{42}$ ) has been shown to rapidly activate microglia through multiple pathways at uM concentration (Franciosi, Choi, Kim, \& McLarnon, 2005; Koenigsknecht \& Landreth, 2004). This activation is triggered by formyl peptide receptor-like 1(FPRL1) (PMID: 11316806) or uptaken by raft aggregation (Persaud-Sawin, Banach, \& Harry, 2009), $\mathrm{P} 2 \mathrm{Y}_{2}$ receptor (H. J. Kim et al., 2012) and cause an inflammatory cascade, accompanied by a nuclear factor kappa-B (NFkB)- 
dependent signaling pathway. In the AD Patients' brains, the SR-A1 (Block, Zecca, \& Hong, 2007; El Khoury, Hickman, Thomas, Loike, \& Silverstein, 1998) of microglia is upregulated, which is also demonstrated for scavenger receptors upon injury and cytokines stimulation.

Energy deficiency also contributes to AD. Recent research (Yao et al., 2009) shown that mitochondrial bioenergetic deficit precedes Alzheimer's pathology in female mouse model of Alzheimer's disease. The research on the relationship of glucose transport and utilization (Gimeno-Bayon, Lopez-Lopez, Rodriguez, \& Mahy, 2014) shown that microglia activation phenotype are closely relate to the adaptation pathway of energy production. All together suggest malfunction of mitochondrial energy production may compose an important factor in the contribution of microglia mediated neurodegeneration.

\subsubsection{AD and microglia}

Microglia activation is closely associated with Alzheimer's disease, and in its over-activated state, contributes to neurotoxicity neuronal death. In AD brain, microglia accumulation around senile $A \beta$ plaques (McGeer, Itagaki, Tago, \& McGeer, 1987) suggests microglia may play an important role in clearing $A \beta$ plagues and in scavenging $A \beta$ plaque damaged neurons. Fig 1.2 shows microglia accumulation around $A \beta$ plaque in the brain of $A D$ transgenic mouse model. 


\section{Microglia cluster around $A B$ plaques}

Microglia (lba-1, brown), $A B$ plaque $(4 G 8$, red)

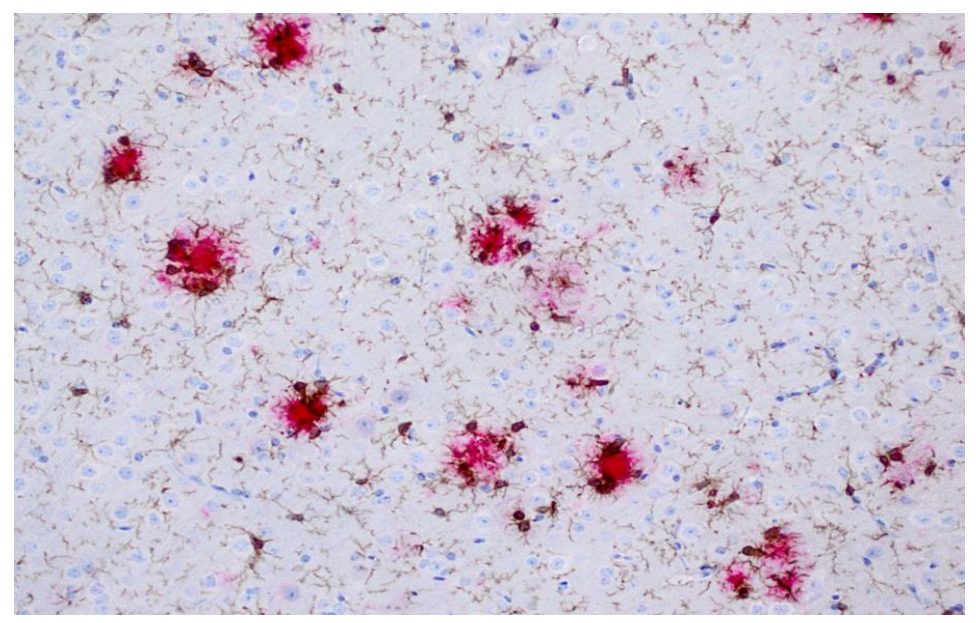

Fig 1.2 Microglia (stained in brown by anti-IBA-1) accumulate around A $\beta$ plaque (stained in Red by 4G8) in transgenic mouse models of Alriheimer's disease. Frank. Heppner, Institute of Neuropathology, Charité - Universitätsmedir̨in Berlin

Although microglia activation is not considered as a specific pathological hallmark of $A D$, the phenomenon is found in $A D$ brain, even years before symptoms become clinically apparent. Fig 1.3 shows a positron emission tomography (PET) imaging of microglia activation in healthy brain and AD patient brain. 


\section{$\underline{\text { PET imaging of microglia in neurodegeneration }}$}

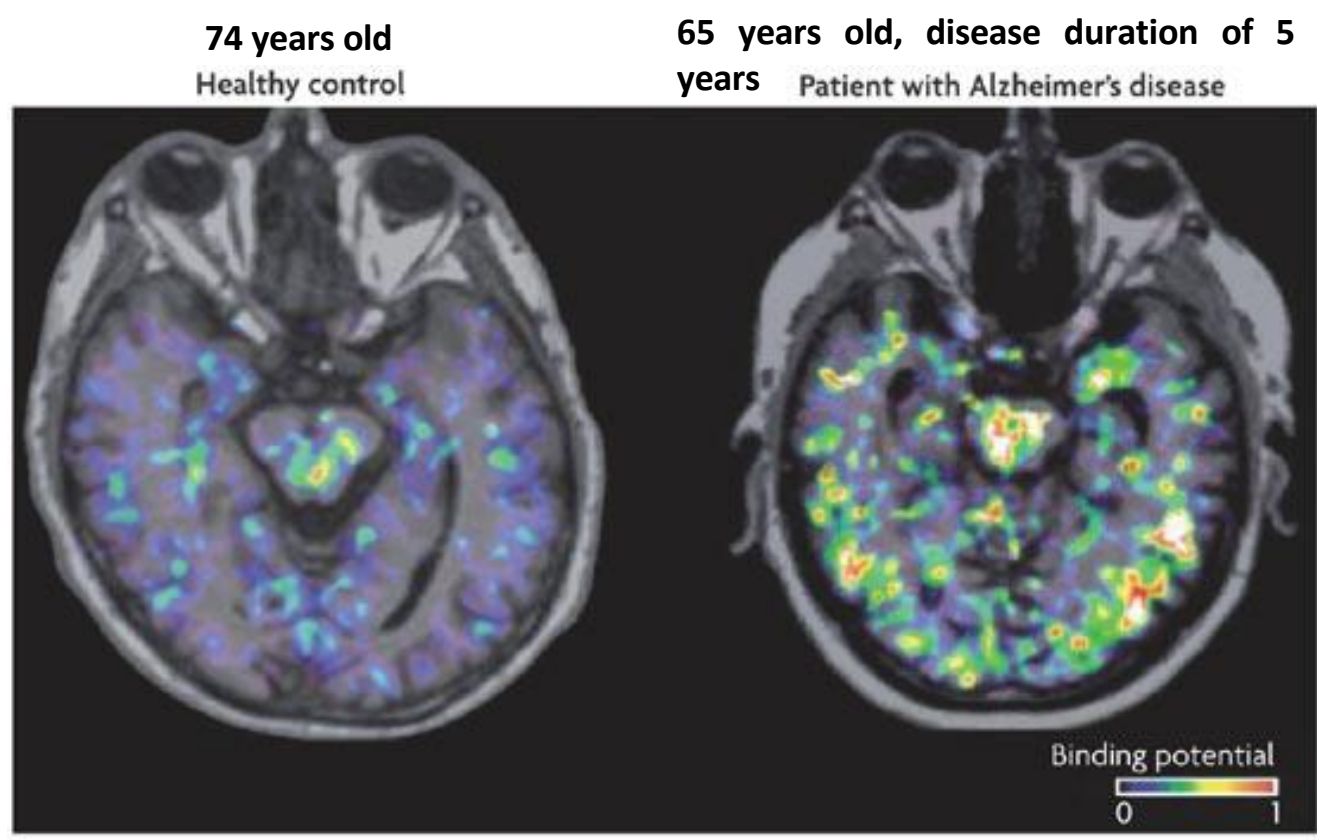

Nature Reviews | Neuroscience

Fig 1.3 The uptake of the ${ }^{11}$ C]-PK11195 ligand to the peripheral benzodiazepine receptor, which is overexpressed in activated microglia, is shown according to color scale. Nature Reviews Neuroscience 8, 5769 (Block et al., 2007)

Microglial activation can be quantified in vivo using PET imaging and $\left[{ }^{11} \mathrm{C}\right]-$ $\underline{\text { PK11195 }}$ (1-(2-chlorophenyl)-N-methyl-N-1(1-methylpropyl)-3isoquinolinecarboxamide). $\left[{ }^{11} \mathrm{C}\right] \mathrm{PK} 11195$ is a highly specific ligand for the peripheral benzodiazepine-binding site (PBR), also called the translocator protein is expressed by cells of the mononuclear macrophage lineage (Papadopoulos, Lecanu, Brown, Han, \& Yao, 2006), and is markedly increased in activated microglia. Using $\left[{ }^{11} \mathrm{C}\right] \mathrm{PK} 11195$ and PET, microglial activation has already 
been demonstrated in several neurodegenerative diseases (Venneti, Lopresti, \& Wiley, 2006) including AD.

Upon activation, microglia mediated inflammatory responses, but their functions remain controversial (Dheen et al., 2007). Chronic activation is believed to be cytotoxic to neurons by releasing pro-inflammatory cytokines and reactive oxygen species (ROS), proteinases and complement proteins. On the other side, alternative microglia activation, usually anti-inflammatory, is necessary in maintaining homeostasis, repair and recovery.

Many researchers, using different in vivo and in vitro models, have shown that soluble oligomers of $A \beta$ activate microglia and induce microglia-mediated neurotoxicity and neuron degeneration (Maezawa, Zimin, Wulff, \& Jin, 2011; Mattson, 2004), thus suppression of microglia activation has been proposed as a potential and effective therapy to treat neurodegenerative disease. But the functions of microglia at low dose $A \beta$ or in early stage $A D$ development still remain unclear. It is unknown if microglial cells are detrimental at the very beginning of $A D$ and how microglia activation phenotypes may influence AD progression.

\subsubsection{Hypothesized microglial activation, neuronal death and the therapeutic relevance.}

In term of further understanding the microglia's role in $A D$, Block et al. has hypothesized a possible correlation of the progression of Alzheimer's disease with the time line of microglial activation(Block et al., 2007). They postulate that after an 
initial unknown instigating stimulus, neuron became damaged; causing microglial activation that will be driven by the further loss of neurons throughout the disease.

Fig 1.4 shows a possible microglial activation correlation with neuronal death and the therapeutic relevance.

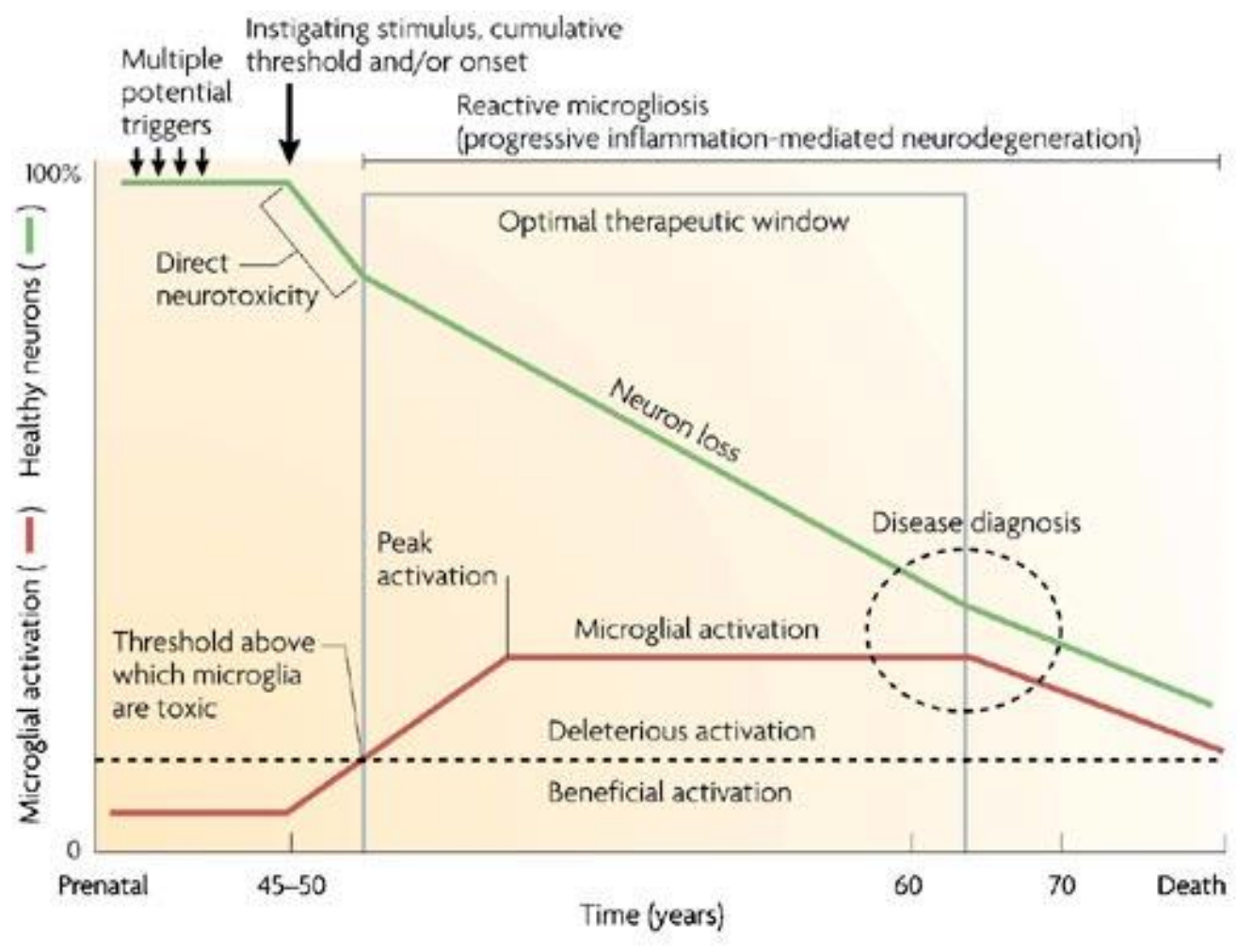

Nature Reviews | Neuroscience

Fig 1.4 Microglial activation, neuronal death and the therapeutic relevance. Nature Reviens

Neuroscience 8, 57-69 (Block et al., 2007) 
Although the reasons of initial stimuli may be different and as well as the progression rate of neuron loss for each patient, microglial activation can change their beneficial role into a deleterious one after the disease pass a threshold of beneficial window. Microglia activation (reactive microgliosis) then may cause further neuronal loss and resulting in a negative feedback of neurotoxicity and worsen neurodegenerative disease.

The current problems with the disease are not only lacking the functional treatment to reverse the pathology but also late diagnosis outside the optimal therapeutic window long after extensive damage has occurred. Lack of knowledge of the microglia's clear role in the disease progression and neuronal damage, and the diagnosis methods holds back possible therapeutic application. If a clear threshold of microglia activation could be determined, then anti-inflammatory therapy could be applied to reduce microglial activation to non-deleterious levels using early detection of microglial activation through, for example, in vivo imaging. This promising approach can delay, reduce the progression of $A D$ before irreversible damage occurs.

\subsection{Energy utilization in the brain}

\subsubsection{Glucose utilization}

The brain has a very high energy consumption demands considering its size. The main energy expenditure is consumed to maintain acting potential generated by nerve cell, as well as axonal and dendritic neuron transmitter 
transport and tissue repair. Although brain can utilize other metabolites in special cases, glucose is the most important fuel for energy generation. Glucose cross the BBB by facilitated diffusion, and is taken up by brain cells via mediated by glucose transporters.

In the cell, glucose is phosphorylated to glucose-6-phosphate that is metabolized further into pyruvate, which is also called glycolytic pathway. Glucose6-phosphate can be also utilized as substrate for the pentose phosphate shunt and converted into glycogen. A fraction of pyruvate can be transported into brain mitochondria and devoted to the oxidative phosphorylation and metabolized in the Krebs cycle. The other fraction of pyruvate in the cytosol is converted to lactate by lactate dehydrogenase. The exact fraction of the proportion is not known in vivo, and $\mathrm{I}$ assume the fraction is flexible due to the condition and environment, especially the energy and other molecular needs.

\subsubsection{Glycolysis}

Glycolysis is the metabolic pathway that converts glucose into pyruvate, which is an oxygen-independent metabolic reaction (shown in Fig 1.5). The end products are used to convert carbohydrates into fatty acids and cholesterol. It utilize the NADH as the reaction substrate by oxidizing NADH and transferring two electrons to pyruvate converted into lactate. 


\section{Glucose}

\section{Hexokin}

\section{Glucose-6-Phosphate}

2 ADP

2 ATP

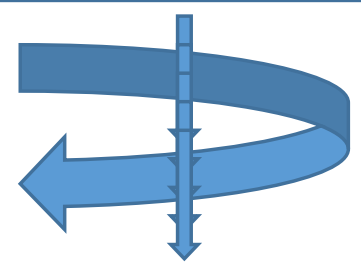

\section{Pyruvate}

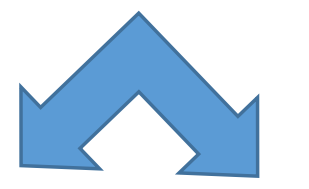

\section{Lactate}

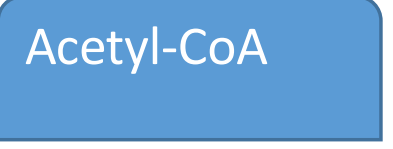

Fig 1.5 Glycolysis and Post-glycolysis process flow chart. Glycolysis is the metabolic pathway that converts glucose $\mathrm{C}_{6} \mathrm{H}_{12} \mathrm{O}_{6}$ into pyruvate via a series of intermediate metabolites. The end product pyrwvate then converted into Lactate by anoxic regeneration or Acetyl-CoA (in mitochondrion) to further synthesize fatty acid and cholesterol.

\subsubsection{Mitochondria respiration}

Mitochondria act as the main powerhouse of the in most eukaryotic cells. Most of the reactions of energy generation are happened in the mitochondria. This ATP production organelle is composed of a double membrane structure; with most of the task completing proteins resides on the inner membrane. The major protein 
forms in electron transport chain (ETC) comprises enzymatic electron donors and acceptors proteins, including NADH dehydrogenase (Complex I, oxidizing the NADH produced from the Krebs cycle), succinate dehydrogenase (Complex II), cytochrome c reductase (Complex III) and cytochrome c oxidase (Complex IV). Each electron donor protein passes electrons to an electron acceptor, which further donates these electrons to downstream acceptor until pass the electrons to terminal electron acceptor-oxygen. All together, they transfer electrons from $\mathrm{NADH}$ and succinate pass through the ETC to oxygen further reduced to water and pump protons $\left(\mathrm{H}^{+}\right)$into the intermembrane space to generate a proton gradient across the inner membrane. The electron transportation releases energy, and ADP is phosphorylated to ATP in the process using the energy thus this process is called oxidative phosphorylation. Fig 1.6 illustrates the structure of the mitochondria and the ETC as well as the substrate of each complex.

A small percentage of electrons may not undergo oxidative phosphorylation but directly leak to oxygen, forming a highly reactive molecule -free-radical superoxide. Superoxide is one of the major contributors of oxidative stress; it has been implicated in many diseases.

As the proton accumulated to certain concentration enough in the intermembrane space, the electrochemical gradient is established to lead protons back to the matrix through the ATP synthase complex and synthesize ATP. Besides supplying cellular energy, mitochondria influence other cellular functions, such as cell signaling, cellular differentiation, and apoptosis, as well as maintaining control of the cell growth. Mitochondria malfunction have been shown to be 
correlated closely with several diseases, including mitochondrial disorders, cardiac dysfunction, heart failure and autism.

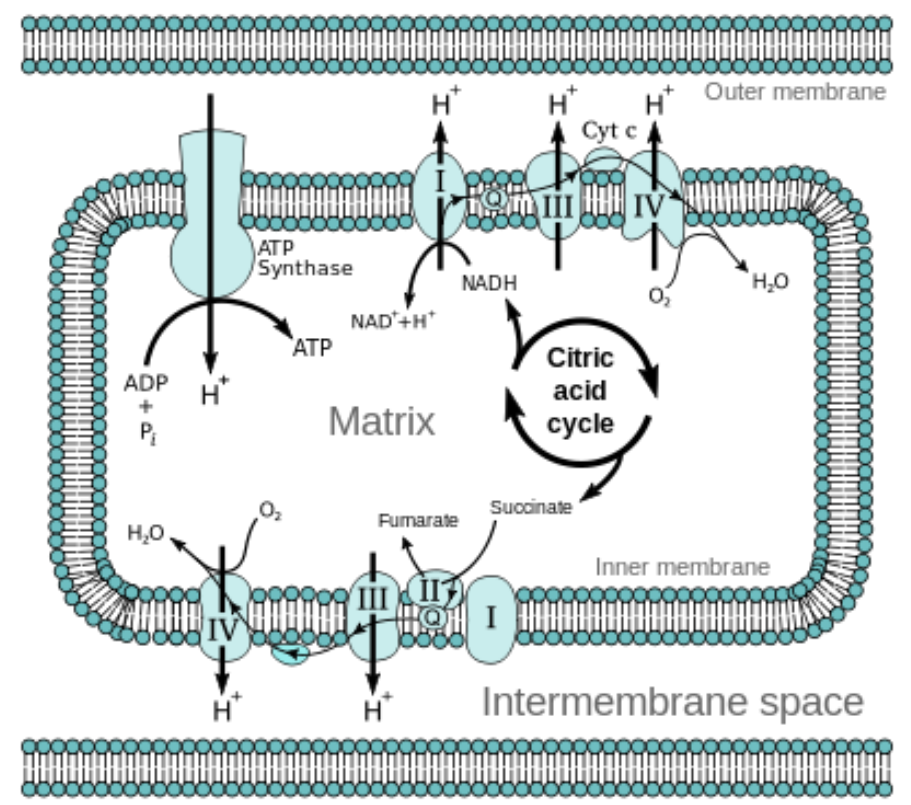

Fig 1.6 Mitochondria and electron transport chain. The electrons pass through ETC and provide the proton gradient to facilitate ATP synthesis. https: / / en.wikipedia.org/wiki/ Electron transport chain

\subsection{Overall connection and novelty}

Mitochondrial dysfunction has been studied intensively as it lead to neuronal cell survival or death, not only because they regulates energy metabolism but also mediate cellular death pathways. The byproduct of energy generation through mitochondrial oxidative phosphorylation-reactive oxygen species (ROS) contribute to oxidative stress and cause damage serve as one of the most important pathogenesis of Alzheimer's disease. Many studies focus in the 
mitochondria functions in neuronal cells, since neurons are highest energy demanding cells in the brain. Other researchers studied the microglia contribution in the Alzheimer's disease progression. But the energy genesis as well as mitochondria function in cell cycle in the microglia under different states in Alzheimer's brains and its relationship towards interaction with surrounding neurons, astrocytes and endothelial cells are not clear.

It has been shown that fibrillary forms of amyloid-beta could induce microglia activation and inflammatory responds in microglia cell line BV-2 and primary microglia cells through Toll like Receptors and integrin. Some researchers believed that resting microglia react to fibrillary form of $A \beta$ but do not detect oligomers or oligomer-induced neuronal damage. But giving the fact that the soluble oligomeric form of $A \beta$ is the most cytotoxic form of $A \beta$, it raised the question: do microglia react with soluble oligomeric $A \beta$ in a manner that help maintain the homeostasis in the early stage before $A \beta$ plaque forms and doing a beneficial job?

In most related experiment involved $A \beta$, the dose ranges from uM to hundreds of uM in vitro were used. But according to post mortem samples from AD patients brain, the average $A \beta$ concentration is at $15 \mathrm{pM}$ compared to less than 5pM in the control group (Perez-Nievas et al., 2013). To better mimic the pathological condition, in this project much lower doses were used to serve in the in vitro model that avoids any high concentration off-target effect. 
CHAPTER 2: OLIGOMERIC ABETA INDUCED MITOCHONDRIAL RESPIRATION CHANGE IN MICROGLIA $\underline{\text { CELLS }}$

\subsection{Introduction}

Microglia could help restore the homeostasis, heal and rescue tissue damage or mediate inflammatory responses upon activation. Their functions remain controversial and are a balance of beneficial and detrimental (Dheen et al., 2007). The chronic activation is believed to be cytotoxic to neurons by releasing pro-inflammatory cytokines and reactive oxygen species (ROS), proteinases and complement proteins. On the other hand, alternative microglia activation, usually anti-inflammatory, is necessary in maintaining homeostasis, repair and recovery.

Many researchers using different in vivo and in vitro model, have shown that soluble oligomers of $A \beta$ activate microglia and induce microglia-mediated neurotoxicity (Maezawa et al., 2011; Mattson, 2004), thus suppression of microglia activation especially microglia-mediated inflammation or elimination of microglia has been designed as a potential and effective therapy to treat neurodegenerative disease.

But the functions of microglia at low dose $A \beta$ or in early stage $A D$ development still remain unclear. Questions of whether microglia starts to be detrimental at very beginning and how microglia activation phenotypes may influence $A D$ development remain. 
Recently, we found that mitochondrial oxidative phosphorylation is affected in a dose-dependent manner by $\mathrm{OA} \beta_{42}$ treatment in a microglia cell line (C8-B4). Basal, maximal and spare respiration capacities of mitochondria increase at low pico-molar concentrations of $\mathrm{oA} \beta_{42}$ and then decrease at higher concentrations. In contrast, the $\mathrm{OA} \beta_{42}$ stimulation does not alter the mitochondrial oxidative phosphorylation in a mouse hippocampal neuronal cell line (HT-22), suggesting a brain cell-specific response to $\mathrm{oA} \beta_{42}$.

Microglia possessed two different potential activation pathways, Classical M1 pro-inflammatory and Alternative M2 anti-inflammatory pathways. Due to two routes of activation and the different roles in inflammatory response, we hypothesize that 1) Low dose $\mathrm{oA} \beta_{42}$ increases mitochondrial oxidativephosphorylation due to the high energy demanding cell activities (Gimeno-Bayon et al., 2014), and this effect vanished at higher dose. 2) The $o A \beta_{42}$ induced mitochondria functional changes are specific in microglia cell types.

The first project is focused on Specific Aim \#1: To determine if $\mathbf{O A} \underline{\beta}_{42}$ influence mitochondrial oxidative-phosphorylation differently at low dose vs high dose in various cell types.

Hypothesis: Low dose $\mathrm{pM} \circ \mathrm{A} \beta_{42}$ increase mitochondrial respiration which is high efficacy energy generation while high dose $A \beta_{42} O$ dampens this effect.

Rationale: Studies using postmortem brains as well as transgenic mouse models of AD (Gimeno-Bayon et al., 2014; Spuch, Ortolano, \& Navarro, 2012) 
have shown that $A \beta$ induced oxidative damage is associated with mitochondria dysfunction during $A D$ progression. $A \beta$ blocks the transport of nuclear-encoded mitochondrial proteins, disrupts electron transport chain, and increases ROS production. But most of the researches focused on late stage of $A D$ or using high dose $A \beta$ treatment to mimic the pathological environment. It make sense that $A \beta$ accumulate in aged brain, but what is more interesting is the response during early stage of the disease progression, and how other cells especially microglia cells works to maintain an optimal working condition.

EXP 1. Evaluation the mitochondrial functional changes influenced by low dose and higher dose of $\mathrm{OA} \beta_{42}$ by measuring the mitochondrial respiration parameter in $\mathrm{OA} \beta_{42}$ treated microglial and neuronal cells.

EXP 2. To evaluate the toxicity of $O A \beta_{42}$ at different concentrations by measure the cell viability using Calcein-AM assay and propidium iodide ( $\mathrm{PI})$ staining.

EXP 3. To further assess the energy metabolism under $\mathrm{OA} \beta_{42}$ stimuli, in some groups carry glycolysis assay to evaluate the energy compensatory mechanism.

Expected Results and potential problems:

Low dose $\mathrm{oA} \beta_{42}$ treatment may cause mitochondrial respiration changes expected to be reflected in Mito-Stress assays. The respiration of mitochondria is expected to be increases in order to support microglial activation. This increase is 
expected to be of small scale and persist for a long time unless the microglia returns to a resting state and don't need the energy support anymore. In contrast, neuronal cells respond little to $\mathrm{oA} \beta_{42}$ at low dose but may be vulnerable at high dose due to the toxicity of $O A \beta_{42}$ to neurons.

Mitochondrial respiration is expected to increase in C8-B4 cells, to response to low dose $o A \beta_{42}$ stimuli. It is known that oA $\beta_{42}$ may impair synaptic plasticity and cognitive function in AD models, so a potential problem is to have a relative low dose but can still cause enough effect. Another possible problem is $\mathrm{oA} \beta_{42}$ characterization, due to the many forms of $A \beta_{42}$, the yield of $o A \beta_{42}$ may not be exactly the same after storage.

\subsection{Material and Method}

\section{Cell culture}

Four cell types were evaluated in this part: 1 . Microglia cell line C8-B4; 2. Neuronal cell line HT-22; 3 Primary mouse glia cells; 4. Primary mouse neurons. They were chosen to be assessed their live cell mitochondrial function using Extracellular Flux Analyzer.

C8-B4 (ATCC) and HT-22 (generous gift of Dr. David Schubert Salk Institute, San Diego, CA; (Jung, Wilson, \& Simpkins, 2006)) cells were grown in Dulbecco's modified Eagle's medium (DMEM; Hyclone) containing 10\% fetal 
bovine serum (FBS; Atlanta biologicals) and 100units $/ \mathrm{ml}-100 \mu \mathrm{g} / \mathrm{ml}$ PenicillinStreptomycin (PS; Hyclone) in $5 \% \mathrm{CO}_{2}$ at $37^{\circ} \mathrm{C}$.

Primary Glia cells were obtained from P2 wild type Sprague Dawley rat, cells were cultured in Dulbecco's modified Eagle's medium (DMEM; Hyclone) containing $10 \%$ fetal bovine serum (FBS; Atlanta biologicals) and 100units/ml$100 \mu \mathrm{g} / \mathrm{ml}$ Penicillin-Streptomycin (PS; Hyclone) in $5 \% \mathrm{CO}_{2}$ at $37^{\circ} \mathrm{C}$. At the end of the cell culture, cells were treated with oA $\beta_{42}$ for 48 hours in $5 \% \mathrm{CO}_{2}$ at $37^{\circ} \mathrm{C}$.

Primary neurons were obtained from E19 embryonic wild type C57BL/6 and HAD transgenic mice carrying background of homozygous APP Swedish genes. Cells were then cultured in neural basal media supplemented with B27 and glutamax DIV 14 days. Cell culture media were changed twice a week $50 \%$ each time, and cellular morphology were closely monitored under microscope. At the end of the cell culture, cells were treated with $\mathrm{oA} \beta_{42}$ for 48 hours in $5 \% \mathrm{CO}_{2}$ at 37 ${ }^{\circ} \mathrm{C}$.

Cells were seeded in the Seahorse 96-well plates and cultured overnight then treated with $3.2 \mathrm{pM}, 16 \mathrm{pM}, 80 \mathrm{pM}, 400 \mathrm{pM}, 2 \mathrm{nM}, 10 \mathrm{nM}, 50 \mathrm{nM}$ oA $\beta_{42}$ for 24 hours (cell lines) or 48 hours (primary cells). The $\mathrm{oA} \beta_{42}$ was prepared according to the published method (Lambert et al., 2001; Logan, Sarkar, Zhang, \& Simpkins, 2011). Synthetic $A \beta_{42}$ (Lifetechnology) was dissolved in hexafluoro-2-propanol (HFIP) and aliquot. Then HFIP was removed by evaporation overnight, store at $80^{\circ} \mathrm{C}$. One aliquot was dissolved in anhydrous dimethyl sulfoxide (DMSO) to $5 \mathrm{mM}$, which was then added to ice cold DMEM without phenol red to achieve a 
concentration of $100 \mu \mathrm{M}$. This solution was incubated at $4{ }^{\circ} \mathrm{C}$ for 24 hours, and then centrifuged at $14,000 \mathrm{~g}$ for $10 \mathrm{~min}$. The supernatant comprised of fibrillar-free oligomers, as well as monomers, was used for the experiments performed in this study. Protein concentration was determined from the supernatant and its molarity was calculated.

\section{Cell Viability assay}

To test whether toxicity is induced during treatment which may influence the total cell number and simultaneously impact OCR value of Seahorse assay, cell viability using fluorescent Calcein-AM dye is also assessed under the same treatment regimen and time.

Cell viability was assessed using Calcein-AM (calcein acetoxymethyl) assay. Cells were washed with PBS and incubated with $1 \mu \mathrm{M}$ Calcein-AM fluorescent probes (Life Technologies) in dark for 30min. The live cells produce green fluorescence by active intracellular esterase which cleaves the Calcein AM dye. Viability was measured in relative fluorescent units (RFU), and expressed as percentage of vehicle-treated control values. To further verify the viability, the propidium iodide $(\mathrm{Pl})$, which binds to nucleic acid when cell membrane was permeable, was also applied to identify dead cells in whole population. 
The Seahorse $\mathrm{XF} 96^{\mathrm{e}}$ measures mitochondrial function by analyzing the rate of oxygen and $\mathrm{pH}$ change in the microenvironment surrounding the cells (as shown in Fig 2.1).
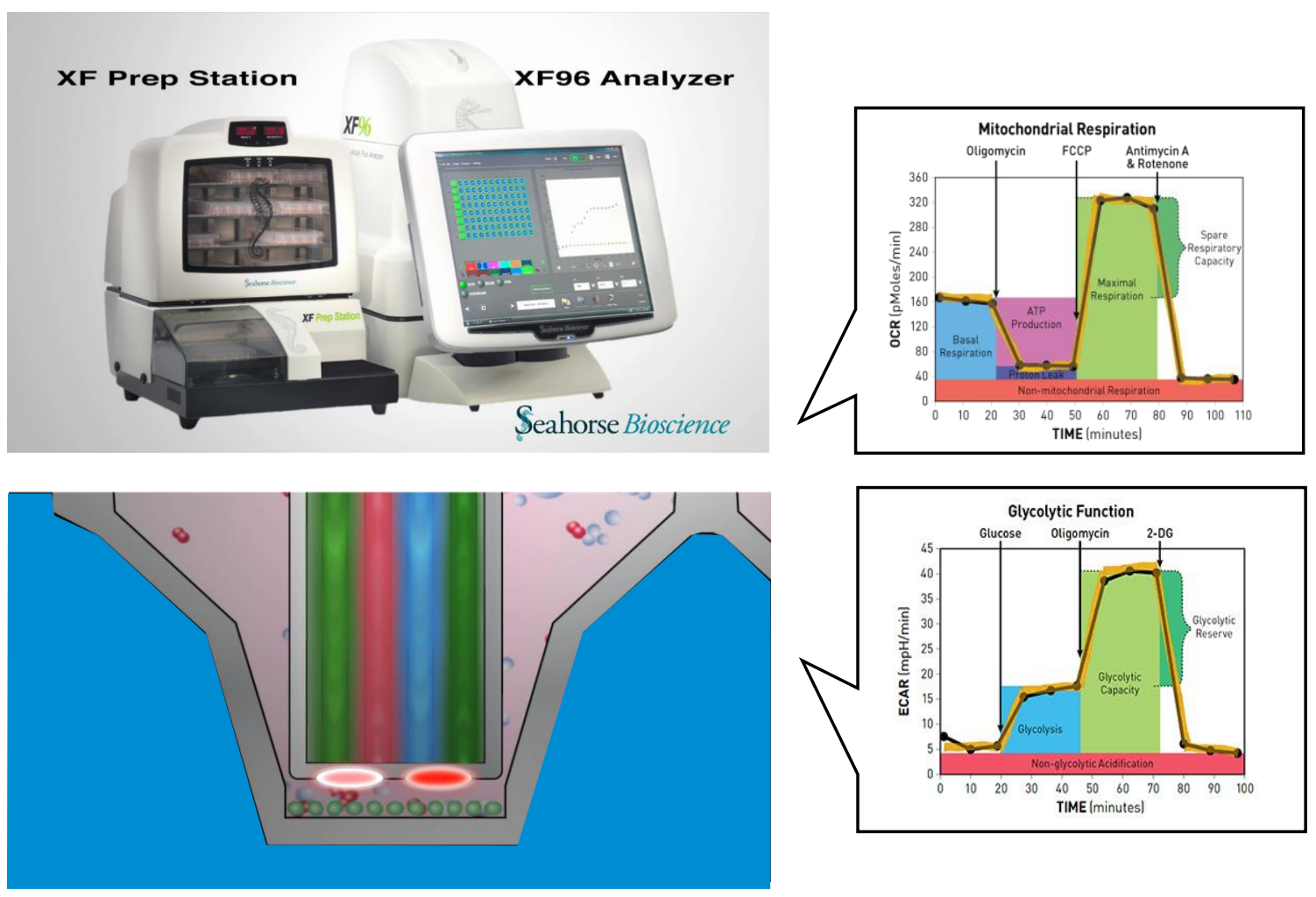

Fig 2.1 Mitochondrial respiration parameter measurement. Light excites the embedded fluorophore then XFe96 measures change in fluorophore emission, the measurement of Oxygen Consumption Rate $($ moles $/ \mathrm{min})=\mathrm{O}_{2}$ consumption $\equiv$ mitochondrial respiration while the Extra Cellular Acidification Rate $(\mathrm{mpH} / \mathrm{min})=H^{+}$Production $\equiv$ glycolysis.

Then oxygen consumption rate (OCR) were measured before and following $1 \mu \mathrm{M}$ Oligomycin, $0.5 \mu \mathrm{M}$ Carbonyl cyanide-4-(trifluoromethoxy)phenylhydrazone 
(FCCP), $1 \mu \mathrm{M} / 1 \mu \mathrm{M}$ Antimycin-A/Rotenone injections to examine the mitochondrial stress parameters of oxidative phosphorylation. Five major mitochondrial stress parameters were measured as shown above.

The extracellular acidification rate (ECAR) were measured before and following the addition of saturating amounts of glucose (10mM), oligomycin (1uM), 2-Deoxy-D-glucose (2-DG, a competitive inhibitor of glucose) $(50 \mathrm{mM})$ to examine the glycolysis, glycolytic capacity and allow calculation of glycolytic reserve and non-glycolytic acidification.

\section{Statistical analysis}

The statistical analysis between the groups with normal distributions was performed using Graphpad (Prism) or SPSS (statistical package for the social sciences, IBM) software. For comparison of multiple treatments, results were analyzed by ANOVA across group. Tukey's test or Dunnett's was used to adjust for multiple comparisons in post hoc pairwise tests. The differences between groups were considered to be statistically significant when $p<0.05$. Results values are reported as mean \pm standard error of means (SEM).

\subsection{Results:}

To test the mitochondrial function in microglia treated with oA $\beta$, we performed Seahorse extracellular flux assay utilizing mouse cerebellum microglia 
cell line C8-B4. The original graph and analyzed results are shown below in Fig 2.2.

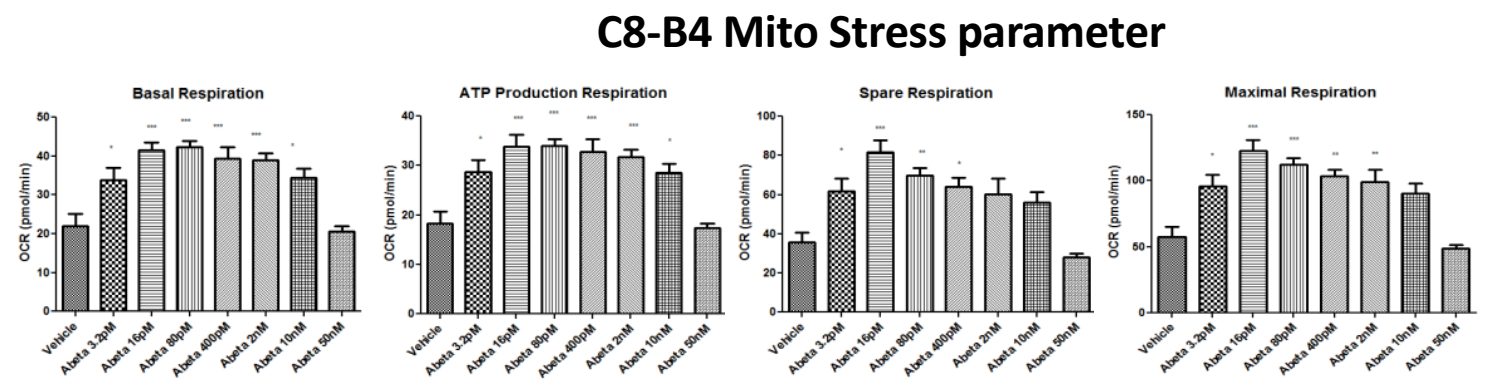

24h

Fig 2.2 Mitochondrial stress parameters were measured as oxygen consumption rates (OCR). C8-B4 mouse microglia cell line (Statistic analysis was done by One-way ANOVA and Dunnett's post hoc analysis. * $p<0.05$, ** $p<0.005$, *** $p<0.0005)$ There were significant differences in most respiration parameters treated with $0 A \beta_{42}$ in $C 8$-B4 cell line.

In most of the groups concentrations of oA $\mathrm{A}$ as low as $3.2 \mathrm{pM}$ caused mitochondrial respiration increased with a maximization at 16 80pM which are pathological relevant concentrations of soluble amyloid- $\beta$ load. This increase rapidly diminished back to baseline at $50 \mathrm{nM}$ oA .

Since OCR is largely influenced by the cell number resides in each well. To differentiate the effect of treatment on microglial mitochondrial respiration vs cell number, in addition to confirming the toxicity dose of oA $\beta$. Cell viability assay has been applied to determine the cell number after $24 \mathrm{~h}$ treatment. Fig 2.3 show the cell viability measured by Calcein-AM assay which suggested that $\mathrm{oA} \beta_{42}$ neither present cytotoxicity nor induce proliferation across all dosage. 


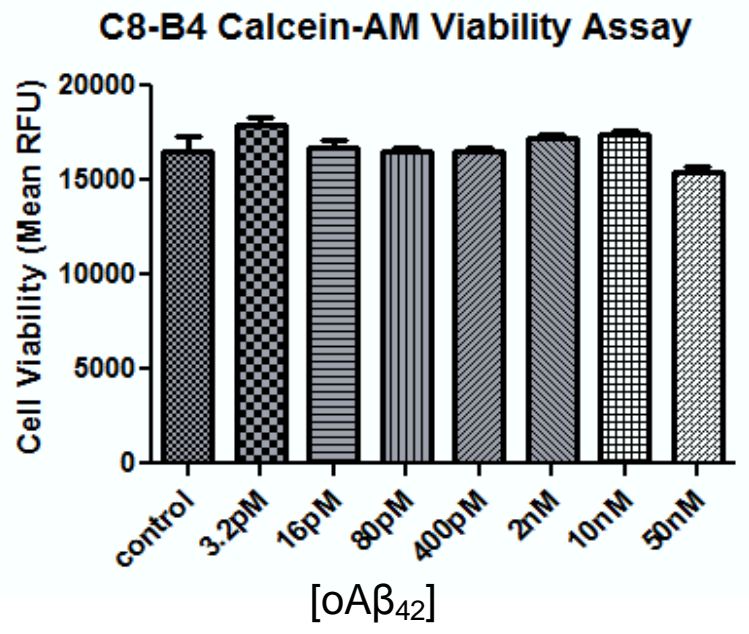

Fig 2.3 Cell viability was measured as Mean Relative Fluorescence Units (RFU). C8-B4 mouse microglia cell line were seeded in 96-well plate at their optimal density overnight and treated with $0 A \beta_{42}$ for 24 hours (Statistic analysis was done by One-way ANOV $A$ and Dunnett's post hoc analysis. * $p<0.05$, ** $p<0.005$, *** $p<0.0005)$ There was no significant differences in all $0 A \beta_{42}$ treatment group in microglial cell line.

We have been using the C8-B4 to represent the response of microglia cells. Since cell lines are transformed cells they may adapt different energy utilization methods other than non-transformed microglia cells in brain. We tested the effect of $\mathrm{OA} \beta$ at the similar dose on primary glia cells.

Primary glia cells are derived from P2 wild type Sprague Dawley rat, cultured in vitro for two weeks and then harvested for further analysis. Fig 2.4 shown the mito stress results of $48 \mathrm{~h}$ treatment in primary glia cells, while we also did $24 \mathrm{~h}$ treatment (result not shown) with less difference probably due to shorter treatment duration. 


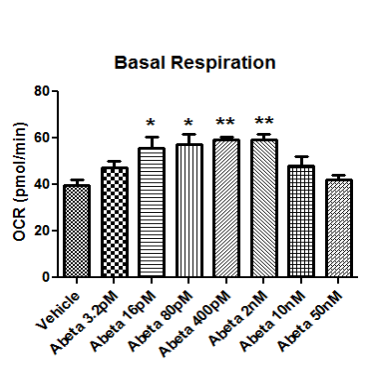

\section{Primary Rat Glia Mito Stress parameter}

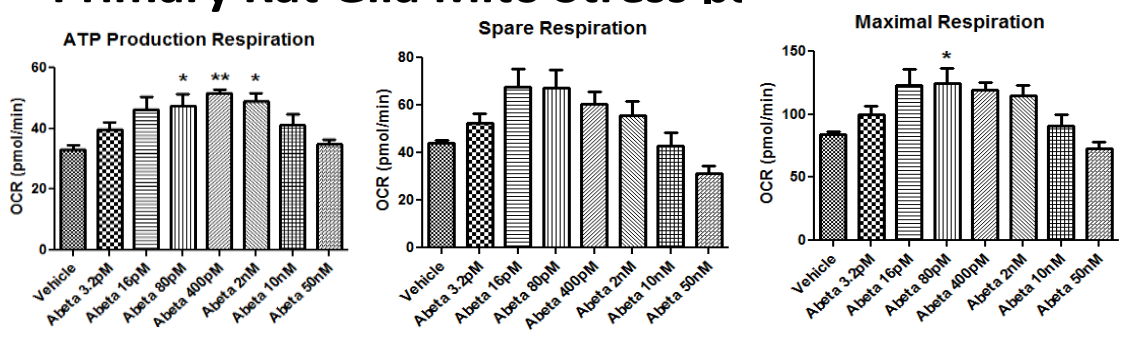

48h treatment

Fig 2.4 Mitochondrial stress parameters were measured as OCR. Rat primary glia cells (Lower panel) were obtained from P2 Sprague-Dawley rats and cultured for 14 days, then counted and seeded in 96-well plate overnight and treated with o A 42 for 48hours. (Statistical analysis was done by One-way ANOV A and Dunnett's post hoc analysis. ${ }^{*} p<0.05$, ** $\left.p<0.005,{ }^{* *} p<0.0005\right)$ There were significant differences in most respiration parameters treated with $O A \beta_{42}$ in primary glia cells, and there was little change in neuronal cell line.

To distinguish the influence of cell proliferation from the real response of OCR to treatment, and in addition to confirm toxicity of oA, cell viability assay was conducted to determine the cell number at the end of treatment. Results shown in Fig 2.5 suggested that $\mathrm{OA} \beta_{42}$ neither present cytotoxicity nor induce proliferation across all dosage. 


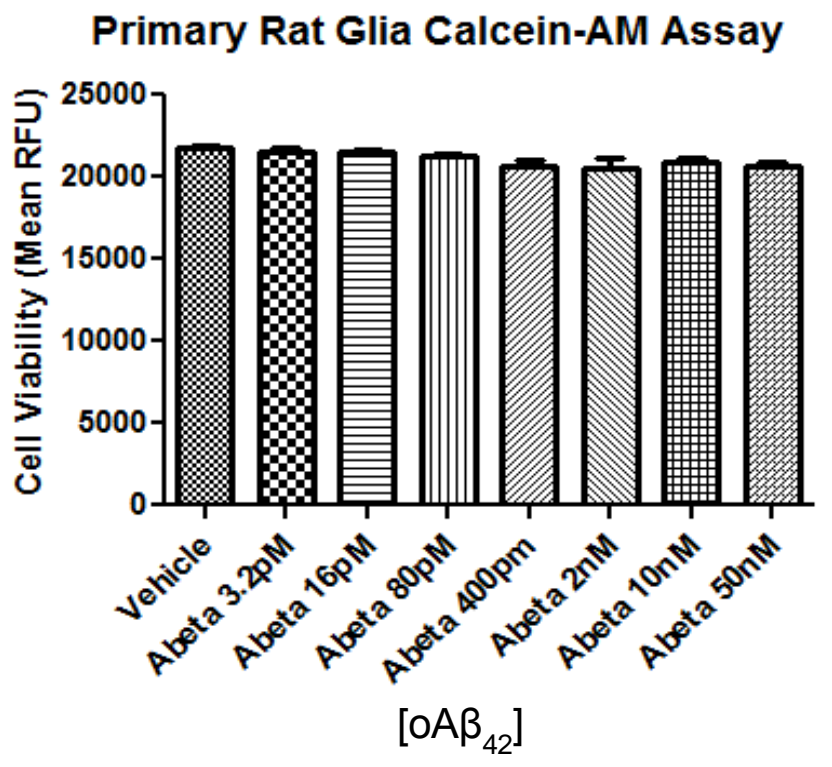

Fig 2.5 Cell viability were measured Mean Relative Fluorescence Units (RFU). Rat primary glia cells were obtained from P2 sprague dawley rats and cultured for 14 days, then counted and seeded in 96-well plate overnight and treated with $0 A \beta_{42}$ for 48 hours. (Statistical analysis was done by One-way $A N O V A$ and Dunnett's post hoc analysis. ${ }^{*} p<0.05$, ** $p<0.005$, *** $\left.p<0.0005\right)$ There was no significant differences in all $0 A \beta_{42}$ treatment group in primary cells, suggest o $A \beta_{42}$ neither present cytotoxicity nor induce proliferation across all dosage.

Fig 2.4 show that the responses pattern of primary glia cells to $\mathrm{oA} \beta$ treatment showed a similar response pattern to that seen in C8-B4 cells. I observed that to achieve more significant difference, the treatment duration in primary glia cell $(48 \mathrm{~h})$ is longer than C8-B4 cell line (24h) probably due to the faster proliferation cycles of cell lines compared to primary cell. Overall the mitochondrial stress assay and the viability assay suggests that C8-B4 cell line represent microglia cells from murine brains very well. 
To examine the effect of $O A \beta$ on neurons at low doses, we performed same set of experiments using three different kinds of cells: 1. Mouse hippocampal cell line HT-22; 2. Primary neuronal cell derived from WT C57BL/6 mouse as well as the primary and 3. Primary neuronal cell from homozygous APP Swedish mutated mouse with C57BL/6 background.
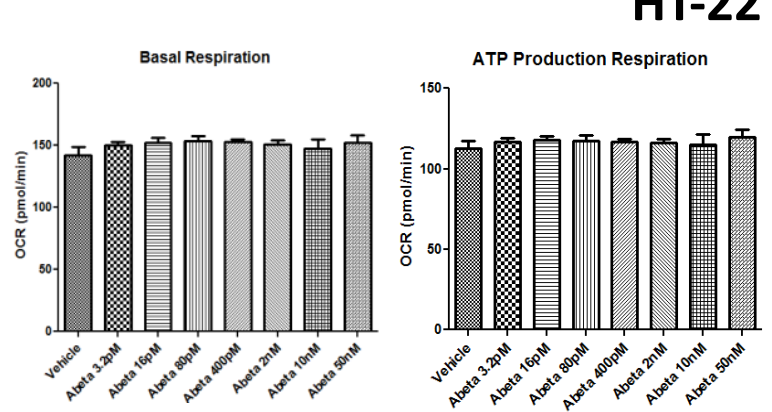

HT-22 Mito Stress parameter
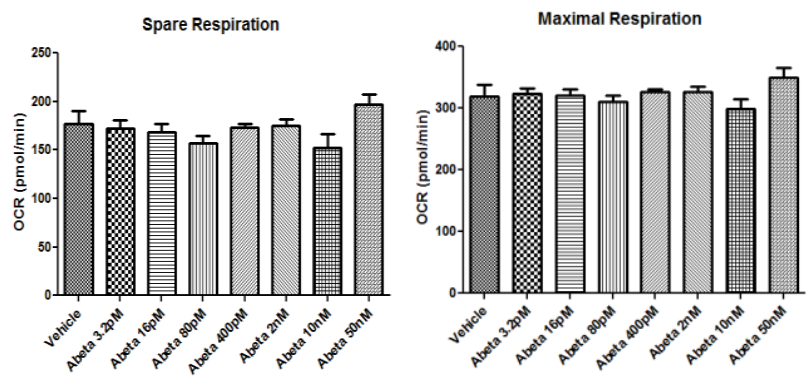

24h treatment

Fig 2.6 Mitochondrial stress parameters were measured as oxygen consumption rates (OCR). HT-22 mouse neuronal cell line (Upper Panel) were seeded in 96-well plate at their optimal density overnight and treated with oAB42 for 24hours. (Statistical analysis was done by One-way ANOV A and Dunnett's post hoc analysis. $\left.{ }^{*} p<0.05,{ }^{*} p<0.005,{ }^{* *} p<0.0005\right)$ There were significant differences in most respiration parameters treated with oA $A 32$ in neuronal cell line HT-22.

In contrast of the increase induced by $\mathrm{OA} \beta$ in both microglia cell line C8-B4 as well as rat primary microglia cells, Fig 2.6 shown that there is no significant change induced by $\mathrm{OA} \beta$ in neuronal cell line HT-22 cells. It suggested that the low dose oA $\beta$ induced mitochondrial functional change is in a cell-specific manner. As before, cell viability Calcein-AM assay was tested to ensure the effect is not caused by the uneven number between different treatment groups. Further cell 
toxicity can be assessed by comparing the cell number in treated group with the vehicle control group.

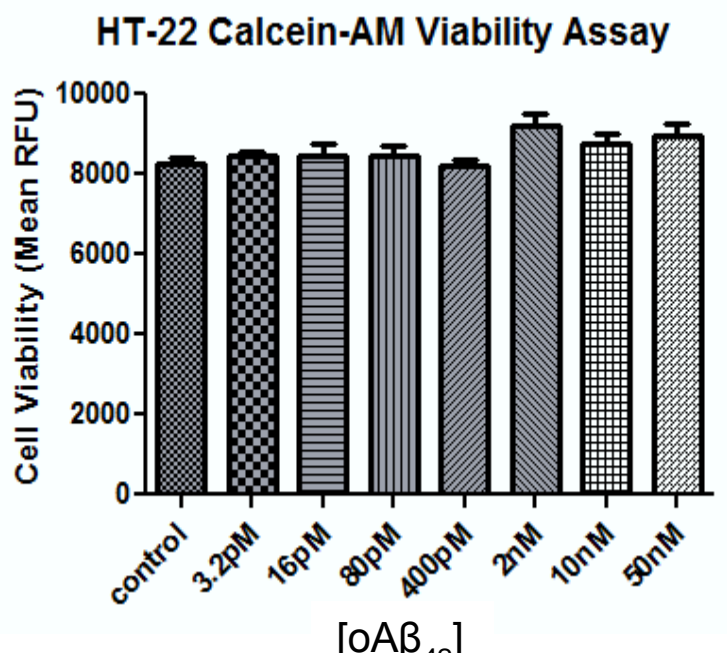

Fig 2.7 Cell viability was measured Mean Relative Fluorescence Units (RFU). HT-22 mouse neuronal cell line were seeded in 96-well plate at their optimal density overnight and treated with o $A \beta_{42}$ for 24 hours. (Statistical analysis was done by One-way ANOVA and Dunnett's post hoc analysis. ${ }^{*} p<0.05$, ** $\left.p<0.005,{ }^{* * *} p<0.0005\right)$ There was no significant differences in all $0 A \beta_{42}$ treatment group in HT-22 cell line suggest o $A \beta_{42}$ neither present cytotoxicity nor induce proliferation across all dosage.

There was no cytotoxity or cell proliferation in HT-22 cells in treated groups (shown in Fig 2.7). These suggested that the $\mathrm{A} \beta$ dosage we applied in these experiments was not toxic to HT-22 cells and did not alter cell proliferation. HT-22 is an immortalized neuronal cell line, thus to verify the representability of HT-22 for neurons, we applied oA $\beta$ treatment to two primary neuronal cells. First we tested the primary cell derived from WT C57BL/6 mouse. 

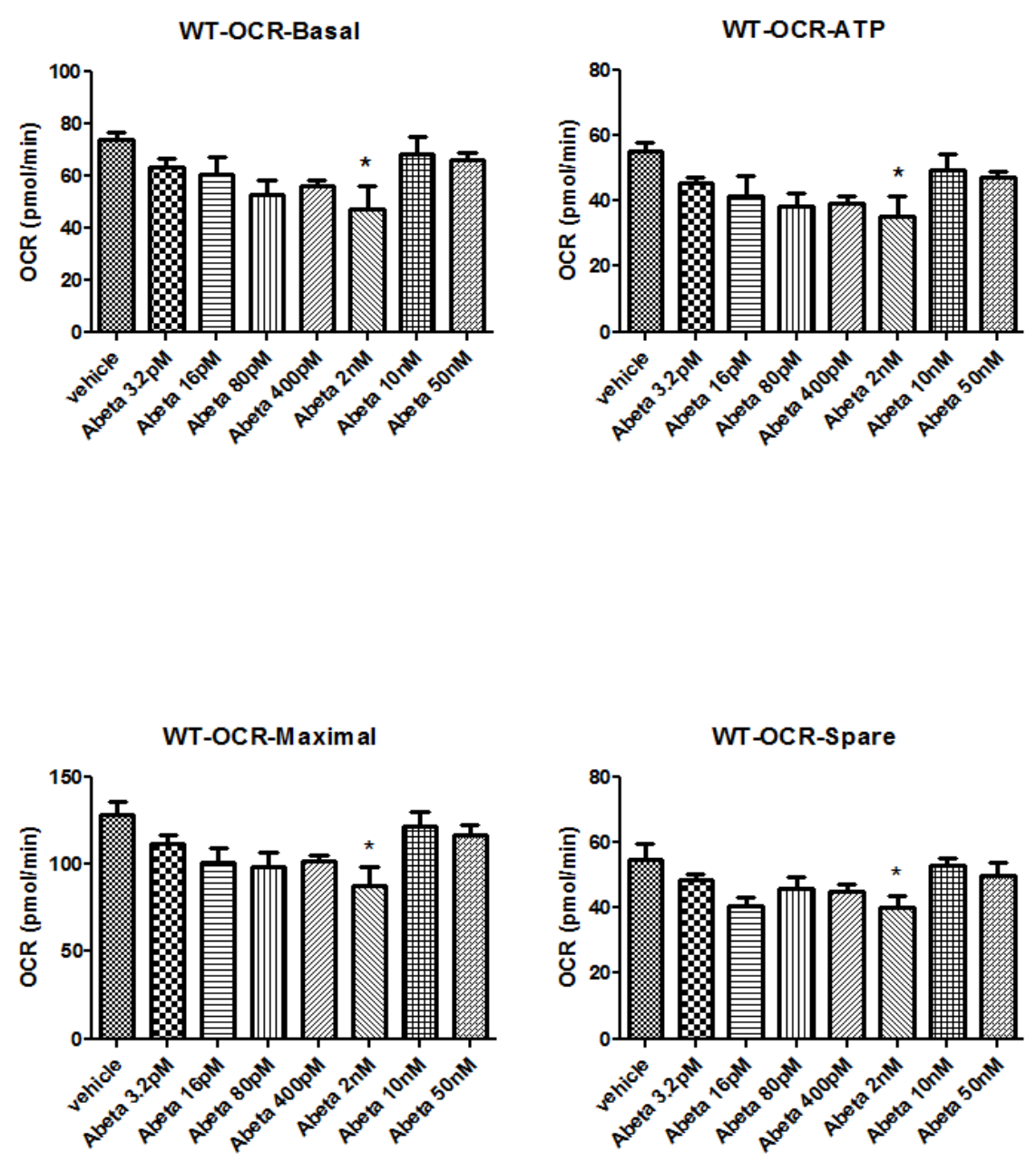

Fig 2.8 Mitochondrial Stress parameter measured by Seahorse assay. All mito stress parameter in WT primary neuronal cells remained same if not declined. Oneway ANOVA with Tukey's test was applied to analysis significant difference. ${ }^{*} p<0.05$ 

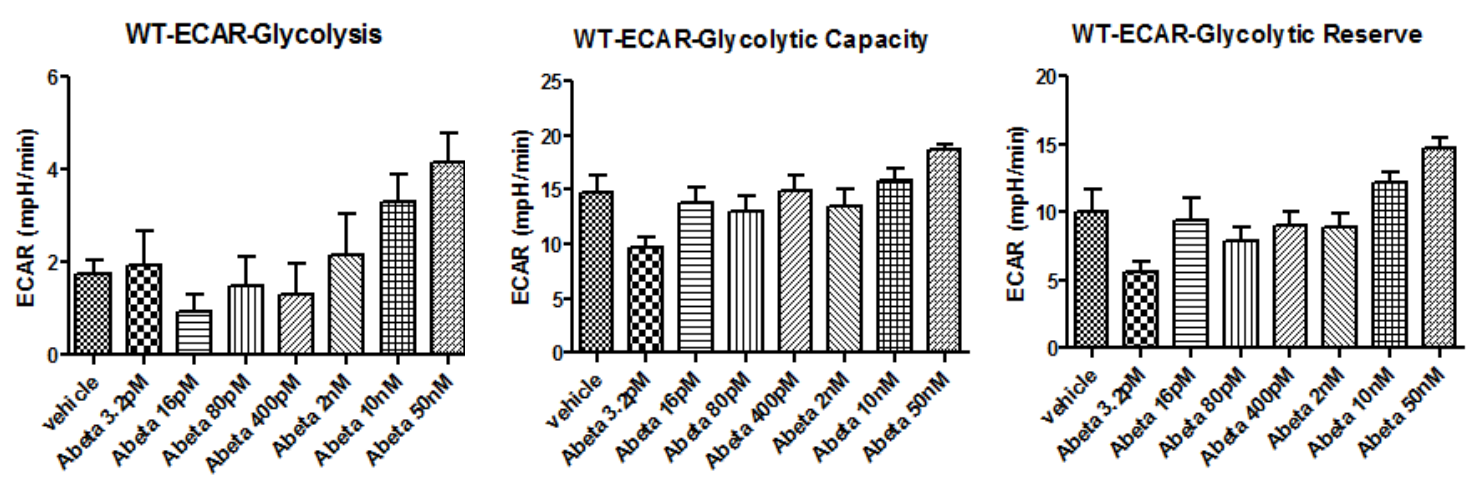

Fig 2.9 Glycolysis Assay measured glycolysis parameters in WT primary neurons. All treatment groups' glycolysis parameter didn't seem to differ from vehicle by Oneway-ANOV A Tukey's Post hoc analysis, although it seems a trend of increase in glycolysis with the increase of Abeta dose.

Fig 2.8 and 2.9 shown the calculated mitostress parameter value and glycolysis parameters respectively. Mitochondrial and glycolysis evaluations through Seahorse extracellular flux experiments shown that there was no significant change of OCR except a small decline at $2 \mathrm{nM}$ oA $\beta$ in all mitochondrial stress parameters and there is no significantly change in all glycolysis parameters except a tread of increase of glycolysis in a dose-dependent manner. 

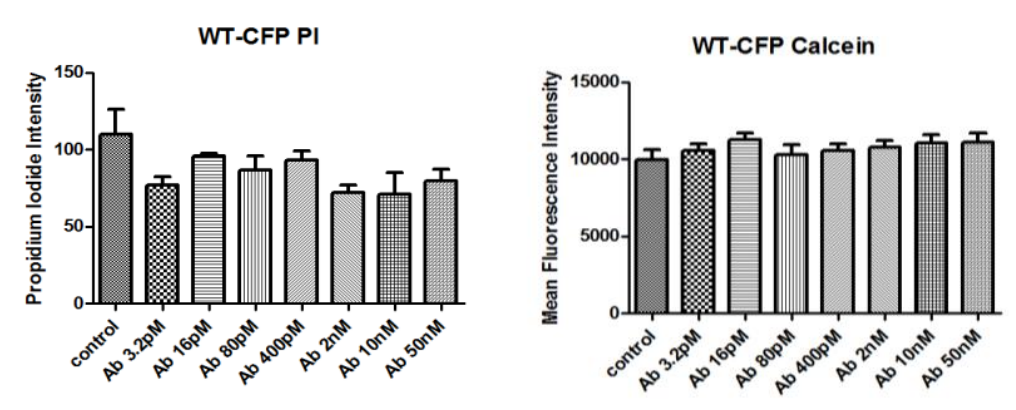

Fig 2.10 Cell Viability of WT primary neurons suggest cell population doesn't change across treatment groups by both PI staining and Calcein-AM Assay. Data analyzed by Oneway-ANOVA Tukey's Post hoc analysis.

Also both PI staining for dead cells and Calcein-AM assay for live cell (Fig 2.10) to test cell viability show no difference betwwen the treated groups vs. vehicle control.

To determine the effect of $O A \beta$ on primary neuron which carry a genetic $A D$ disease background, mutated with an insertion of humanized homozygous amyloid beta precursor protein Swedish gene sequence. With the mutation, the transgenic cell can manufacture human APP protein with the control of mouse Thy 1.2 regulatory element.

Fig 2.11 and 2.12 shown the calculated mitostress parameter value and glycolysis parameters respectively. 

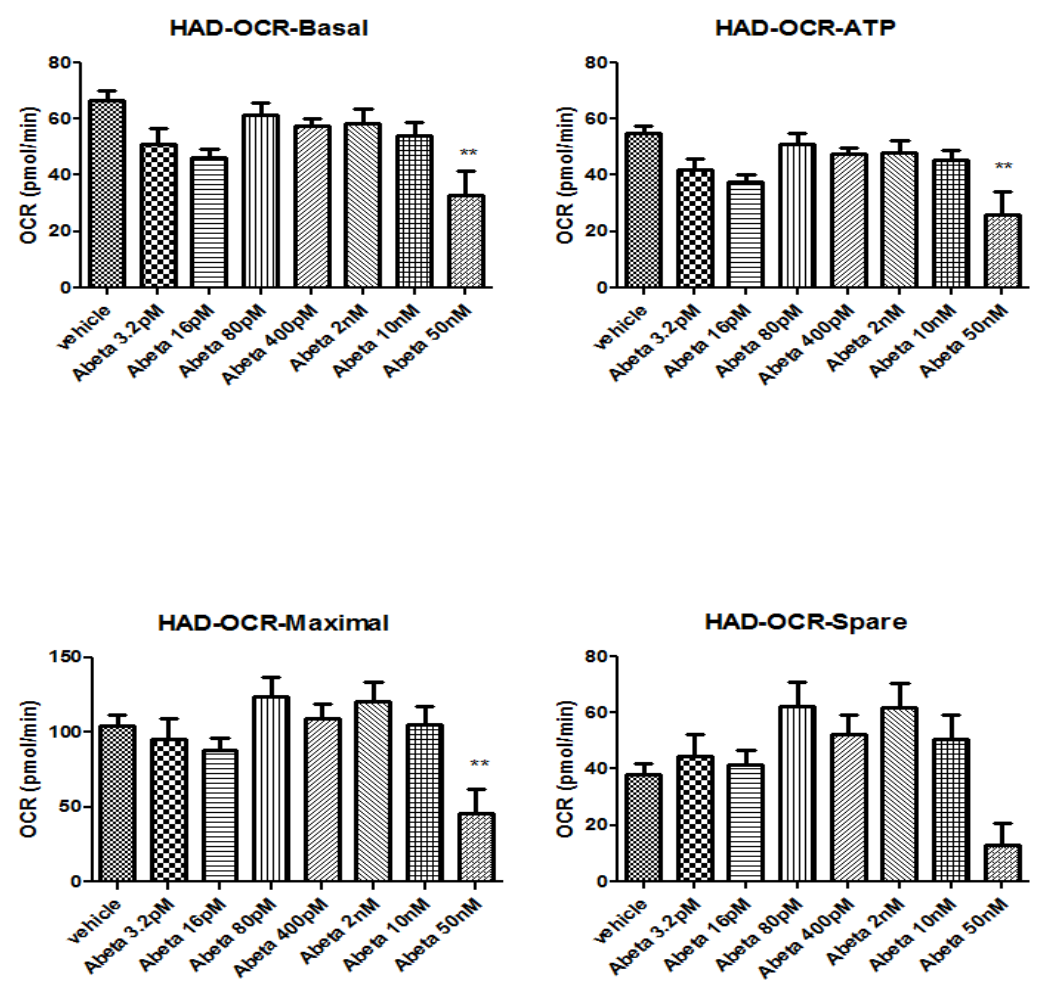

Fig 2.11 Mitochondrial stress parameter measured by Seahorse Assay. Instead of increase of mito stress parameter in mouse primary glia, all mito stress parameter in HAD primary neuronal cells remained same except a small decline at 50nM. Oneway ANOV A with Tukey's test was applied to analysis significant difference.

Seahorse extracellular flux experiments shown that there was no significant change of OCR except a small decline at $50 \mathrm{nM}$ oA $\beta$ in all mitochondrial stress parameters (Fig 2.11) and there is no significantly change in all glycolysis parameters (Fig 2.12). 

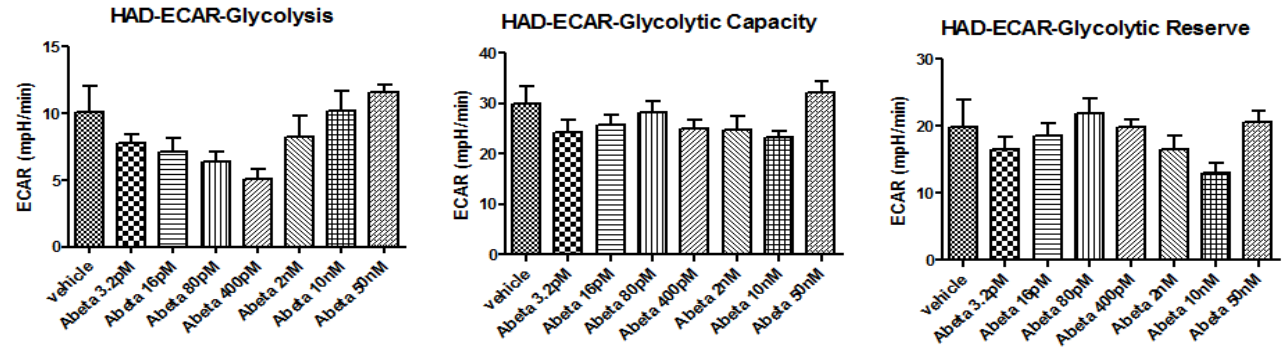

Fig 2.12 Glycolysis Assay measured glycolysis parameters in HAD primary neurons. All treatment groups' glycolysis parameter didn't seem to differ from vebicle by Oneway-ANOV A Tukey's Post hoc analysis, although it seems a trend of increase in glycolysis with the increase of Abeta dose.
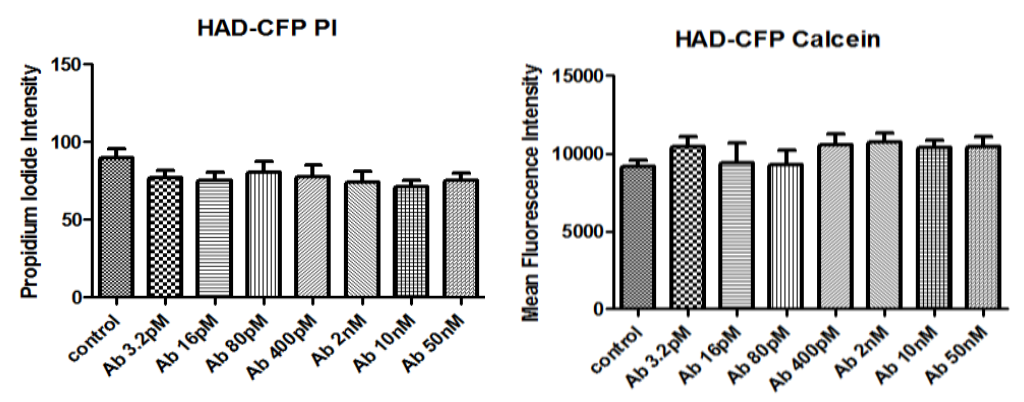

Fig 2.13 Cell Viability assay of HAD primary neurons, Cell number doesn't change across treatment groups in WT primary neurons by both PI staining and Calcein-AM Assay. Data analyzed by Oneway-ANOVA Tukey's Post hoc analysis.

We use both PI staining for dead cells and Calcein-AM assay for live cell to test cell viability. None of them show any difference between the treated groups vs. vehicle control group. 


\subsection{Discussion}

In this project we tested the effect of various concentration of $o A \beta(p M-n M)$ in different cell types. Overall there is no effect of oA $\beta$ on all viability was observed suggested the dosage we used in this series of experiments is not toxic to either microglia cells or neuronal cells. In this study, our experiments using oA $\beta$ as an insult to mimic the AD amyloid- $\beta$ environment in microglia cell line C8-B4. Also by utilizing different type of cells, we tested the specificity of the mitochondrial response in different cell type upon oA $\beta$ stimulation. Further we examine whether cell lines could represent non-transformed cells in term of their response pattern in mitochondrial respiration and glycolysis assay. In all conditions, we also tested cell viability simultaneously ensure that potential treatment effect were not the result of changes in cell number. Our experiments results have successfully shown an intracellular molecular response in term of oxygen consumption rate (OCR) change upon $o A \beta$ stimuli, suggesting that microglial cell indeed respond to the soluble form of oligomeric $A \beta$.

The observed changes upon low dose oA $\beta$ stimuli specifically in microglial cells provide evidence of early involvement of microglia before $A \beta$ plaque formation. Thus raise the possibility that microglial function can be controlled by regulate mitochondria function, thus the fate of beneficial or detrimental pathway of microglia could be controlled in AD.

It is known that besides age, gender is another major risk factor of Alzheimer's disease. The incidence of $A D$ is higher in women than in men. It 
cannot be simply attributed to the higher longevity of women. It has been suspected that a specific pathogenic mechanism behind the higher incidence of AD cases in women. One postulated hypothesis is that mitochondria from young women are protected against amyloid-beta toxicity than males. The mitochondria protect cells by generating less reactive oxygen species and release less apoptogenic signals while this advantage is lost in mitochondria in aged female $A D$ patients (Vina \& Lloret, 2010). One pitfall of these experiments is that gender difference could not be reflected using this in vitro model although the C8-B4 cells originally derived from female mouse, the gender effect is more systematic effect. Another drawback is the low yield of oligomeric $A \beta$ synthesis. Large fraction of material $A \beta$ converted into insoluble form during synthesis which results in the high cost of $O A \beta$ reagent preparation. The multiple compositions of $O A \beta$ with different number of oligomerization is also a problem, it may contribute to the variance of groups with different concentration.

Previous studies have shown that amyloid-beta oligomer at low nanomolar concentrations activate microglia and also induce microglial neurotoxicity (2011 JBC) in primary mice microglia cells. Researches (Perez-Nievas et al., 2013) using post mortem samples suggested that although soluble amyloid- $\beta$ did not differ among groups between $A D$ vs control by immunoblotting and ELISA, but oligomeric amyloid- $\beta$ load was significant higher in demented cases with Alzheimer's disease (15pM in AD while $<5 \mathrm{pM}$ in Control). Thus oligomeric form is critical among all types of amyloid-beta peptides in AD. Although there are studies 
focused on the microglia cells in $A D$, little is known about the mitochondrial functions in microglia in AD. What we did in this project has fill the gap of the low dose effect in $A D$ in vitro model, also further explore the role that mitochondria plays upon oA $\beta$ stimulation. The results of the cell specific response provide an evidence of microglia function in early $A D$ suggest that the postulate of microglia therapy is prominent in $A D$ treatment development. 
CHAPTER 3: OLIGOMERIC ABETA INDUCED MICROGLIA ACTIVATION AND PHENOTYPICAL POLARIZATION

\subsection{Introduction}

Based on the results of the first projects, we confirmed that microglial cells but not neuronal cells indeed respond to very low dose of soluble oA $\beta$ specifically. The next question is: do microglia cells change their morphology when their mitochondrial functions get changed upon $O A \beta$ stimuli, do they undergo phagocytosis preparation by upregulate the energy production? Or are they under a classical activation in preparation for the released regulatory cytokines.

Another question need to be addressed in this part is to test the response of other brain cell types upon the low dose oA $\beta$, since little is known about the neuronal response under such condition. In this chapter, my project is focused to answer the question raised above and I hypothesize that: 1) Low dose oA $\beta_{42}$ increases microglial oxidative phosphorylation respiration and induces microglia activation favors $M 2$ phagocytic pathway while higher dose $\mathrm{OA} \beta_{42}$ shuffled the activation toward pro-inflammatory pathway. 2) Low and high level of $o A \beta_{42}$ induce different microglia activation type which favors anti- or pro-inflammation, respectively. 3) The favored activation phenotype is depending on the mitochondrial respiration stimulation. 
Rationale: Due to the fast engulfment and morphology change, M2 pathway is hypothesized to be more energy demanding compared to M1, thus the mitochondrial oxidative-phosphorylation, the main energy supply process, is regulated accordingly. Microglia are constantly surveying surrounding environment (Tremblay et al., 2011), prevent and slow AD by clearing A $\beta$. In AD brain, microglia cells accumulate at the site of fibrillary $A \beta$ plaques. The uptake of the most menacing $A \beta$ species o $A \beta$ by microglia is receptor-independent pinocytosis.

Exp. 1 Microglia phenotypical changes assessed by translocation of NFkB, and $\mathrm{M} 1$ or M2 phenotypical markers expression as well as other activation marker expression assessed by flow cytometry.

Exp. 2 Microglial morphology change assessed by confocal fluorescent immunocytochemistry microscope imaging staining the shape of the microglial cells. Together mitochondria localization in microglial cells upon oA $\beta$ stimuli is assessed by mitochondrial counterstain using mitochondrial tracker (mito-red).

Exp. 3 Microglial transcriptive change during $\mathrm{OA} \beta_{42}$ induced activation. In addition to the general activation marker IBA-1, M1 activation markers (Chhor et al., 2013; Crain, Nikodemova, \& Watters, 2013) iNOS; CCL2; IL-1 $\beta$ and TNFa, M2 activation markers (Cherry, Olschowka, \& O'Banion, 2014) Arg1; IL-10; YM1/2 and TGF- $\beta$ ) (Crain et al., 2013; Michelucci, Heurtaux, Grandbarbe, Morga, \& Heuschling, 2009) were measured after $24 \mathrm{~h}$ treatment of $\mathrm{oA} \beta_{42}, 10 \mathrm{ng} / \mathrm{ml}$ LPS (M1 positive control), $1 \mathrm{ng} / \mathrm{ml} \mathrm{IL-4}$ and IL-10 combination (M2 positive control). These 
markers were evaluated by real-time PCR. In the preliminary study, IL-10 was upregulated in $\mathrm{OA} \beta_{42}$ treated C8-B4 cells and could be a possible candidate that increases the mitochondrial function by $\mathrm{oA} \beta_{42}$.

Exp. 4 Microglia phagocytosis function was assessed by a fluorescent microsphere assay. Cells were treated with $O A \beta_{42}$, LPS for 24hours, then incubated with fluorescent dye Nile red Microsphere ( $d=1 \mu \mathrm{m})$ (Life Technology). Confocal microscopic images will be taken, and numbers of microsphere engulfed into microglia were counted. To better quantify microsphere intake, alternatively flow cytometry assay was used to compare a mean fluorescence intensity (MFI) change.

Expected Results and potential problems:

Microglia phenotypical changes are expected in to be reflected in rtPCR assays. The $M 2$ activation is expected to be induced with $\mathrm{oA} \beta_{42}$ treatment. However, not all M2 markers increase to same extent. LPS induces typical M1 activation, and it can also regulate M2 markers. An IL-4 + IL-10 combination was used to induce typical M2 activation. We expected no change or subtle change in M1 activation, while M2 markers expression increase was anticipated. 


\subsection{Material and Method}

\section{Cell Culture}

C8-B4 (ATCC) cells were grown in Dulbecco's modified Eagle's medium (DMEM; Hyclone) containing 10\% fetal bovine serum (FBS; Atlanta biologicals) and 100units $/ \mathrm{ml}-100 \mu \mathrm{g} / \mathrm{ml}$ Penicillin-Streptomycin (PS; Hyclone) in $5 \% \mathrm{CO}_{2}$ at $37^{\circ} \mathrm{C}$.

\section{Immunocytochemistry Staining}

We prepared rinsed coverslips well by sterile $\mathrm{H}_{2} \mathrm{O}$ (three times 5 min each) into flat bottom 6-well plate, then allow coverslips to dry completely and sterilize them under UV light overnight. C8-B4 cells were grown on glass coverslips overnight, then rinsed briefly in phosphate-buffered saline (PBS). Cells were fixed using $4 \%$ paraformaldehyde in PBS $\mathrm{pH} 7.4$ for $10 \mathrm{~min}$ at room temperature, then washed three times with ice cold PBS. We incubated the samples for 10 min with PBS containing $0.25 \%$ Triton X-100 to permeablize cells, then cells were washed in PBS three times for 5 min. Cells were incubate with 1\% BSA in PBS for $1 \mathrm{~h}$ to block nonspecific binding of the antibodies. We then incubate cells in the diluted primary antibody in $1 \% \mathrm{BSA}$ in PBS in sealed container overnight at $4^{\circ} \mathrm{C}$. We washed the cells three times in PBS, 5 min each wash, then incubated cells with the secondary antibody in $1 \%$ BSA for $1 \mathrm{hr}$ at room temperature in the dark. Cells were washed three times with PBS for 5 min each in the dark, then coverslips were mounted with a drop of mounting medium containing DAPI. Coverslips were 
sealed with nail polish to prevent drying and movement under microscope and the slides were cured for $24 \mathrm{hrs}$ and stored in dark at $-20^{\circ} \mathrm{C}$ or $+4^{\circ} \mathrm{C}$.

\section{Flow cytometry}

To measure the activation phenotype, microglia were subjected to flow cytometry analysis. After treatment with $\mathrm{OA} \beta_{42}$ and LPS for 24 hours, the cultured cells were counted and incubated with fluorophore-conjugated primary antibodies anti-CD40, anti-CD206, anti-IBA-1. Mean fluorescent Intensities were measured using Fortessa Flow Cytometer, and analyzed by FCS express software.

\section{Real-time PCR}

Total RNA was purified from cultured cells using the RNeasy micro kit (Qiagen) for total RNA extractions. RNA was reverse transcribed using the Applied-Biosystem with $2 \mu \mathrm{g}$ total RNA sample from C8B4 microglial or primary microglial cells. The reverse transcription reaction was performed in a total volume of $20 \mu \mathrm{L}$ containing $2 \mathrm{uL}$ 10X Reaction Buffer, $0.8 \mu \mathrm{L} 25 \mathrm{X}$ dNTP mix, $2 \mu \mathrm{L}$ 10X RT random primers, $1 \mu \mathrm{L}$ multiscribe reverse transcriptase, $1 \mu \mathrm{L}$ Rnase inhibitor, 3.2 $\mu \mathrm{L}$ Nuclease-free water and $10 \mu \mathrm{L} \mathrm{RNA}$ sample for $10 \mathrm{~min}$ at $25^{\circ} \mathrm{C}, 2 \mathrm{~h}$ at $37^{\circ} \mathrm{C}$ and 5 min at $85^{\circ} \mathrm{C}$. Individual $25 \mu \mathrm{L} \mathrm{SYBR} \mathrm{Green} \mathrm{real-time} \mathrm{PCR} \mathrm{reactions} \mathrm{consisted} \mathrm{of}$ $2.5 \mu \mathrm{L}$ of cDNA, $12.5 \mu \mathrm{L} 2 \mathrm{X}$ SYBR Green mix (Applied Bioscience), and $5 \mu \mathrm{L}$ of each $12.5 \mu \mathrm{M}$ optimized forward and reverse primers and $5 \mu \mathrm{L}$ RNase-free water. 
Primer sequences designed are described in Table 3.1.

\begin{tabular}{|c|c|c|}
\hline Target & Forward & Reverse \\
\hline IBA1 & CTT-TTG-GAC-TGC-TGA-AGG-C & $\begin{array}{l}\text { GTT-TCT-CCA-GCA-TTC-GCT- } \\
\text { TC }\end{array}$ \\
\hline iNOS & CAA-GCA-CCT-TGG-AAG-AGG-AG & $\begin{array}{l}\text { AAG-GCC-AAA-CAC-AGC-ATA- } \\
\text { CC }\end{array}$ \\
\hline CCL2 & $\begin{array}{l}\text { CAC-TCA-CCT-GCT-GCT-ACT- } \\
\text { CAT-TC }\end{array}$ & $\begin{array}{l}\text { GCT-TCT-TTG-GGA-CAC-CTG- } \\
\text { CTG }\end{array}$ \\
\hline IL1- $\beta$ & GCT-TCA-GGC-AGG-CAG-TAT-C & $\begin{array}{l}\text { AGG-ATG-GGC-TCT-TCT-TCA- } \\
\text { AAG }\end{array}$ \\
\hline TNF- $\alpha$ & GGT-TCT-GTC-CCT-TTC-ACT-CAC & T-GCC-TCT-TCT-GCC-AGT-TCC \\
\hline Arg1 & TCA-CCT-GAG-CTT-TGA-TGT-CG & $\begin{array}{l}\text { CTG-AAA-GGA-GCC-CTG-TCT- } \\
\text { TG }\end{array}$ \\
\hline IL-10 & CCA-AGC-CTT-ATC-GGA-AAT-GA & $\begin{array}{l}\text { TTT-TCA-CAG-GGG-AGA-AAT- } \\
\text { CG }\end{array}$ \\
\hline TGF- $\beta$ & TGC-GCT-TGC-AGA-GAT-TAA-AA & $\begin{array}{l}\text { CGT-CAA-AAG-ACA-GCC-ACT- } \\
\text { CA }\end{array}$ \\
\hline YM1/2 & CAG-GGT-AAT-GAG-TGG-GTT-GG & $\begin{array}{l}\text { CAC-GGC-ACC-TCC-TAA-ATT- } \\
\text { GT }\end{array}$ \\
\hline
\end{tabular}

Table 3.1 shows the sequence of forward and reverse primers of target RNA transcripts to evaluate microglial activation polarization by rtPCR assay. 


\section{Phagocytosis assay}

Microglial phagocytosis was measured by uptake of fluorescent microspheres. C8-B4 cells or primary microglia cells were cultured in DMEM containing $10 \%$ FBS on glass coverslips overnight and treated with $\mathrm{OA} \beta_{42}$, IL-4, IL10 and/or LPS. At the end of treatment, cells were incubated with Microsphere (1 $\mu \mathrm{m}$ in diameter) in PBS containing $1 \mathrm{mg} / \mathrm{ml} \mathrm{BSA}$ for additional $30 \mathrm{~min}$. Cells are washed with PBS and fixed with $4 \%$ paraformaldehyde and stained with Alexa Fluor 488 Phalloidin (Life Technology) for visualization, mounted with ProLong Gold anti-fade reagent(Life Technology).

To better quantify the extent of phagocytosis in a given number of cells, microglia were subjected to flow cytometry analysis. After treated with $\mathrm{oA} \beta_{42}$ and LPS for 24 hours, the cultured cells were counted and incubated with fluorescent microsphere for $1 \mathrm{~h}$. Mean fluorescent Intensities were measured using Fortessa Flow Cytometer, and analyzed by FCS express software.

\section{Statistical analysis}

The statistical analysis between the groups with normal distributions was performed using Graphpad (Prism) or SPSS (statistical package for the social sciences, IBM) software. For comparison of multiple treatments, results were analyzed by ANOVA across group. Tukey's test or Dunnett's was used to adjust for multiple comparisons in post hoc pairwise tests. The differences between 
groups were considered to be statistically significant when $p<0.05$. Results values are reported as mean \pm standard error of means (SEM).

\subsection{Results}

Since we observed an increase in mitochondrial respiration at low doses of $\mathrm{OA} \beta$, we then assessed if C8-B4 cell are activated under these conditions. So we carried out immunocytochemistry staining of $\mathrm{NFkB}$, a transcription factor which translocate from cytosol to nucleus upon microglial activation. C8-B4 cells were treated with LPS 10ng/ml for 24hrs as a positive control shown in Fig 3.1.

The images of NF-kB translocation show the results of minor sign of translocation. There is a small trend of increased translocation as oA $\beta$ treatment concentration increases. But the translocation was not obvious enough to be quantified using fluorescent imaging. 

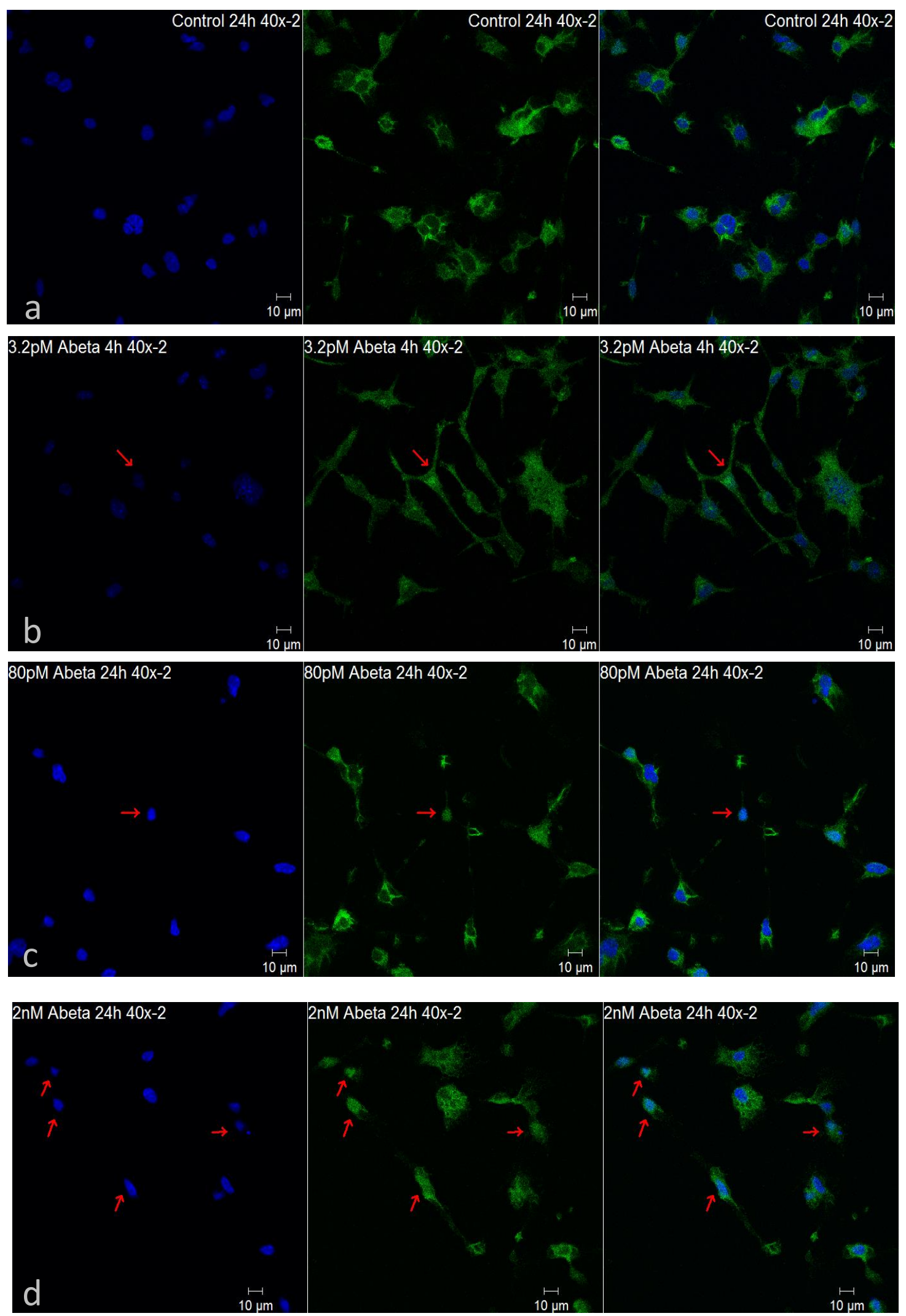


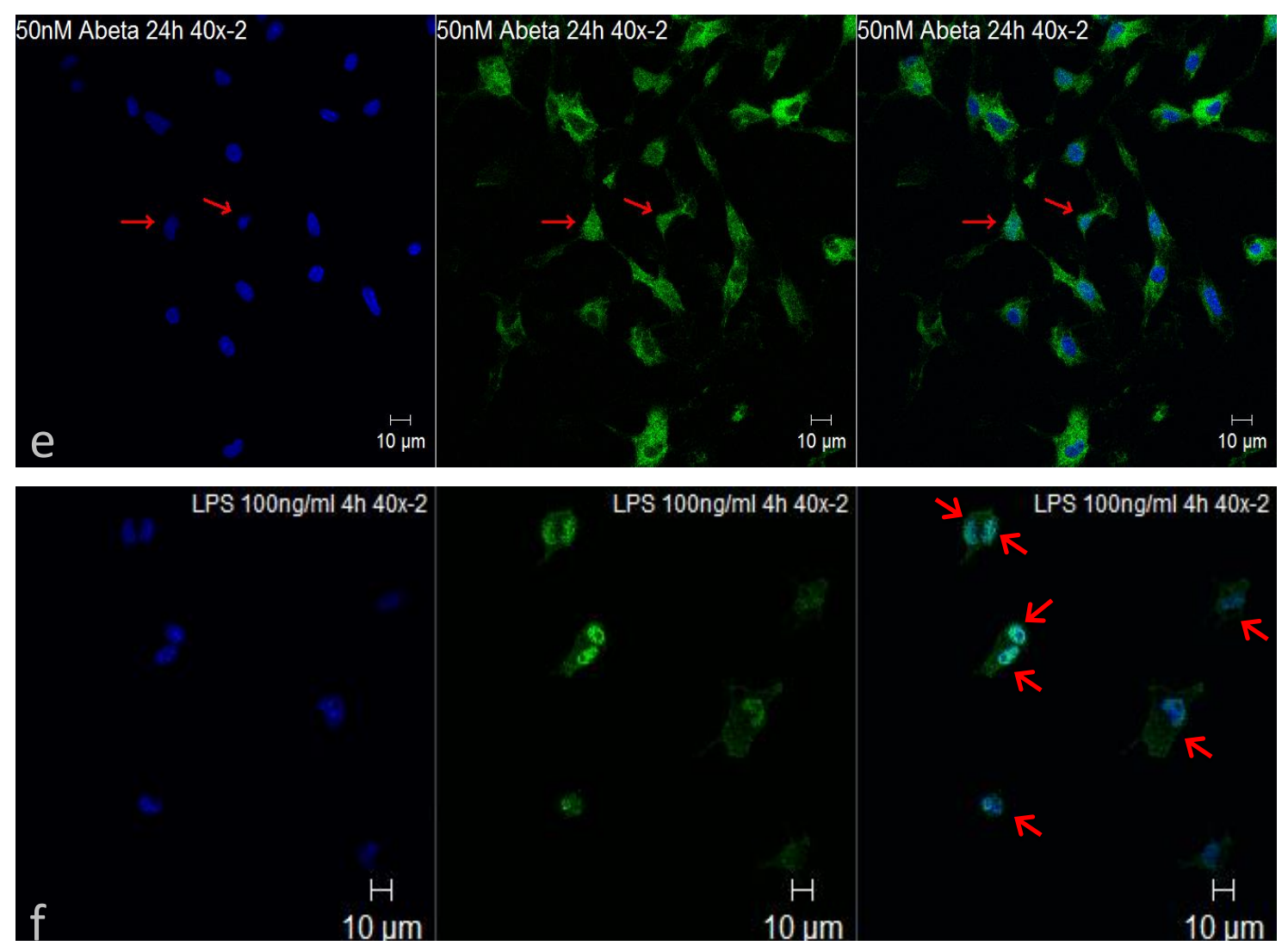

Fig 3.1 shows Immunocytochemistry images of NFkB translocation after 24h treatment of a) control, b) 3.2pM o $A \beta$, c) $80 p M \circ A \beta$, d) $2 n M \circ A \beta$, e) $50 \mathrm{n} \circ A \beta$ and f) $4 \mathrm{~b}$ treatment of $10 \mathrm{ng} / \mathrm{ml} \mathrm{LPS}$. D $A P I$ (Blue, left panel), NFkB (Green, middle panel) and overlay right panel. Red Arron indicate the translocation position.

Since it is hard to qualitatively and quantitatively judge the activation status of C8-B4 cells induced by soluble oA $\beta$, we performed a flow cytometry assay using typical M1 (CD40) and M2 (CD206) markers of microglial activation, to determine if oA $\beta$ induced microglia phenotypical changes. C8-B4 cells were cultured overnight, and then treated with $o A \beta_{42}$ for $24 \mathrm{~h}$. At the end of the treatment, cells will be collected and incubated with primary antibodies of general activation marker IBA-1 (Serrano-Pozo, Gomez-Isla, Growdon, Frosch, \& Hyman, 2013), M1 
activation markers CD40(Hjorth et al., 2013), and M2 activation marker CD206 (Bedi, Smith, Hetz, Xue, \& Cox, 2013). All activation markers expression will be measured by the mean fluorescent intensity (MFI) change.
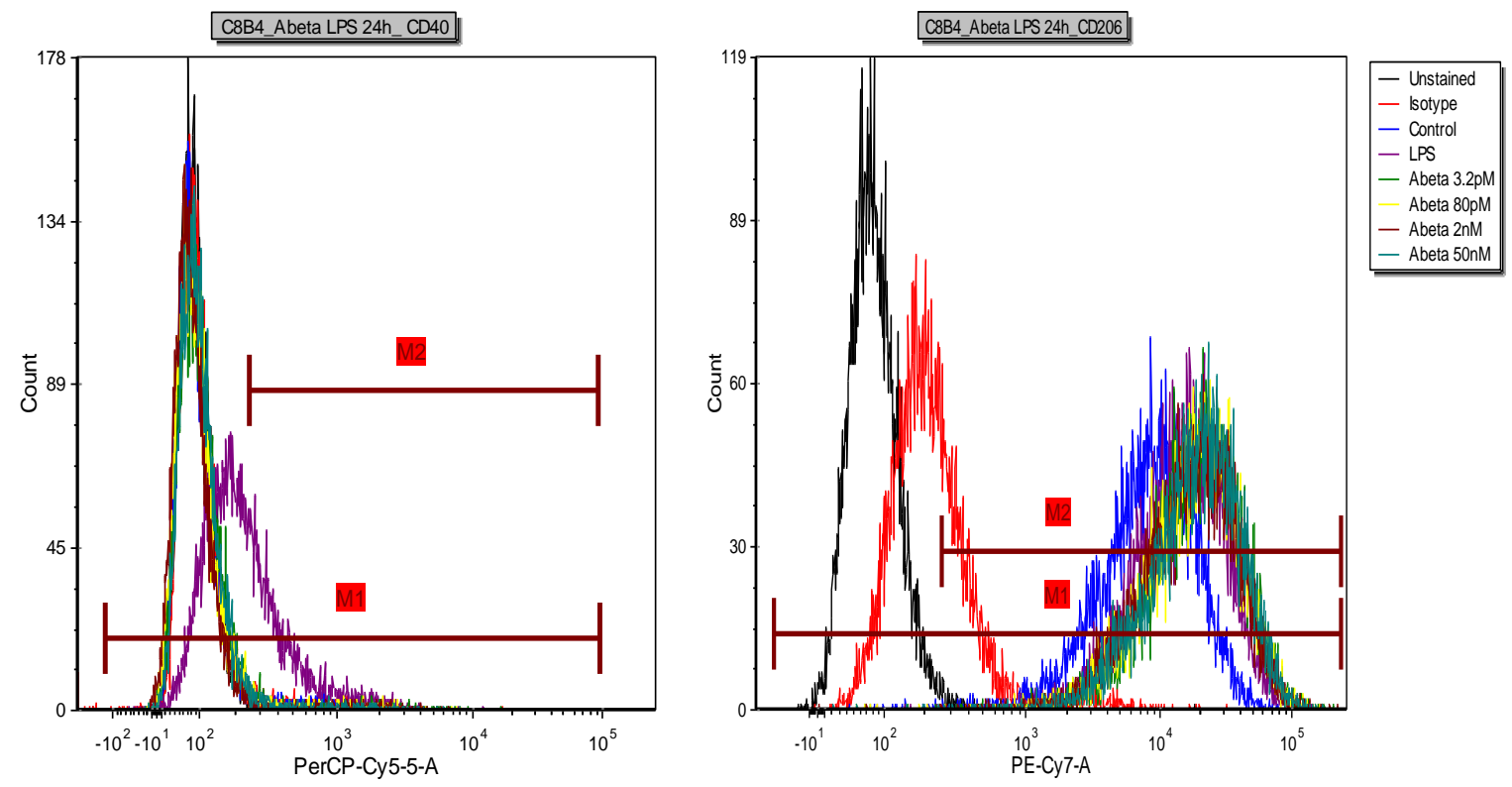

Fig 3.2 Histogram of flow cytometry assay using M1 (CD40) and M2 (CD206) marker after 24h oA $\beta$ treatment in C8-B4 cells. X-axis is single fluorescent intensity, $Y$-axis is cell count.

As we can see in Fig 3.2, the oA $\beta$ treated groups did not induced M1 specific activation compared to control group, but induced M2 specific activations slightly (peak shift right compared to control group). Both M1 marker-CD40 and M2 marker-CD206 did not shown a significant difference between the oA $\beta$ treated groups. LPS treatment triggered an increase in Mean Fluorescent Intensity (peak shift to right). Interestingly LPS also induced M2 activation according to CD206 peak shift. 
To confirm the activation indeed happened, we performed flow cytometry assay using IBA-1 (ionized calcium-binding adapter molecule 1), a specific microglial marker which up-regulated during activation process.

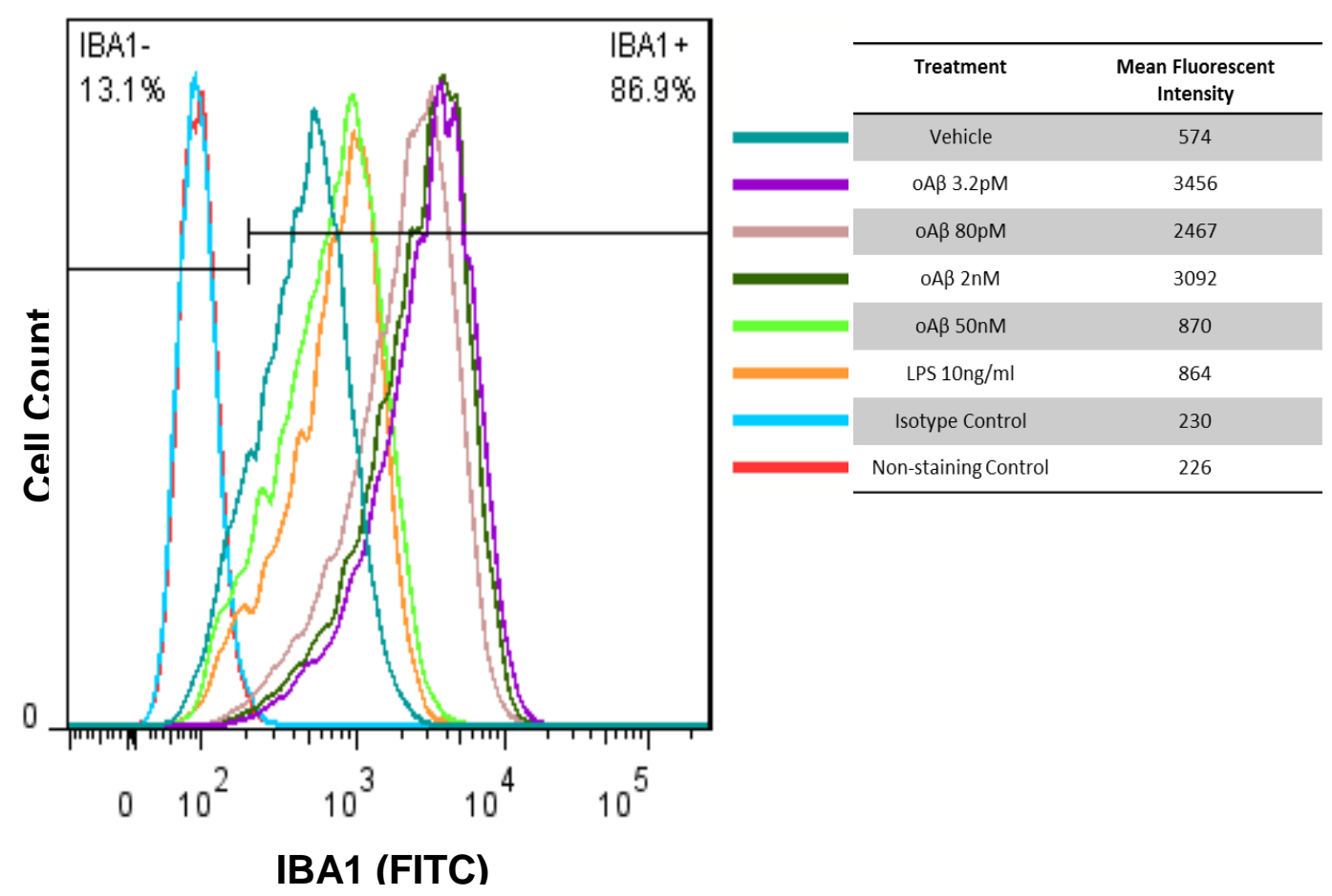

Fig 3.3 Flow cytometry assay of IBA-1 expression. IB $A-1$ upregulation in higher at low dose o $A \beta_{42}$ treatment compare to bigher dose $0 A \beta_{42}$ treatment.

As Fig 3.3 shows that IBA-1 expression was upregulated in all treatment groups, but lower doses of $\mathrm{OA} \beta(3.2 \mathrm{pM}, 80 \mathrm{pM}, 2 \mathrm{nM})$ induced more shift of the peak meaning the upregulation of IBA-1 is more compared to higher dose of oA $\beta$ (50nM) and LPS induced upregulation.

Overall the Flow cytometry assay of IBA-1 expression in C8-B4 cell shown that IBA-1 upregulation upon $\mathrm{OA} \beta_{42}$ treatment was increased at low dose, and 
declines at higher dose. This change follows a pattern which is very similar to the pattern of mitochondrial respiration change shown in Chapter 2. MFI of CD40 increased only in LPS groups but not in $A \beta_{42} \mathrm{O}$ groups. $C D 206$ shows increase in all $O A \beta_{42}$ groups with no significant difference between doses while increase less extent in LPS group.

To investigate the possible association between mitochondrial function and cell function at low dose of $\mathrm{oA} \beta_{42}$ treatment, we evaluated microglia phenotypical changes with microglia phagocytosis function. I also conducted the mechanistic study based on the phenotypical changes.

Previous literatures (Kettenmann et al., 2011) have described the morphology change accompaning phenotypical change during microglial activation. In the typical "resting" stage, microglia cells appear quite different from macrophage. They send out long branching processes to survey the surrounding environment. Once they detect any signal as a threat to the homeostasis, they are triggered into transition to activated states with an amoeboid shape to be able to phagocytose cell debris, lipids and apoptotic cells.

We carried out immunofluorescent imaging to observe cellular morphology change under different dose of $\mathrm{OA} \beta$. Also mitochondria were stained simultaneously in order to observe any mitochondrial localization change. C8-B4 cells were treated with $O A \beta$ and LPS for $24 \mathrm{~h}$ and stained with Calcein-AM (Green), DAPI (Blue) and Mito-tracker Red (Red). 


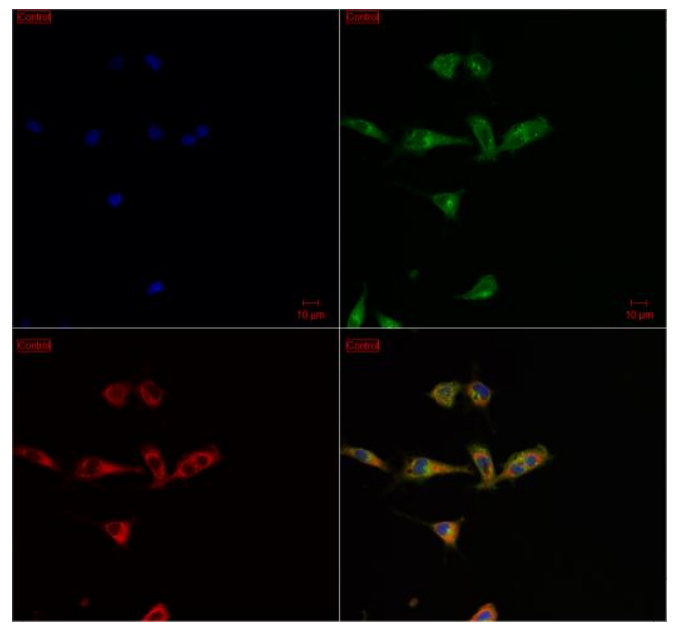

a) Control

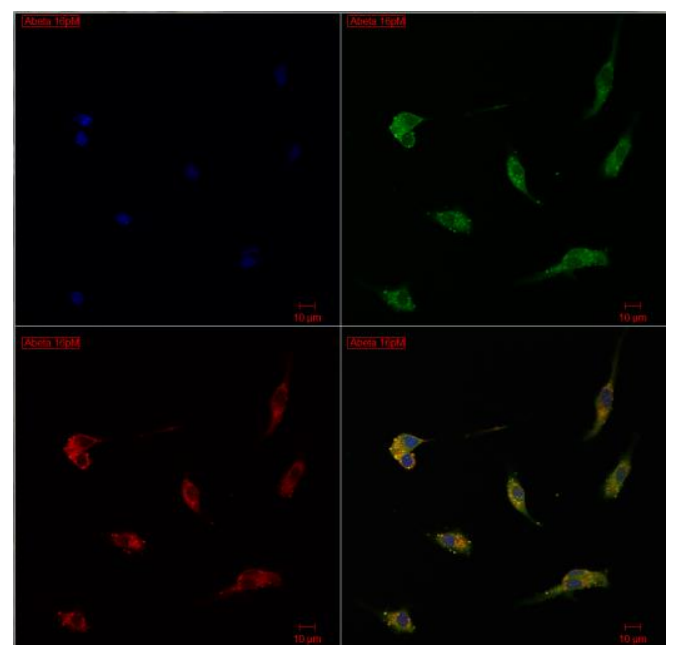

c) $O A B 16 \mathrm{pM}$

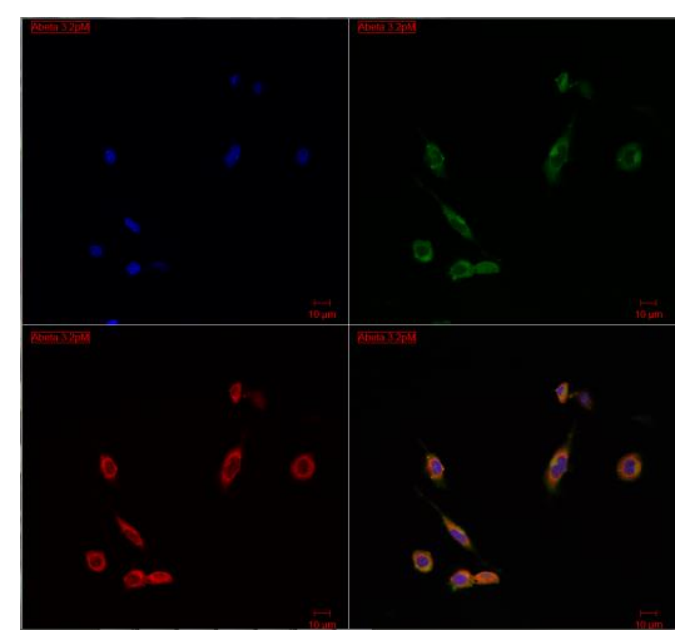

b) $\mathrm{oA} 33.2 \mathrm{pM}$

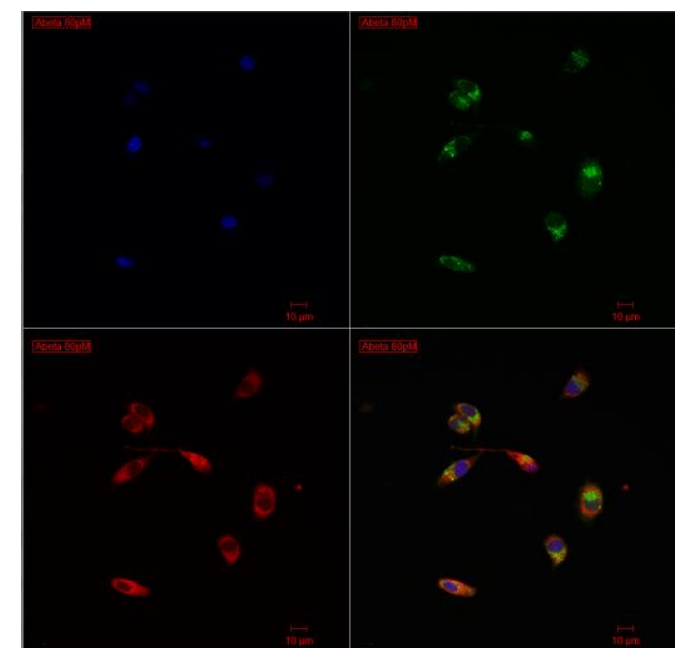

d) $O A \beta 80 \mathrm{pM}$ 


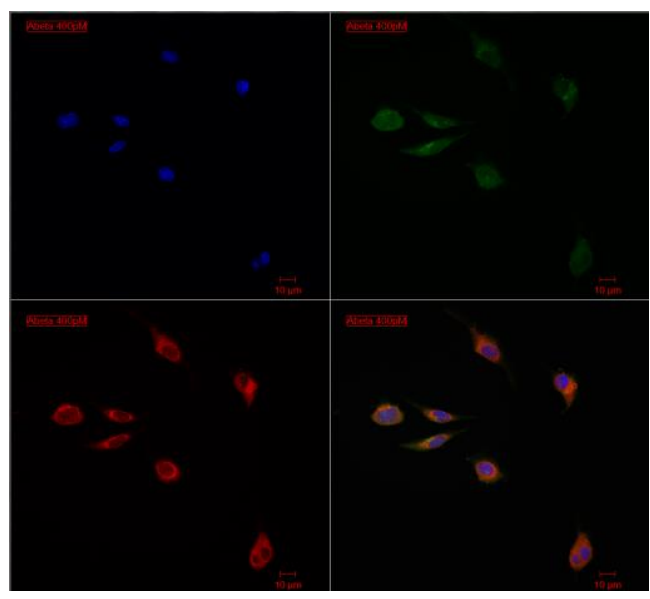

e) oA 400pM

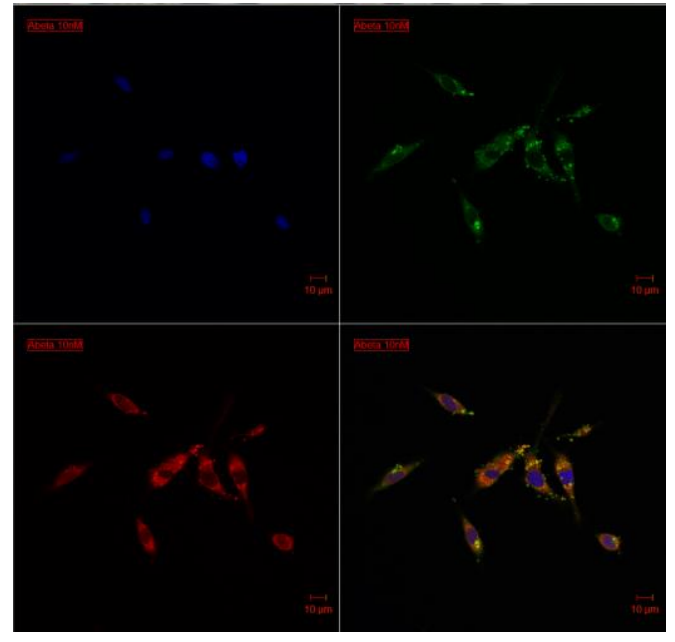

g) $O A \beta 10 \mathrm{nM}$

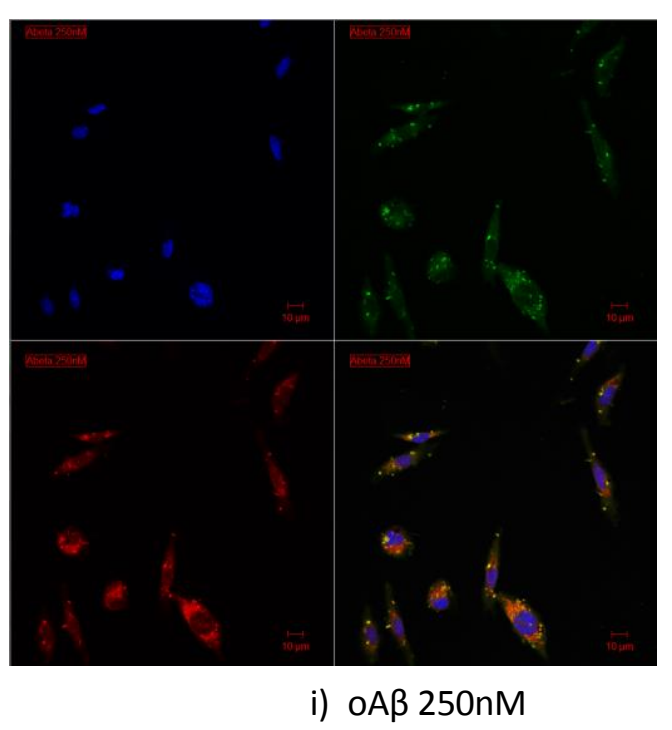

i) $O A \beta 250 \mathrm{nM}$

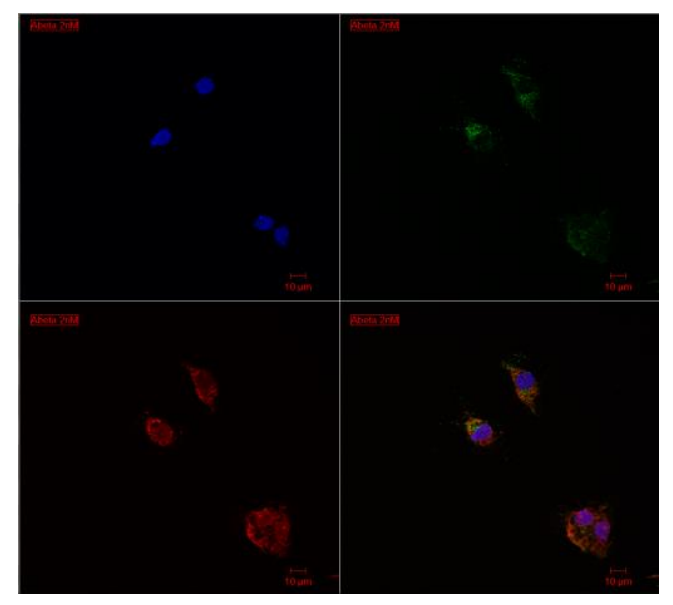

f) $O A \beta 2 n M$

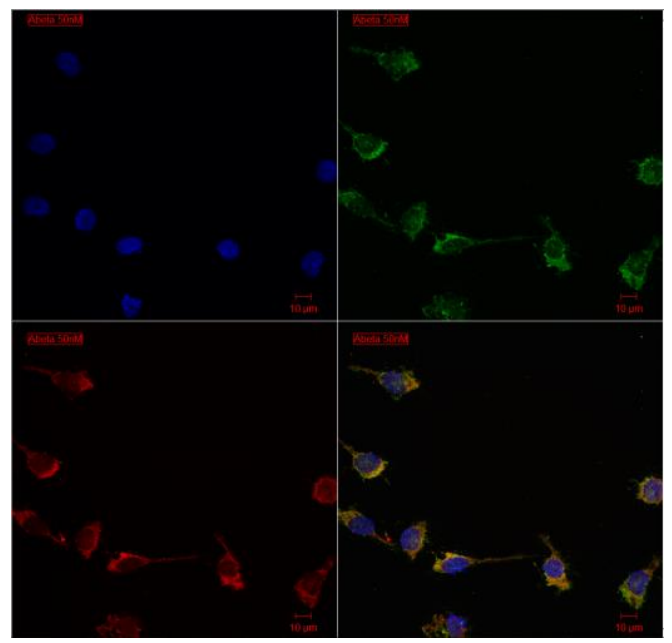

h) $O A \beta 50 \mathrm{nM}$ 
Fig 3.4 Immunofluorescent imaging bottom left) and Merge (bottom right).of C8-B4 cell after 24h treatment at various doses of o $A \beta$ : a) vebicle control, b) 3.2pM, c) 16pM, d) 80pM, e) 400pM, f) 2nM, g) 10nM, b) 50nM, i) 250nM. In each graph, cells were stained with DAPI (Blue, top left), Calcein-AM (Green, top right), Mito Tracker Red (Red,

Confocal imaging (Fig 3.4) did not show significant morphological change, nor show a relationship between mitochondria size and location at any oA $\beta$ concentration (3.2pM to $250 \mathrm{nM})$.

To further specify phenotypical changes at a molecular level, I performed rtPCR assay using multiple M1 (iNOS, IL-1 $\beta$, CCL-2, TNF- $\alpha$ ) and M2 (Arg1, IL-10, YM1/2, TNF- $\alpha$ ) markers. Data were obtained by calculating $\Delta \Delta \mathrm{C}_{\mathrm{T}}$ value, $\Delta \Delta \mathrm{C}_{\mathrm{T}}=$ $\Delta \mathrm{C}_{\mathrm{T} 1}$ (treated) $-\Delta \mathrm{C}_{\mathrm{T} 2}$ (control). Normalized target gene expression level $=2^{\Delta \Delta \mathrm{CT}}$. 

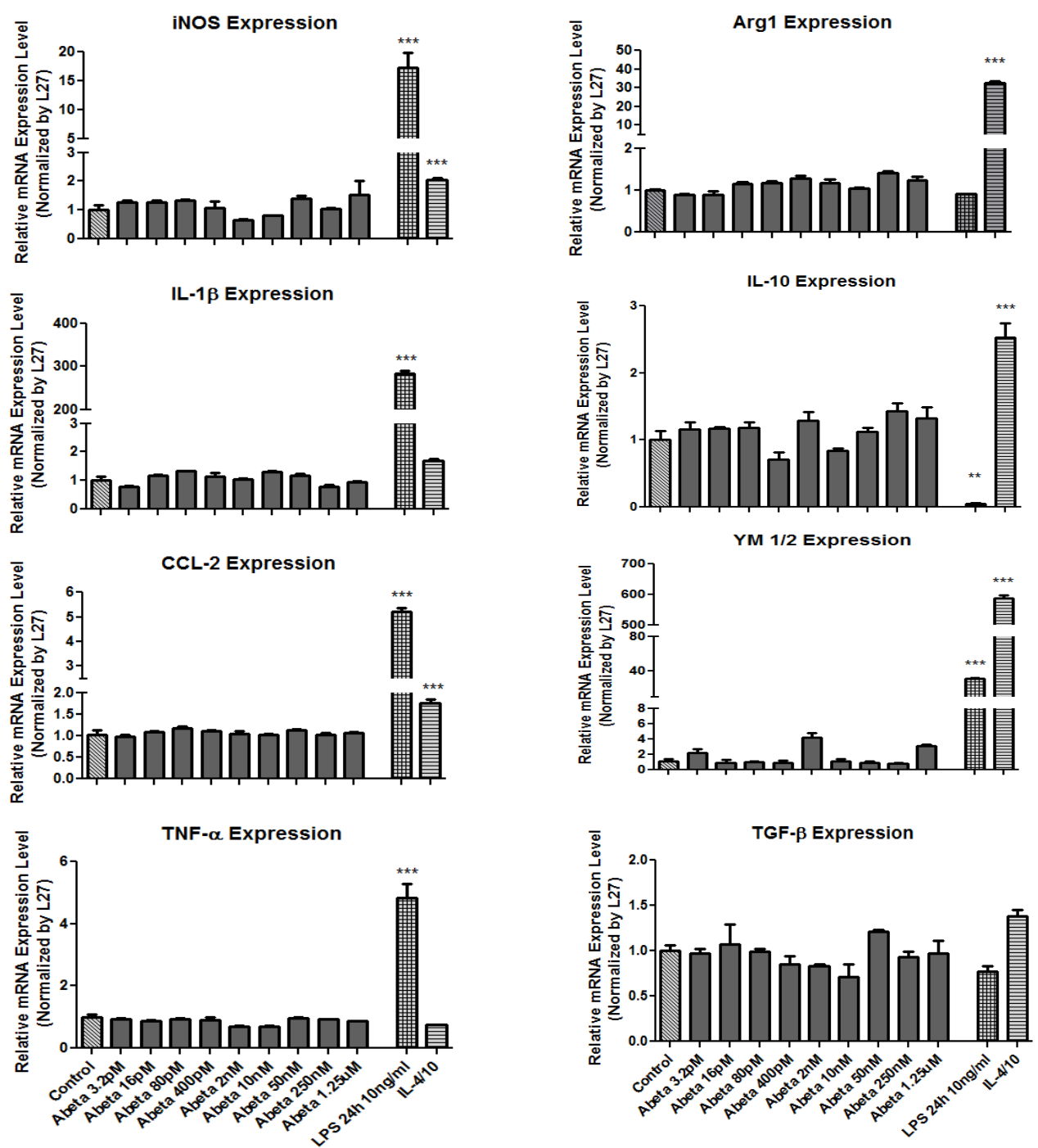

Fig 3.5 Relative $m \mathrm{RN} A$ expression level (normalized by L27 bousekeeping gene) detected by rtPCR assay. Microglial classical activation markers $(M 1$, Left panel) and alternative activation markers $(M 2$, right panel) expression in C8-B4 cells after 24h treatment. Lipopolysaccharide (LPS) and IL-4/IL-10 combo are M1, M2 positive controls accordingly.

Fig 3.5 show rtPCR results of multiple M1 and M2 marker gene expression, suggested oA $\beta$ across the dosage used from $\mathrm{pM}$ to $\mathrm{uM}$ does not induce a specific M1 and M2 gene regulation change. The positive control in each group (LPS and 
IL-4/10) shown that the markers chosen for each phenotype works fine with the temperature and cycle determined in our experiment settings. We notice that LPS also induce some M2 activation (YM1/2) which was also observed in our CD206 flow cytometry assay. Some marker, such as TGF- $\beta$, did not respond to IL4/10 combination positive control, demonstrated that certain stimuli initiate specific spectrum of regulatory marker. These data suggest that there is not a clear cut of the M1 and M2 marker.

To test whether phagocytosis is influenced by the mitochondrial respiration change under $\mathrm{OA} \beta$ treatment, we performed a phagocytosis assay using fluorescent beads to measure the ability of the general engulfment of microglia cells, the cells were cultured overnight and treated with a variety dose of oA $\beta$ and LPS as a positive control for $24 \mathrm{~h}$. One hour before the end of treatment, cells were incubated with fluorescent (Nile red) microsphere at $37^{\circ} \mathrm{C}$, with their corresponding baseline group at $4{ }^{\circ} \mathrm{C}$. It is considered that $4^{\circ} \mathrm{C}$ is low enough to force cell into a hibernate state that prevent any phagocytosis activity, thus can provide a clean background of baseline. 


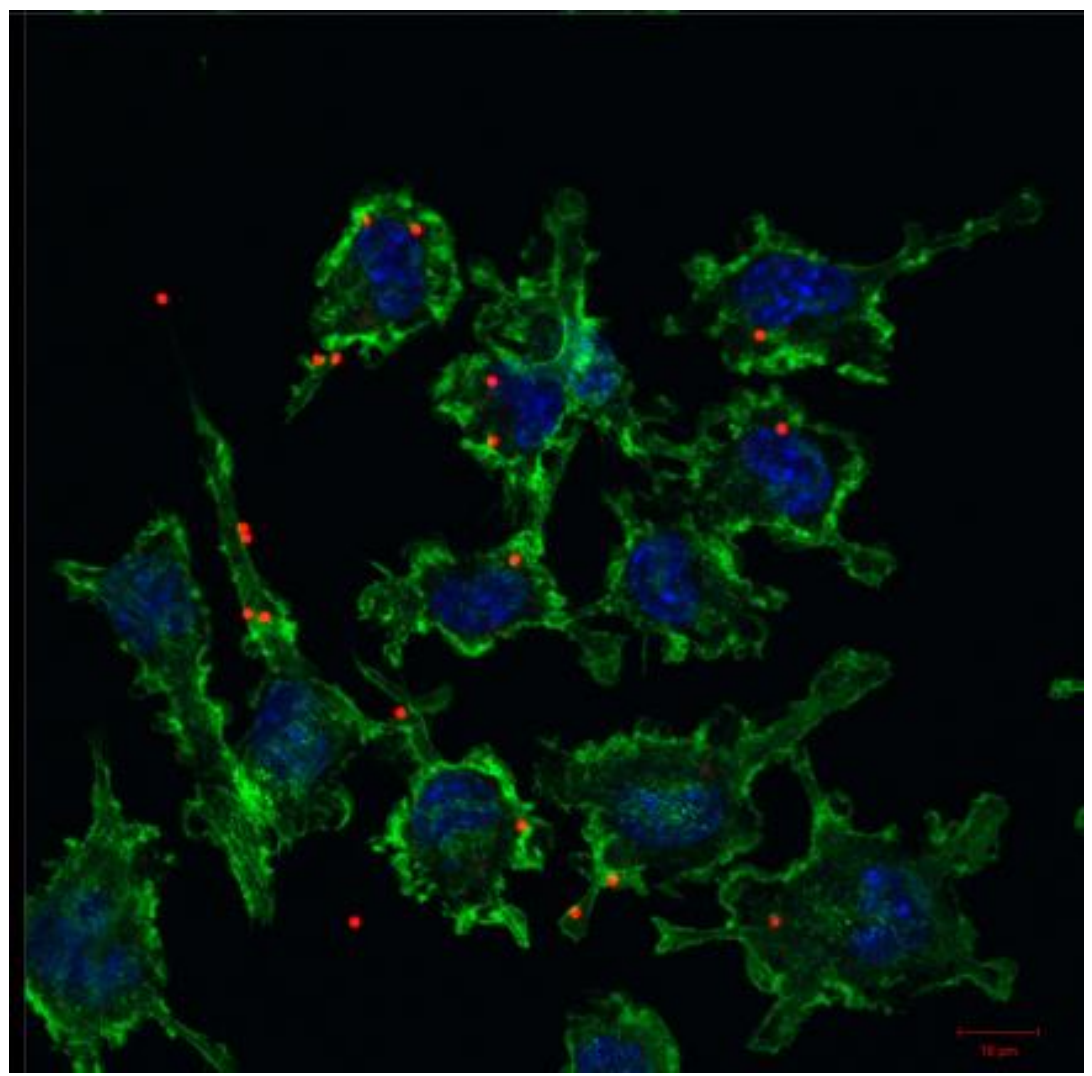

Fig 3.6 Fluorescent Confocal Imaging of microglia cell C8-B4 phagocytosis assay. Nile Red microsphere nitrile beads (Red, $d=1 u M$, Lifetechnology), Phalloidin (Green), DAPI (Blue)

Fig 3.6 show a representative picture of the phagocytosis of microglia cells. The cell morphology is stained by the actin binding Phalloidin in green. The red microsphere is clearly located either inside the cell (phagocytosis) or bond at the surface of the cellular membrane. 


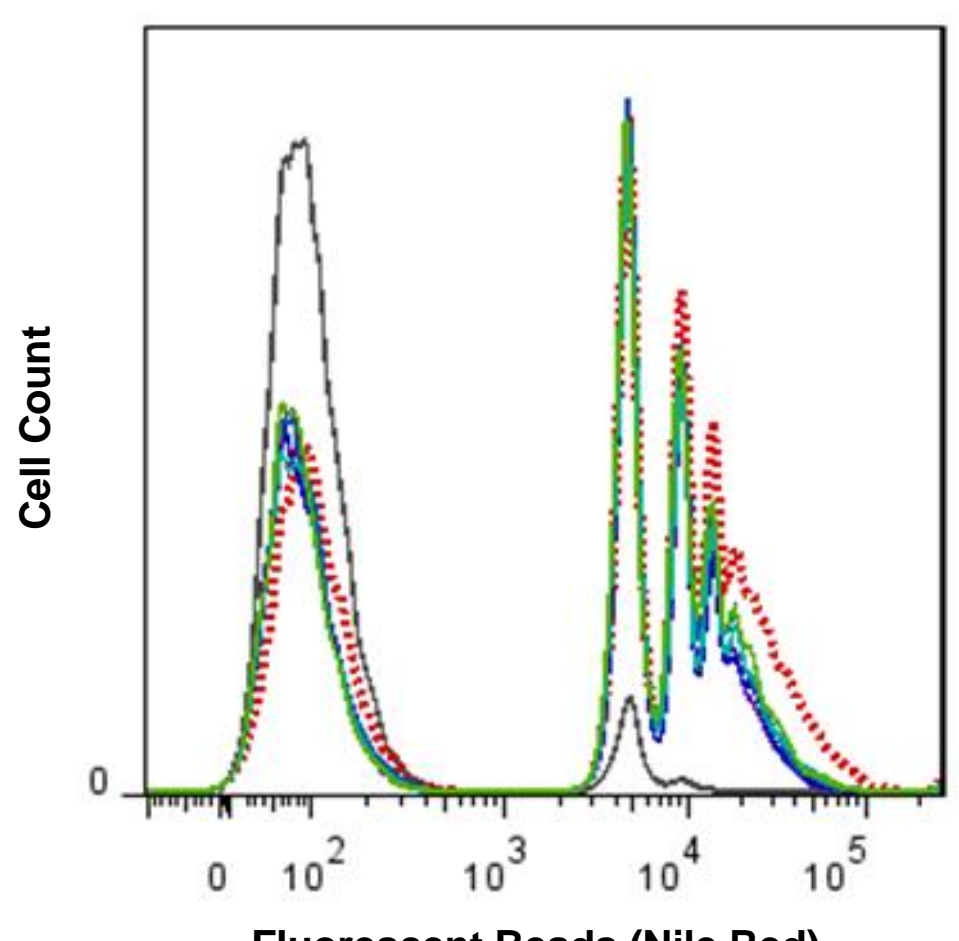

Fluorescent Beads (Nile Red)

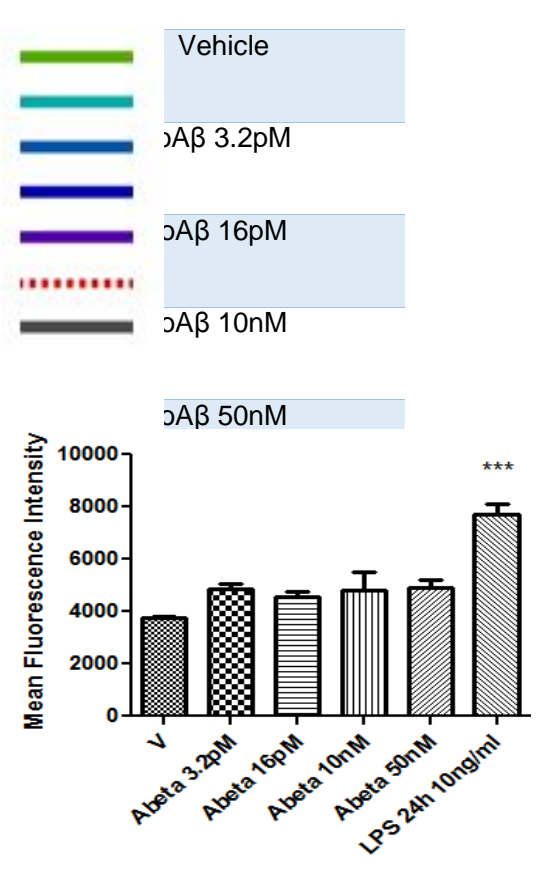

Fig 3.7 Histogram of Flow Cytometry phagocytosis assay using Nile-red fluorescent microsphere (d=1um). Mean Fluorescence Intensity (MFI) of the positive peaks show a significant increase of MFI only in LPS treated group by 2 folds. All o $A \beta$ treated groups show little increase compared to vehicle group. Although it seems to be tread of increase, there is no significant difference under statistical analysis. (Statistical analysis was done by One-way ANOV A and Dunnett's post hoc analysis. ${ }^{* * *} p<0.0005$ )

Flow cytometry assay using the fluorescent beads and C8-B4 cells provides better quantification of the extent of phagocytosis in microglia cells. In the histogram graph, the peaks on the right half of the graphs represent the single, double, triple and 4+ beads engulfed into the microsphere, the mean fluorescent intensity increases as the peak shift to right. Fig 3.7 suggested that the $\mathrm{OA} \beta$ didn't induce phagocytosis although there is a small trend of increase in the MFI, this was not significant. LPS induced 2-fold change of MFI and served a good positive control. 
Based on the experiment results shown above, we answered the question that although oA $\beta$ induced M2-like microglia activation, it does not inducing phagocytosis. Thus the energy increase by oA $\beta$ treatment may not contribute to any clearing of $\mathrm{OA} \beta$ through phagocytosis, suggesting there might be other clearing mechanism associated with $\mathrm{A} \beta \beta$ stimuli or other cellular activity going on without cellular morphology change.

\subsection{Discussion}

In this project we answered the question of whether a M2-like activation induced by low dose oA $\beta$ is correlated with phagocytosis activity which assumed to be energy demanding. The answer by flow cytometry assay suggested no phagocytosis occurred at the dose of oA $\beta$ tested. NFkB translocations usually happen upon activation, and believed to be a more classical pathway of activation. In our project, this activation assay - NFkB translocation was not utilized suggest that this pathway is not utilized at the low dose oA $\beta$ stimuli. This needs to be further confirmed.

The activation marker staining methods worked well as we expected although M2 marker was not increase strongly. This may due to the very low dose of the stimuli that cause a prolonged mild response. There is a limitation that the microglia possessed morphology with shorter elongation of the cellular extensions (mitochondria clumped around nucleus) compared to neuron and astrocytes which make it hard to distinguish individual mitochondria even with confocal microscope. 
So the task of observation of the relationship of mitochondrial location and microglia phenotypical change was not achieved.

The similar patterns of microglia activation with mitochondrial respiration suggest there is a relationship between these mitochondria and activation, although the activation could not be further specified. Although previous study (2014 neurobiology of aging) shown that resting microglia react to $A \beta_{42}$ fibrils but do not detect oligomers by their morphology change, it is not sufficient to judge that resting state microglia does not react with $\mathrm{A} \beta$. Since microglia could undergo some molecular changes that does not reflect from the morphology changes. As shown in our experiment, the morphology of microglia does not change under pM$\mathrm{nM}$ oA $\beta$ treatment but the mitochondrial respiration ability and some protein expression level are regulated under the treatment without cause cellular shape change.

To further investigate the mechanism underlying the cell specific response on mitochondria respiration upon low dose oA $\beta$ treatment, there are some future experiments that can be done

To examine the function of microglia scarvenge ability, Scavenger receptor A-Scara1 (Yu \& Ye, 2014) level could be assessed. Scara1 is thought to be important in soluble oA $\beta$ clearance, thus Scara 1 protein expression and gene regulation could be tested after $\mathrm{OA} \beta_{42}$ treatment in C8-B4 cell and primary glia cells. Scara1 protein level could be determined by western blot, and gene expression is tested by rtPCR assay. In addition, to determine whether $\mathrm{OA} \beta_{42}$ 
affects Scara1-related phagocytosis, selective shRNA library could be used to silence Scara1, then microglia phagocytosis and mitochondrial respiration could be assessed.

To test mitochondrial health, fission and fusion protein expression are to be assessed. Due to the morphology limitation, mitochondrial size distribution cannot be visualized as in neurons, so fusion protein Mitofusin 1 (MFN1), Mitofusin 2 (MFN2) as well as fission protein Dynamin-related protein 1 (Drp1) and its phosphorylated form p-Drp1 could be tested either by western blot or ELISA using different kind of cell types. 
CHAPTER 4: MITOCHONDRIAL RESPIRATION VS. MICROGLIAL PHAGOCYTOSIS

\subsection{Introduction}

In Chapter 3 we discussed the relationship of phagocytosis vs the mitochondrial respiration induced by oA $\beta$ treatment. We have shown that microglia cell could respond to low doses of the soluble form of oA $\beta$, probably in a way to lower the environmental amyloid- $\beta$ burden and help maintain the homeostasis. Since the oA $\beta$ induced a M2-like activation and usually M2 activation is considered to be phagocytosis preferred, it is originally believed that the oA $\beta$ induced mitochondrial respiration increase is associated with phagocytosis activity which may demand higher energy supplement with cellular movement and shape reformation. However the phagocytosis assay demonstrated that there was no phagocytosis at the time of respiration increase suggests the activation is not involving phagocytosis. Thus oA $\beta$ appears to not induce an amyloid clearing mechanism through phagocytosis.

Although during phagocytosis cell undergoes more microfilament movement, membrane folding, vesicle forming, construction change, fusing and digestion, it is still unclear whether the phagocytosis activity is more energy consuming or not? If so, what will be the major energy supply pathway in microglia under phagocytosis to provide the necessary fuel enough for a series of phagocytic activities? 
In this chapter, we investigated the relationship of mitochondrial respiration and other energy supply pathway vs. microglia phagocytosis activities.

\subsection{Material and Method}

\section{Cell culture}

C8-B4 (ATCC) cells were grown in DMEM containing 10\% fetal bovine serum and $100 \mathrm{units} / \mathrm{ml}-100 \mu \mathrm{g} / \mathrm{ml}$ Penicillin-Streptomycin in $5 \% \mathrm{CO}_{2}$ at $37^{\circ} \mathrm{C}$.

\section{Phagocytosis assay}

To better quantify the extent of phagocytosis in given number of cells, microglia were subjected to flow cytometry analysis. Treat C8-B4 cell with LPS and Rotenone for 24 hours. One hour before the end of the treatments, samples were incubated with fluorescent microsphere. The phagocytosis is proportional to the incubation time with fluorescent beads until it reaches a plateau at maximal amount that each microglia cell can handle. Mean fluorescent Intensities were measured using Fortessa Flow Cytometer, and analyzed by FCS express software.

\section{Cell Viability assay}

Cell viability was assessed using Calcein-AM (Calcein acetoxymethyl) Assay. Cells were washed with PBS and incubated with $1 \mu \mathrm{M}$ Calcein-AM fluorescent probes (Life Technologies) in the dark for $30 \mathrm{~min}$. Live cells produce 
green fluorescence by active intracellular esterase which cleaves the Calcein AM dye. Viability was measured in relative fluorescent units (RFU), and expressed as percentage of vehicle-treated control values.

\section{Mito Stress and Glycolysis parameter}

The mitochondrial respiration function and glycolysis is measured by analyzing the rate of oxygen and $\mathrm{pH}$ change in the microenvironment using Seahorse extracellular flux analyzer as described in Chapter 2.

\subsection{Results}

To investigate whether mitochondrial respiration is the main source of the phagocytosis activity, we apply LPS treatment as the positive control of phagocytosis. At the same time, we apply rotenone, the specific inhibitor of mitochondrial respiration electron transport chain complex I enzyme to shut down most of the oxidative phosphorylation in mitochondria. To correlate the energy supply resources, we performed mitochondrial respiration evaluation and glycolysis assay simultaneously. 


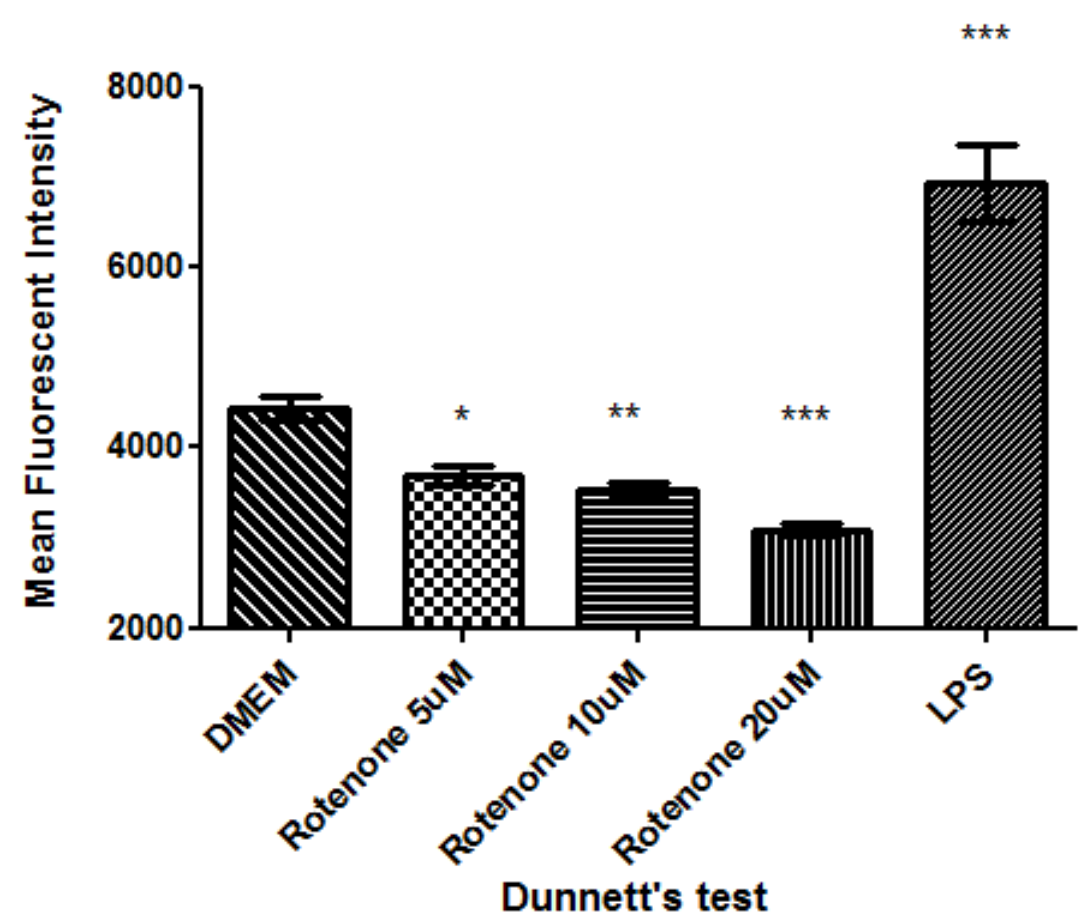

Fig 4.1 Mean Fluorescent Intensity calculated from flow cytometry phagocytosis assay. C8-B4 cells treated with Rotenone (5uM, 10uM, 20uM) and LPS $10 \mathrm{ng} / \mathrm{ml}$ for $24 \mathrm{~h}$. (Statistical analysis was done by One-way ANOV A and Dunnett's post hoc analysis. ${ }^{*} p<0.05$, ** $p<0.005$, *** $p<0.0005$ )

Fig 4.1 shown a dose-dependent decrease in rotenone treated group of C8B4 cells, suggested that rotenone induced a decrease in phagocytic activities. Since rotenone is mitochondrial inner membrane electron transport chain complex I inhibitor, it hinted that phagocytosis in C8-B4 cells may largely dependent on oxidative phosphorylation happened in mitochondria. LPS is known to induce phagocytosis thus serve as a positive control.

As a gold standard to induce phagocytosis, LPS is used as a phagocytosis inducer by working through the surface toll-like-receptor mediated signaling 
cascade. Thus to investigate the relationship of phagocytosis vs energy supply, we use different dose of LPS to test both Mito Stress parameters and glycolysis ability.

Fig 4.2 shown LPS doesn't affect the basal and ATP related mitochondrial respiration but decrease the maximal and spare respiration in mitochondria. Surprisingly, the results are opposite to what we hypothesized that phagocytosis requires much energy which shifts the cellular energy supply gear into a more oxidative phosphorylation favored pathway. The results indicate that during phagocytosis, the machinery of mitochondria to generate spare ATP, which directly associated with the ability of maximal respiration, is decreased. With the basal and ATP associated respiration were not affected LPS did decrease the mitochondria's ability to produce more ATP, when cells encounter an energy crisis. Rotenone inhibits all parameters of mitochondrial respiration to zero. 

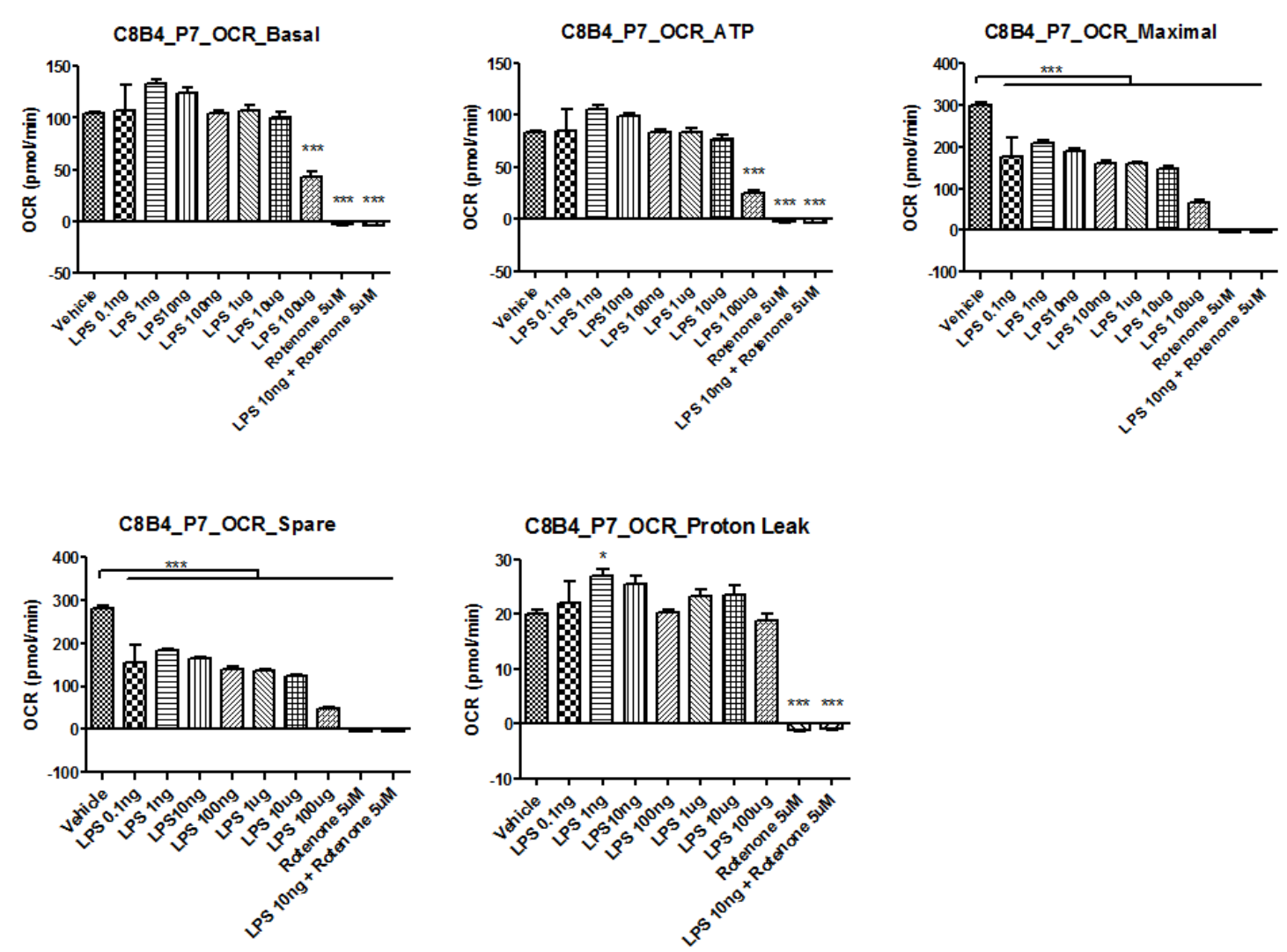

Fig 4.2 mitochondrial stress parameters were measured as oxygen consumption rates (OCR) in C8B4 mouse microglia cell line (Statistic analysis was done by One-way ANOV A and Dunnett's post hoc analysis. $\left.{ }^{*} p<0.05,{ }^{* *} p<0.005,{ }^{* *} p<0.0005\right)$ There were significant differences in maximal and spare respiration parameters treated with LPS in C8-B4 cell line. The reduction of basal and ATP production OCR in $100 \mathrm{ug} / \mathrm{ml}$ group is presumably caused by cytotoxicity. Rotenone $5 \mathrm{uM}$ is enough to inbibit the OCR to zero while LPS combination treatment doesn't reverse or remedy the rotenone inbibitory effect.

When mitochondrial function is inhibited, cells utilize other energy source and/or reduce the energy expenditure. Glycolysis is one of the major energy generation reactions besides oxidative phosphorylation, and usually it change 
reciprocally with mitochondrial respiration. Compared to mitochondrial ox-phos respiration, glycolysis generate much less energy per glucose, but the whole reaction provide the substrate for mitochondria, and other reaction material.
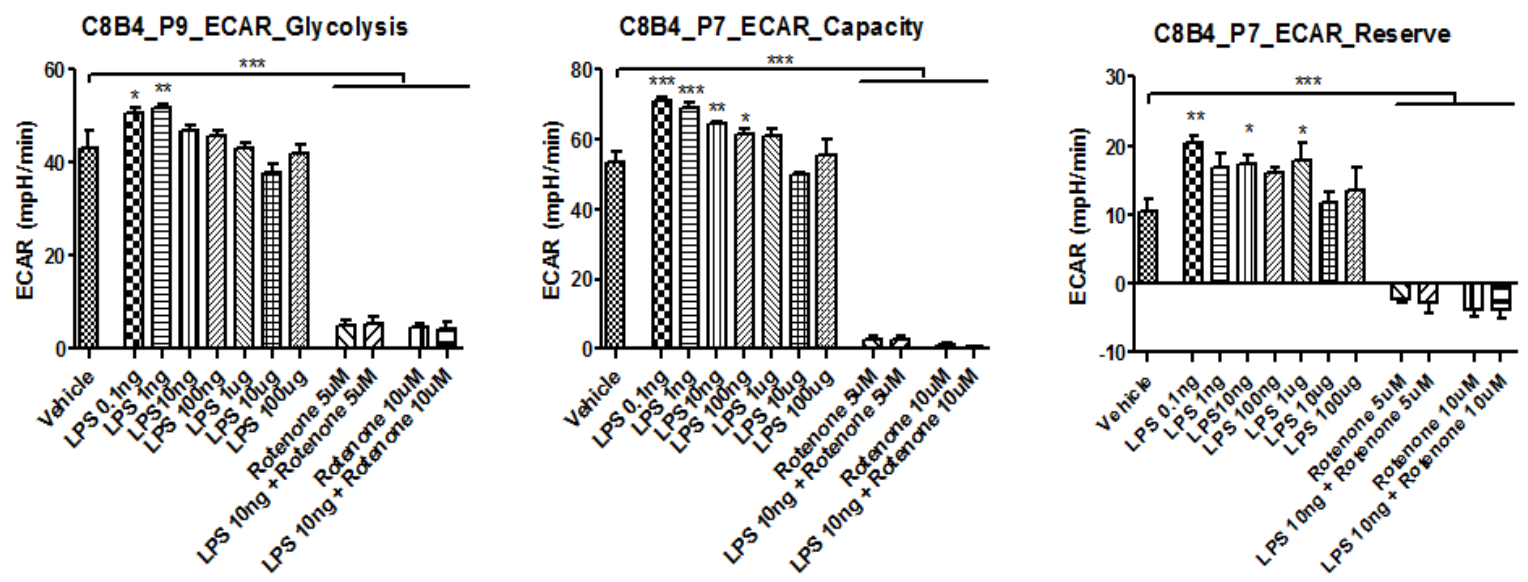

Fig 4.3 Glycolysis parameters calculated by ECAR from Glycolysis Assay in C8-B4 cells. Low dose LPS treatment seems to induce a little increase in all three glysolysis parameters. Rotenone with or without LPS combination inbibit all glycolysis to a very low level. (Oneway-ANOV A Tukey's Post hoc analysis)

Fig 4.3 shows the glycolysis parameters measured in LPS treated C8-B4 cells suggested that energy compensation may be involved. The LPS phagocytosis probably depends on glycolysis provided energy rather than mitochondria provided energy. Interestingly, rotenone not only inhibits the mitochondria oxphos respiration, it also inhibit the glycolysis. In this case, rotenone reduced both energy reaction pathway to a very low level, but C8-B4 survived over 
24h suggested that either the microglia cell line could utilize other energy source to replenish the shortage of energy supply, or it restricted its energy expenditure accordingly to a much lower level by shutting down some features of cellular function in order to survive under the extreme condition. C8-B4 cells survival tested by PI and Calcein-AM assay suggested that C8-B4 cell well survived after $24 \mathrm{~h}$ in under both $5 \mathrm{uM}$ and $10 \mathrm{uM}$ rotenone treatment.
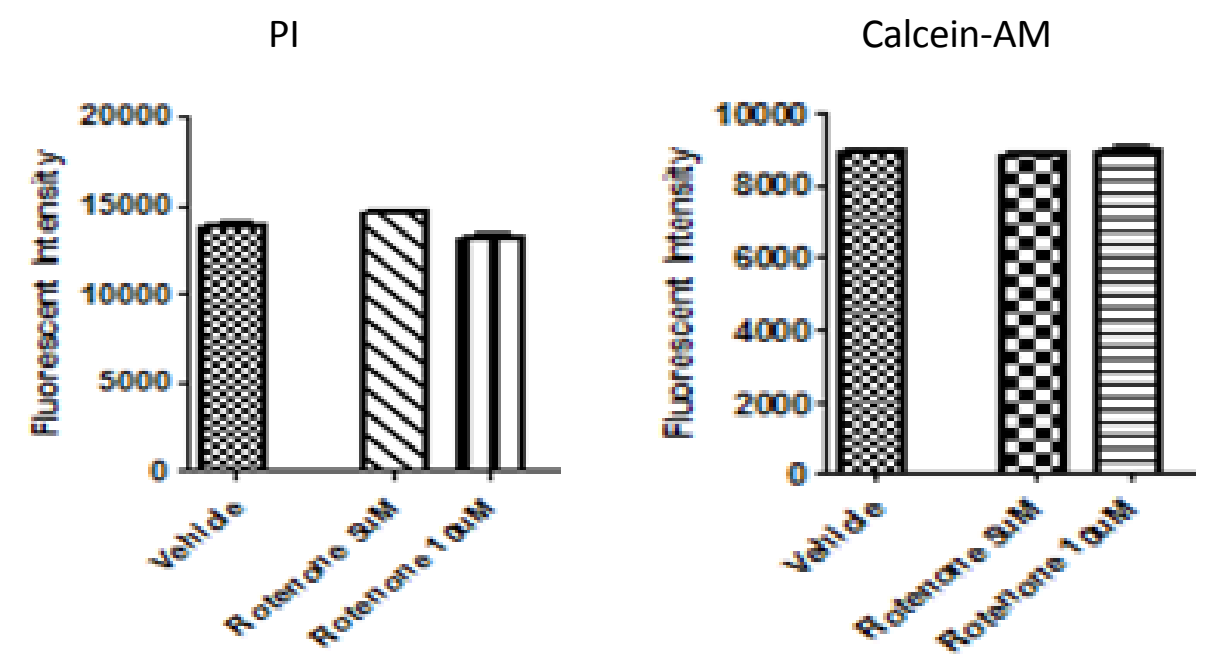

Fig 4.4 Viability of C8-B4 cells treated with rotenone $5 \mathrm{uM}$ and 10uM for 24hs PI and CalceinAM assay. No significant difference in rotenone treated group compared to vebicle control. 
To document that there is a energy supply needed for the phagocytosis, rotenone was co-administered with various dose of LPS to test whether its inhibition effects on oxphos and glycolysis also exhibit in phagocytosis.

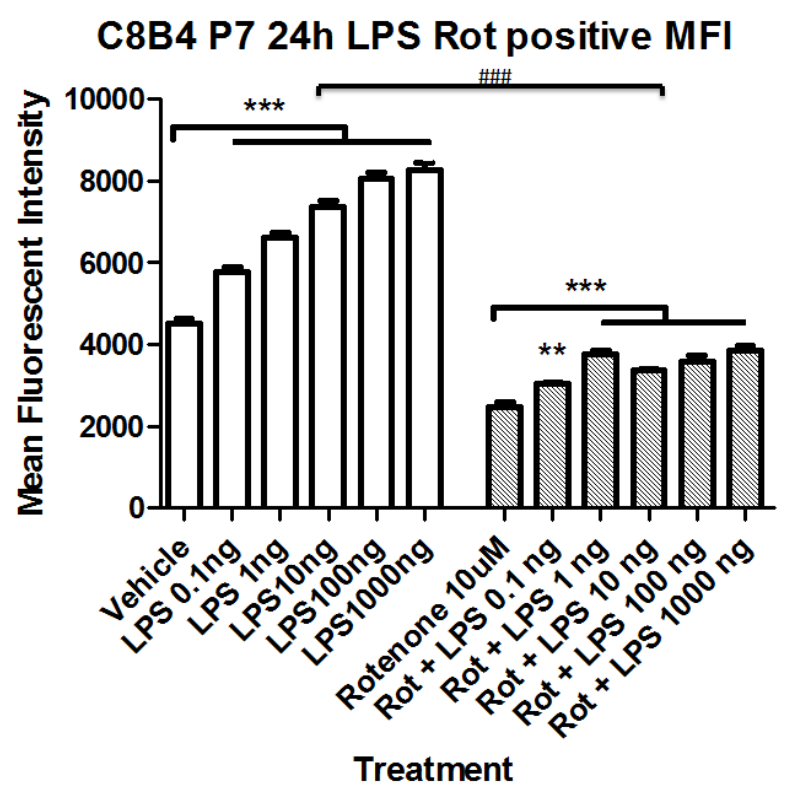

Fig 4.5 Mean Fluorescent Intensity calculated from flow cytometry phagocytosis assay. C8-B4 cells treated with LPS $(0.1,1,10,100,1000 \mathrm{ng} / \mathrm{ml})$ with or without Rotenone 10uM for 24h. (Two-wayANOVA, * stands for the comparison within same treatment group. \# stands for the comparison in different treatment group under same LPS regimen.)

Fig 4.5 shows that the rotenone inhibits basal phagocytosis compared to vehicle group, which duplicated the result in Fig 4.1. LPS has been shown to induce a dose-dependent increase of phagocytosis in C8-B4 cell after $24 \mathrm{~h}$ treatment. Compare to Fig 4.3, the increase of phagocytosis is not direct 
proportional to the increase of glycolysis change suggest that the phagocytosis is not solely dependent on glycolysis for energy supply. Since rotenone inhibits both oxphos and glycolysis in the C8-B4 cells, the rotenone treated C8-B4 has a reduced ability to phagocytose. The co-treated group induced an increase compared to $10 \mathrm{uM}$ rotenone group suggested that LPS treatment could reverse or partially remedy the rotenone inhibition on glycolysis. LPS may lead to initiate glycolysis reaction which avoiding the rotenone inhibition on glycolysis in order to generate ATP needed in microglial phagocytosis.

\subsection{Discussion}

The energy expenditure in neuron has been extensively studied, as neurons are high energy demanding, high glucose consuming cells in the brain. In contrast, microglia, due to their multi-function, multi-phenotype, and dynamic states, are not well characterized for their energy demand and mitochondria function. Considering the digesting process in the later phases of phagocytosis, it make sense that glycolysis is preferred, since glycolysis help generate more acidic molecule in cytosol when low $\mathrm{pH}$ environment is needed to break down and digest engulfed material. To better and more efficiently serve its job, lysosome ideal $\mathrm{pH}$ environment is around 4.5, a relatively acidic fluidity to better provide a working condition for hydrolytic enzymes which breaking down virtually all kinds of bimolecular targets. Glycolysis is favored over mito-respiration in energenesis during immunogenic induced activation of microglia cell line C8B4 due to 
preparation of acidity from anaerobic respiration for phagocytic lysosome, only when critical survival energy supply is fulfilled.

Others results shown that rotenone could induce microglia cell (BV-2) directly (Gao, Chen, Hu, \& Wang, 2013). Rotenone IC50 varies from $0.1 \mathrm{nM}$ to 100 nM (W. S. Choi, Kruse, Palmiter, \& Xia, 2008), at nanomolar rotenone stimulates microglia and enhances phagocytic activity without affecting mitochondrial membrane potential (Emmrich, Hornik, Neher, \& Brown, 2013) (Chang et al., 2011). It further supports the hypothesis that the fluctuation of mitochondrial energy production would affect microglial activation.

Microglia can still maintain similar level of basal mitochondrial oxphos to cope with basal activity needs other than phagocytosis. The phagocytosis may depend more on glycolysis not for the ATP generated.

One pitfall in our experiment is the inhibition of oxphos by rotenone is not complete. Since Complex II, III are not inhibited, there is still other possible ways to provide electron transport to generate a proton gradient, although the contribution through this route is very limited. In the future, to fully inhibit the oxphos reaction, 1uM Antimycin A (a complex III inhibitor) can be co-treated with rotenone to fully inhibit the whole ETC reaction.

Another possible experiment is to test the cytosol pH change after LPS treatment with an increased phagocytosis activity to test the hypothesis that the glycolysis is favored because of its acidic end production is beneficial to digest phagocytosed particles. The $\mathrm{pH}$ change may be subtle and transient since the 
proton may be segmented and utilized in other organelles very quickly without fluctuating whole cell $\mathrm{pH}$ too much for a long time. 
CHAPTER 5: DISCUSSION

Microglia, the immune cell in the brain, protects neuron by digesting $A \beta$ plaque in Alzheimer's disease (AD) (C. Y. Lee \& Landreth, 2010).Upon activation, microglia cells could present pro- or anti-inflammatory phenotypes (Varnum \& Ikezu, 2012). Along the disease progress, microglia shifts its anti-inflammatory to pro-inflammatory phenotype, which may results in inefficiently $A \beta$ clearance and inflammatory burden.

Since gliosis is considered to be another main factor contributes to $A D$, manipulating microglia activation is believed to be both beneficial for plaque reducing and for reducing inflammatory pressure. However, the role of microglia in brain is not yet fully understood, while some researchers argue the necessity of microglia in the neurodegenerative disease progression. BY utilizing ColonyStimulating Factor 1 receptor (CSF1R) inhibitor, microglia cells could be largely eliminated in healthy WT young mice (a microglia depleted mouse model). Dr. Green and his co-workers found out that the microglia depleted mice are healthy, fully viable and have no obvious defects. What's more, they don't appear behavior impairments nor cognition \& motor function deficits (Elmore et al., 2014). In spite of all the possible hypothesized microglial contributions to neuronal degenerative disease, the minimal influence of microglia depletion in healthy brain suggests the complex role microglia plays in the brain system which needs to be addressed and further studied. 
Many groups recently use in vitro and in vivo models to test the different roles of microglia activation phenotypes, as well as the feasibility of microglia activation inducing reagents as possible therapeutic methods. But lack of efficient and accurate way to determine the activation status make results analysis difficult to interpret. But overall it is possible that understanding microglia activation will play an important role in eliminating or at least postponing the occurrence of $A D$.

Alzheimer's disease (AD) is a neurodegenerative disease which is irreversible and progress overtime. AD is the most common form of dementia, causing memory loss and cognition decline as well as changes in other brain functions. AD is the 6th leading death in the United State, in 2015 together with other type of dementias; it cost $\$ 226$ billion to American society. By 2050 , these costs could rise as high as $\$ 1.1$ trillion (http://www.alz.org/facts). Until now the etiology of the disease is still not understood, and no treatment can stop the disease progressing.

The greatest risk factor known of $A D$ is age, but other risk factors include family history, genetic background, head trauma, heart disease, high blood pressure, diabetes and high cholesterol. There are two main neuropathological hall marks of $A D$ pathology, extracellular fibrillar $\beta$-amyloid $(A \beta)$ deposition and intracellular hyperphosphorylated tau neurofibrillary tangles (NFT)(Querfurth \& LaFerla, 2010). There is still debate about the role of the two hall marks in the AD pathological molecular mechanisms. But it is believed that the aggregation of $A \beta$, either by overproduction of $A \beta$ or the failure of clearance of the $A \beta$, cause 
neurotoxicity which further cause synaptic dysfunction, neuronal cell death, cognition impairment.

While the Amyloid Hypothesis is supported, there are still several questions that cannot be answered. If the $A \beta$ is the causative factor, why removing $A \beta$ fabrillar tangle does not rescue the progression of AD (Salloway et al., 2009) ? And why $A \beta$ is also found in healthy brains, never develop dementia (Aizenstein et al., 2008)? Other factors, such as gliosis-inflammation of glial cells, is considered to be an important contributor to $A D$ pathoetiology. Extracellular $A \beta$ can induce microglia activation by binding to certain receptors such as receptor for advanced glycation end products (RAGE) and CD36, resulting in activated microglia cells and release of cytokine, chemokines, ROS release. The released substance could be pro- or anti-inflammatory, which could be detrimental or beneficial depending on individual condition. Fibrillar $A \beta$ can interact with CD14; TLR2; TLR4, thus trigger inflammatory signaling pathway. It is reasonable that phagocytosis of $A \beta$ by microglia cells decrease during the disease progression. Thus at the late stage of $A D$ although $A \beta$ levels are still high, the ability to clear $A \beta$ reach at capacity or even reduced (Hickman, Allison, \& El Khoury, 2008; Sastre, Richardson, Gentleman, \& Brooks, 2011).

Microglia cells are innate immune cells in the brain and compose $1 / 10^{\text {th }}$ of the cell population of CNS. They are important in first-line defense against pathogens, clearance of damaged cell and debris, monitoring neural environment, repair, and also critical in brain development. They share many common receptors 
with peripheral immune cells, such as major histocompatibility complex (MHC), and cluster of differentiation (CD) receptors.

Upon activation, microglia display 2 major activation phenotypes in response to the cytokines, chemokine, and innate immune surface receptors presented in the environment. Between different activation types, microglia cells bind with different profiles of specific ligands and express different markers and have different effects on neuronal functions such as synaptic plasticity, neurogenesis, etc.

First activation phenotype is classical activation, which is characterized by release of pro-inflammatory factors such as matrix metalloproteinase (Jourquin et al., 2003), interleukins, monocyte chemotactic protein-1 (S. H. Kim, Han, Azam, Yoon, \& Dinarello, 2005), tumor necrosis factor (Combs, Karlo, Kao, \& Landreth, 2001) and interferon-gamma (Ponomarev, Shriver, \& Dittel, 2006). The second activation phenotype is alternative activation with two sub category, antiinflammatory and deactivation phenotypes. Under anti-inflammatory phenotype, microglia cells enhance neurogenesis (Carpentier \& Palmer, 2009), increase phagocytosis and synaptic plasticity (Nolan et al., 2005), and improve spatial learning (Kiyota et al., 2010). Under deactivation phenotype, microglia cells secrete IL-10 and TGF- $\beta$ and enhance neurogenesis and wound healing.

Activated microglia in close vicinity to amyloid plaques can internalize and degrade $A \beta$ in different manners. For the soluble $A \beta$ form, microglia respond with pinocytosis and LDL receptor-related proteins (LRPs) pathway. For fibrillar plaque, 
microglia cells bind through its surface receptors to initiate intracellular signaling pathway that either stimulate phagocytosis or cytokine release.

Similar to peripheral immune cells, microglia cells also undergo an agerelated decline of immune functions. Compare to the normal brain, $A D$ brain shows exacerbated impairment like dystrophic microglia with shortened telomere (Flanary, Sammons, Nguyen, Walker, \& Streit, 2007) which may be caused by A $\beta$. Also microglia morphology is changed in aged mice by forming few bifurcation, few branches and reduced total branch length (Baron, Babcock, Nemirovsky, Finsen, \& Monsonego, 2014).

Although the mechanism of $A \beta$ induced microglia activation is still not fully understood, much researches studied the possible surface molecules which respond to $A \beta$ stimuli associated with inflammatory response. Table 5.1 has listed the reacting surface molecules which bind direct to $A \beta$ stimulation (Left), and the inflammatory molecules of microglial cells in response to $A \beta$ stimulation secreted (Right). 
Table. 5.1

\begin{tabular}{|c|c|}
\hline $\begin{array}{l}\text { Microglia Surface receptor to A } \\
\text { stimulation }\end{array}$ & $\begin{array}{l}\text { Inflammatory mediator released upon } A \beta \\
\text { stimulation }\end{array}$ \\
\hline Integrin (Sonkar, Kulkarni, \& Dash, 2014) & IL1- $\beta$ (Parajuli et al., 2013) \\
\hline $\begin{array}{l}\text { CD36(Sheedy et al., 2013) } \\
\text { SR-A (Schmidt, Yan, Yan, \& Stern, 2001) }\end{array}$ & $\begin{array}{l}\text { TNFa (Yang, Shang, Zhao, Fang, \& } \\
\text { Chen, 2013) }\end{array}$ \\
\hline CD47 (Floden \& Combs, 2011) & NO \\
\hline TLR2, TLR4 & CXCL8(IL-8) (Franciosi et al., 2005) \\
\hline $\begin{array}{l}\text { CD14 (Reed-Geaghan, Savage, Hise, \& } \\
\text { Landreth, 2009) }\end{array}$ & $\begin{array}{l}\text { MCP-1(CCL2) (Cho et al., 2013) } \\
\text { CX3CR1 (S. Lee et al., 2010) }\end{array}$ \\
\hline P2X7 (Sanz et al., 2009) & MIP-1 $\alpha(C C L 3)$ (Fiala et al., 1998) \\
\hline RAGE(Fang et al., 2010) & $\begin{array}{l}\text { CXCL10 (Lyons, Murphy, Clarke, \& } \\
\text { Lynch, 2011) } \\
\text { Prostaglandins (Bate, Kempster, \& } \\
\text { Williams, 2006; Nagano, Kimura, \& } \\
\text { Takemura, 2010) }\end{array}$ \\
\hline
\end{tabular}

Table 5.1 Inflammatory mediators released by microglia corresponding to microglial surface receptors and their binding ligands.

While inflammation hypothesis draw a lot of attention in the field, many approaches have been applied to control the activation of microglia in order to either clear $A \beta$ or further reduce the inflammatory level (D. C. Lee et al., 2013). 
Microglia activation could be manipulated by TLR activation such as administration of LPS. The results are opposites based on different experiments settings, some observed a less profound amyloid deposition (DiCarlo, Wilcock, Henderson, Gordon, \& Morgan, 2001), while others observe a reduced amyloid clearance, which probably due to a mutated TLR4 background in APP mice which lead to reduced response of CCL3, CCL4 and IL-1 (Song et al., 2011). Based on the opposite results it is hard to determine the role of microglia activation. But in general study show that acute LPS or TLR4 KO causes microglia activation, promoting amyloid clearance, while chronic LPS or CD14 KO causes reduced microglia activation and increased $A \beta$ deposition. Lack of a standard microglia activation evaluation increases the difficulty in judging the different activation states and the benefit outcomes for $A \beta$ reduction. While LPS treatment induces microglia activation, LPS fails to reduce NFTs in Tg4510 mouse. In vitro model show that Interleukin-1 induces phosphorylated tau accumulation through microglia.

On the other hand, anti-inflammatory drugs have been applied to test the Alzheimer's Inflammation hypothesis. Non-steroidal Ibuprofen and PPAR-y agonist pioglitazone have been applied to Tg2576 APP mice. Ibuprofen treatment reduced $A \beta$ deposition and phosphotyrosine in activated microglia, reduced IL-1 $1 \beta$ and astrocyte activation marker GFAP (Lim et al., 2000). Pioglitazone as well as rosiglitazone also reduce the amyloid level and microglia activation. Some other drugs such as COX-2 selective drug, celecoxib show similar results (J. K. Choi et 
al., 2010). Curcumin, an extract from turmeric, has been tested in APP mice and $A \beta$ infusion model. Interestingly, it suppress the amyloid and IL-2 while increase the activation of microglia surrounding $A \beta$ plaque deposits (Yan et al., 2001). Due to the lack of fully characterization of the activated microglia phenotype induced by curcumin, it is hard to determine whether curcumin could mediate microglia activation only lead to $A \beta$ clearance without generating excess pro-inflammatory cytokines.

Prospecting the immunotherapy in AD treatment, the effect of antibodies against $A \beta$ on the microglia activation has been tested in APP mice (Morgan, 2009; Schenk et al., 1999). Depending on the antibody administration regimen and experiment design difference, the microglia activation marker expressions are not consistent.

Neurodegenerative diseases are characterized not only by activation of microglia but also by the mitochondrial dysfunction. Mitochondrial dysfunction in microglial cells has been observed to inhibit part of M2 activation which is usually considered to be associated with cellular self-healing and antiinflammatory responses (Ferger et al., 2010). When microglia get activated by bacterial lipopolysaccharide and interferon-gamma, the microglial mitochondrial morphology changed to more elongated shapes with an increase in the abnormalities such as circular cristae or ring- and U-shaped membranes (Banati et al., 2004). Researchers recently found out that mitochondrial dynamics are closely associated to production of pro-inflammatory mediators upon LPS stimulated 
microglial cell lines. Mitochondria fission activity was observed up-regulated following LPS stimulation and mitochondria localization with mitochondria fission protein Dynamin-related protein 1 (Drp1) is also increased through a NF-kB and Mitogen-Activated Protein Kinase (MAPK) mediated pathways (Park et al., 2013).

Inflammation caused by microglia activation is considered an important component of $A D$ neuropathology. Due to the complex role of microglia in CNS, and the even more complex status after activation, much research have led to very opposite conclusion regarding the function of microglia in $A D$. Using various $A D$ model both in vivo and in vitro, microglia cells are associated with both $A \beta$ clearance and inflammation. The effects of treatment or manipulations on microglia activation phenotypes are limited at present. But recent studies show that the antiinflammatory methods show a positive effect in $A D$ model. Also manipulation of specific microglia activation has a potential for possible treatment of $A D$ and needs to be further investigated.

While experiments on $A \beta$ plaque clearance show positive results, there is lack of cognitive behavior tests that support a positive clinical outcome. If the differentiations of microglia activation phenotypes positively correlate with the $A D$ progression, it may enable us new methods to diagnosis and intervention. 


\section{BIBLIOGRAPHY}

Aizenstein, H. J., Nebes, R. D., Saxton, J. A., Price, J. C., Mathis, C. A., Tsopelas, N. D., . . . Klunk, W. E. (2008). Frequent amyloid deposition without significant cognitive impairment among the elderly. Arch Neurol, 65(11), 1509-1517. doi: 10.1001/archneur.65.11.1509

Banati, R. B., Egensperger, R., Maassen, A., Hager, G., Kreutzberg, G. W., \& Graeber, M. B. (2004). Mitochondria in activated microglia in vitro. J Neurocytol, 33(5), 535-541. doi: 10.1007/s11068-004-0515-7

Baron, R., Babcock, A. A., Nemirovsky, A., Finsen, B., \& Monsonego, A. (2014). Accelerated microglial pathology is associated with Abeta plaques in mouse models of Alzheimer's disease. Aging Cell, 13(4), 584-595. doi: 10.1111/acel.12210

Bate, C., Kempster, S., \& Williams, A. (2006). Prostaglandin D2 mediates neuronal damage by amyloid-beta or prions which activates microglial cells. Neuropharmacology, 50(2), 229237. doi: 10.1016/j.neuropharm.2005.09.008

Bedi, S. S., Smith, P., Hetz, R. A., Xue, H., \& Cox, C. S. (2013). Immunomagnetic enrichment and flow cytometric characterization of mouse microglia. J Neurosci Methods, 219(1), 176-182. doi: 10.1016/j.jneumeth.2013.07.017

Block, M. L., Zecca, L., \& Hong, J. S. (2007). Microglia-mediated neurotoxicity: uncovering the molecular mechanisms. Nat Rev Neurosci, 8(1), 57-69. doi: 10.1038/nrn2038

Carpentier, P. A., \& Palmer, T. D. (2009). Immune influence on adult neural stem cell regulation and function. Neuron, 64(1), 79-92. doi: 10.1016/j.neuron.2009.08.038

Chang, C. Y., Song, M. J., Jeon, S. B., Yoon, H. J., Lee, D. K., Kim, I. H., . . Park, E. J. (2011). Dual Functionality of Myeloperoxidase in Rotenone-Exposed Brain-Resident Immune Cells. American Journal of Pathology, 179(2), 964-979. doi: 10.1016/j.ajpath.2011.04.033

Cherry, J. D., Olschowka, J. A., \& O'Banion, M. K. (2014). Neuroinflammation and M2 microglia: the good, the bad, and the inflamed. J Neuroinflammation, 11, 98. doi: 10.1186/1742-2094-11-98

Chhor, V., Le Charpentier, T., Lebon, S., Ore, M. V., Celador, I. L., Josserand, J., . . Fleiss, B. (2013). Characterization of phenotype markers and neuronotoxic potential of polarised primary microglia in vitro. Brain Behav Immun, 32, 70-85. doi: 10.1016/j.bbi.2013.02.005

Cho, H., Hashimoto, T., Wong, E., Hori, Y., Wood, L. B., Zhao, L., . . . Irimia, D. (2013). Microfluidic chemotaxis platform for differentiating the roles of soluble and bound amyloid-beta on microglial accumulation. Sci Rep, 3, 1823. doi: 10.1038/srep01823

Choi, J. K., Jenkins, B. G., Carreras, I., Kaymakcalan, S., Cormier, K., Kowall, N. W., \& Dedeoglu, A. (2010). Anti-inflammatory treatment in AD mice protects against neuronal pathology. Exp Neurol, 223(2), 377-384. doi: 10.1016/j.expneurol.2009.07.032

Choi, W. S., Kruse, S. E., Palmiter, R. D., \& Xia, Z. (2008). Mitochondrial complex I inhibition is not required for dopaminergic neuron death induced by rotenone, MPP+, or paraquat. Proc Natl Acad Sci $U$ S A, 105(39), 15136-15141. doi: 10.1073/pnas.0807581105

Combs, C. K., Karlo, J. C., Kao, S. C., \& Landreth, G. E. (2001). beta-Amyloid stimulation of microglia and monocytes results in TNFalpha-dependent expression of inducible nitric oxide synthase and neuronal apoptosis. J Neurosci, 21(4), 1179-1188. 
Crain, J. M., Nikodemova, M., \& Watters, J. J. (2013). Microglia express distinct M1 and M2 phenotypic markers in the postnatal and adult central nervous system in male and female mice. J Neurosci Res, 91(9), 1143-1151. doi: 10.1002/jnr.23242

Dheen, S. T., Kaur, C., \& Ling, E. A. (2007). Microglial activation and its implications in the brain diseases. Curr Med Chem, 14(11), 1189-1197.

Dibaj, P., Zschuntzsch, J., Steffens, H., Scheffel, J., Goricke, B., Weishaupt, J. H., . . Neusch, C. (2012). Influence of methylene blue on microglia-induced inflammation and motor neuron degeneration in the SOD1(G93A) model for ALS. PLoS One, 7(8), e43963. doi: 10.1371/journal.pone.0043963

DiCarlo, G., Wilcock, D., Henderson, D., Gordon, M., \& Morgan, D. (2001). Intrahippocampal LPS injections reduce Abeta load in APP+PS1 transgenic mice. Neurobiol Aging, 22(6), 1007-1012.

El Khoury, J., Hickman, S. E., Thomas, C. A., Loike, J. D., \& Silverstein, S. C. (1998). Microglia, scavenger receptors, and the pathogenesis of Alzheimer's disease. Neurobiol Aging, 19 (1 Suppl), S81-84.

ElAli, A., \& Rivest, S. (2015). Microglia in Alzheimer's disease: A multifaceted relationship. Brain Behav Immun. doi: 10.1016/j.bbi.2015.07.021

Elkabes, S., DiCicco-Bloom, E. M., \& Black, I. B. (1996). Brain microglia/macrophages express neurotrophins that selectively regulate microglial proliferation and function. $J$ Neurosii, 16(8), 2508-2521.

Elmore, M. R., Najafi, A. R., Koike, M. A., Dagher, N. N., Spangenberg, E. E., Rice, R. A., .. . Green, K. N. (2014). Colony-stimulating factor 1 receptor signaling is necessary for microglia viability, unmasking a microglia progenitor cell in the adult brain. Neuron, 82(2), 380-397. doi: 10.1016/j.neuron.2014.02.040

Emmrich, J. V., Hornik, T. C., Neher, J. J., \& Brown, G. C. (2013). Rotenone induces neuronal death by microglial phagocytosis of neurons. FEBS J, 280(20), 5030-5038. doi: $10.1111 /$ febs.12401

Fang, F., Lue, L. F., Yan, S., Xu, H., Luddy, J. S., Chen, D., . . . Yan, S. S. (2010). RAGEdependent signaling in microglia contributes to neuroinflammation, Abeta accumulation, and impaired learning/memory in a mouse model of Alzheimer's disease. FASEB J, 24(4), 1043-1055. doi: 10.1096/fj.09-139634

Ferger, A. I., Campanelli, L., Reimer, V., Muth, K. N., Merdian, I., Ludolph, A. C., \& Witting, A. (2010). Effects of mitochondrial dysfunction on the immunological properties of microglia. J Neuroinflammation, 7, 45. doi: 10.1186/1742-2094-7-45

Fiala, M., Zhang, L., Gan, X., Sherry, B., Taub, D., Graves, M. C., . . Roher, A. E. (1998). Amyloid-beta induces chemokine secretion and monocyte migration across a human blood--brain barrier model. Mol Med, 4(7), 480-489.

Flanary, B. E., Sammons, N. W., Nguyen, C., Walker, D., \& Streit, W. J. (2007). Evidence that aging and amyloid promote microglial cell senescence. Rejuvenation Res, 10(1), 61-74. doi: $10.1089 /$ rej.2006.9096

Floden, A. M., \& Combs, C. K. (2011). Microglia demonstrate age-dependent interaction with amyloid-beta fibrils. J Alzheimers Dis, 25(2), 279-293. doi: 10.3233/JAD-2011-101014

Franciosi, S., Choi, H. B., Kim, S. U., \& McLarnon, J. G. (2005). IL-8 enhancement of amyloid-beta (Abeta 1-42)-induced expression and production of pro-inflammatory cytokines and COX-2 in cultured human microglia. J Neuroimmunol, 159(1-2), 66-74. doi: 10.1016/j.jneuroim.2004.10.006 
Gao, F., Chen, D., Hu, Q., \& Wang, G. (2013). Rotenone directly induces BV2 cell activation via the p38 MAPK pathway. PLoS One, 8(8), e72046. doi: 10.1371/journal.pone.0072046

Gimeno-Bayon, J., Lopez-Lopez, A., Rodriguez, M. J., \& Mahy, N. (2014). Glucose pathways adaptation supports acquisition of activated microglia phenotype. J Neurosci Res, 92(6), 723-731. doi: 10.1002/jnr.23356

Giudetti, A. M., Romano, A., Lavecchia, A. M., \& Gaetani, S. (2015). The role of brain cholesterol and its oxidized products in Alzheimer's disease. Curr Alzheimer Res.

Hanisch, U. K., \& Kettenmann, H. (2007). Microglia: active sensor and versatile effector cells in the normal and pathologic brain. Nat Neurosci, 10(11), 1387-1394. doi: 10.1038/nn1997

Hickman, S. E., Allison, E. K., \& El Khoury, J. (2008). Microglial dysfunction and defective beta-amyloid clearance pathways in aging Alzheimer's disease mice. J Neurosci, 28(33), 8354-8360. doi: 10.1523/JNEUROSCI.0616-08.2008

Hjorth, E., Zhu, M., Toro, V. C., Vedin, I., Palmblad, J., Cederholm, T., . . . Schultzberg, M. (2013). Omega-3 fatty acids enhance phagocytosis of Alzheimer's disease-related amyloid-beta42 by human microglia and decrease inflammatory markers. $J$ Alz̧heimers Dis, 35(4), 697-713. doi: 10.3233/JAD-130131

Jourquin, J., Tremblay, E., Decanis, N., Charton, G., Hanessian, S., Chollet, A. M., . . Rivera, S. (2003). Neuronal activity-dependent increase of net matrix metalloproteinase activity is associated with MMP-9 neurotoxicity after kainate. Eur J Neurosci, 18(6), 1507-1517.

Jung, M. E., Wilson, A. M., \& Simpkins, J. W. (2006). A nonfeminizing estrogen analog protects against ethanol withdrawal toxicity in immortalized hippocampal cells. $J$ Pharmacol Exp Ther, 319(2), 543-550. doi: 10.1124/jpet.106.103630

Kettenmann, H., Hanisch, U. K., Noda, M., \& Verkhratsky, A. (2011). Physiology of microglia. Physiol Rev, $91(2), 461-553$. doi: 10.1152/physrev.00011.2010

Kim, H. J., Ajit, D., Peterson, T. S., Wang, Y., Camden, J. M., Gibson Wood, W., . . . Weisman, G. A. (2012). Nucleotides released from Abeta(1)(-)(4)(2) -treated microglial cells increase cell migration and Abeta(1)(-)(4)(2) uptake through P2Y(2) receptor activation. J Neurochem, 121(2), 228-238. doi: 10.1111/j.1471-4159.2012.07700.x

Kim, S. H., Han, S. Y., Azam, T., Yoon, D. Y., \& Dinarello, C. A. (2005). Interleukin-32: a cytokine and inducer of TNFalpha. Immunity, 22(1), 131-142. doi: 10.1016/j.immuni.2004.12.003

Kiyota, T., Okuyama, S., Swan, R. J., Jacobsen, M. T., Gendelman, H. E., \& Ikezu, T. (2010). CNS expression of anti-inflammatory cytokine interleukin-4 attenuates Alzheimer's disease-like pathogenesis in APP+PS1 bigenic mice. FASEB J, 24(8), 3093-3102. doi: 10.1096/fj.10-155317

Koenigsknecht, J., \& Landreth, G. (2004). Microglial phagocytosis of fibrillar beta-amyloid through a beta1 integrin-dependent mechanism. J Neurosci, 24(44), 9838-9846. doi: 10.1523/JNEUROSCI.2557-04.2004

Lambert, M. P., Viola, K. L., Chromy, B. A., Chang, L., Morgan, T. E., Yu, J., . . Klein, W. L. (2001). Vaccination with soluble Abeta oligomers generates toxicity-neutralizing antibodies. J Neurochem, 79(3), 595-605.

Lee, C. Y., \& Landreth, G. E. (2010). The role of microglia in amyloid clearance from the AD brain. J Neural Transm, 117(8), 949-960. doi: 10.1007/s00702-010-0433-4 
Lee, D. C., Rizer, J., Hunt, J. B., Selenica, M. L., Gordon, M. N., \& Morgan, D. (2013). Review: experimental manipulations of microglia in mouse models of Alzheimer's pathology: activation reduces amyloid but hastens tau pathology. Neuropathol Appl Neurobiol, 39(1), 69-85. doi: 10.1111/nan.12002

Lee, S., Varvel, N. H., Konerth, M. E., Xu, G., Cardona, A. E., Ransohoff, R. M., \& Lamb, B. T. (2010). CX3CR1 deficiency alters microglial activation and reduces beta-amyloid deposition in two Alzheimer's disease mouse models. Am J Pathol, 177(5), 2549-2562. doi: 10.2353/ajpath.2010.100265

Lim, G. P., Yang, F., Chu, T., Chen, P., Beech, W., Teter, B., . . . Cole, G. M. (2000). Ibuprofen suppresses plaque pathology and inflammation in a mouse model for Alzheimer's disease. J Neurosci, 20(15), 5709-5714.

Logan, S. M., Sarkar, S. N., Zhang, Z., \& Simpkins, J. W. (2011). Estrogen-induced signaling attenuates soluble Abeta peptide-mediated dysfunction of pathways in synaptic plasticity. Brain Res, 1383, 1-12. doi: 10.1016/j.brainres.2011.01.038

Lyons, A., Murphy, K. J., Clarke, R., \& Lynch, M. A. (2011). Atorvastatin prevents age-related and amyloid-beta-induced microglial activation by blocking interferon-gamma release from natural killer cells in the brain. J Neuroinflammation, 8, 27. doi: 10.1186/1742-2094$8-27$

Maezawa, I., Zimin, P. I., Wulff, H., \& Jin, L. W. (2011). Amyloid-beta protein oligomer at low nanomolar concentrations activates microglia and induces microglial neurotoxicity. $J$ Biol Chem, 286(5), 3693-3706. doi: 10.1074/jbc.M110.135244

Mattson, M. P. (2004). Pathways towards and away from Alzheimer's disease. Nature, 430(7000), 631-639. doi: 10.1038/nature02621

McGeer, P. L., Itagaki, S., Tago, H., \& McGeer, E. G. (1987). Reactive microglia in patients with senile dementia of the Alzheimer type are positive for the histocompatibility glycoprotein HLA-DR. Neurosci Lett, 79(1-2), 195-200.

McKhann, G., Drachman, D., Folstein, M., Katzman, R., Price, D., \& Stadlan, E. M. (1984). Clinical diagnosis of Alzheimer's disease: report of the NINCDS-ADRDA Work Group under the auspices of Department of Health and Human Services Task Force on Alzheimer's Disease. Neurology, 34(7), 939-944.

Michelucci, A., Heurtaux, T., Grandbarbe, L., Morga, E., \& Heuschling, P. (2009). Characterization of the microglial phenotype under specific pro-inflammatory and anti-inflammatory conditions: Effects of oligomeric and fibrillar amyloid-beta. $J$ Neuroimmunol, 210(1-2), 3-12. doi: 10.1016/j.jneuroim.2009.02.003

Morgan, D. (2009). The role of microglia in antibody-mediated clearance of amyloid-beta from the brain. CNS Neurol Disord Drug Targets, 8(1), 7-15.

Morris, G. P., Clark, I. A., Zinn, R., \& Vissel, B. (2013). Microglia: a new frontier for synaptic plasticity, learning and memory, and neurodegenerative disease research. Neurobiol Learn Mem, 105, 40-53. doi: 10.1016/j.nlm.2013.07.002

Nagano, T., Kimura, S. H., \& Takemura, M. (2010). Prostaglandin E2 reduces amyloid betainduced phagocytosis in cultured rat microglia. Brain Res, 1323, 11-17. doi: 10.1016/j.brainres.2010.01.086

Nimmerjahn, A., Kirchhoff, F., \& Helmchen, F. (2005). Resting microglial cells are highly dynamic surveillants of brain parenchyma in vivo. Science, 308(5726), 1314-1318. doi: $10.1126 /$ science. 1110647 
Nolan, Y., Maher, F. O., Martin, D. S., Clarke, R. M., Brady, M. T., Bolton, A. E., . . Lynch, M. A. (2005). Role of interleukin-4 in regulation of age-related inflammatory changes in the hippocampus. J Biol Chem, 280(10), 9354-9362. doi: 10.1074/jbc.M412170200

Papadopoulos, V., Lecanu, L., Brown, R. C., Han, Z., \& Yao, Z. X. (2006). Peripheral-type benzodiazepine receptor in neurosteroid biosynthesis, neuropathology and neurological disorders. Neuroscience, 138(3), 749-756. doi: 10.1016/j.neuroscience.2005.05.063

Parajuli, B., Sonobe, Y., Horiuchi, H., Takeuchi, H., Mizuno, T., \& Suzumura, A. (2013). Oligomeric amyloid beta induces IL-1beta processing via production of ROS: implication in Alzheimer's disease. Cell Death Dis, 4, e975. doi: 10.1038/cddis.2013.503

Park, J., Choi, H., Min, J. S., Park, S. J., Kim, J. H., Park, H. J., . . . Lee, D. S. (2013). Mitochondrial dynamics modulate the expression of pro-inflammatory mediators in microglial cells. J Neurochem, 127(2), 221-232. doi: 10.1111/jnc.12361

Perez-Nievas, B. G., Stein, T. D., Tai, H. C., Dols-Icardo, O., Scotton, T. C., Barroeta-Espar, I., . . . Gomez-Isla, T. (2013). Dissecting phenotypic traits linked to human resilience to Alzheimer's pathology. Brain, 136(Pt 8), 2510-2526. doi: 10.1093/brain/awt171

Perry, V. H., Nicoll, J. A., \& Holmes, C. (2010). Microglia in neurodegenerative disease. Nat Rev Neurol, 6(4), 193-201. doi: 10.1038/nrneurol.2010.17

Persaud-Sawin, D. A., Banach, L., \& Harry, G. J. (2009). Raft aggregation with specific receptor recruitment is required for microglial phagocytosis of Abeta42. Glia, 57(3), 320-335. doi: 10.1002/glia.20759

Ponomarev, E. D., Shriver, L. P., \& Dittel, B. N. (2006). CD40 expression by microglial cells is required for their completion of a two-step activation process during central nervous system autoimmune inflammation. J Immunol, 176(3), 1402-1410.

Querfurth, H. W., \& LaFerla, F. M. (2010). Alzheimer's disease. N Engl J Med, 362(4), 329-344. doi: $10.1056 /$ NEJMra0909142

Raichle, M. E., \& Gusnard, D. A. (2002). Appraising the brain's energy budget. Proc Natl Acad Sci U S A, 99(16), 10237-10239. doi: 10.1073/pnas.172399499

Reed-Geaghan, E. G., Savage, J. C., Hise, A. G., \& Landreth, G. E. (2009). CD14 and toll-like receptors 2 and 4 are required for fibrillar A \{beta\}-stimulated microglial activation. $J$ Neurosci, 29(38), 11982-11992. doi: 10.1523/JNEUROSCI.3158-09.2009

Salloway, S., Sperling, R., Gilman, S., Fox, N. C., Blennow, K., Raskind, M., . . Bapineuzumab 201 Clinical Trial, I. (2009). A phase 2 multiple ascending dose trial of bapineuzumab in mild to moderate Alzheimer disease. Neurology, 73(24), 2061-2070. doi: 10.1212/WNL.0b013e3181c67808

Sanz, J. M., Chiozzi, P., Ferrari, D., Colaianna, M., Idzko, M., Falzoni, S., . . . Di Virgilio, F. (2009). Activation of microglia by amyloid \{beta\} requires P2X7 receptor expression. J Immunol, 182(7), 4378-4385. doi: 10.4049/jimmunol.0803612

Sastre, M., Richardson, J. C., Gentleman, S. M., \& Brooks, D. J. (2011). Inflammatory risk factors and pathologies associated with Alzheimer's disease. Curr Aląheimer Res, 8(2), 132-141.

Scheffel, J., Regen, T., Van Rossum, D., Seifert, S., Ribes, S., Nau, R., . . . Hanisch, U. K. (2012). Toll-like receptor activation reveals developmental reorganization and unmasks responder subsets of microglia. Glia, 60(12), 1930-1943. doi: 10.1002/glia.22409 
Schenk, D., Barbour, R., Dunn, W., Gordon, G., Grajeda, H., Guido, T., . . . Seubert, P. (1999). Immunization with amyloid-beta attenuates Alzheimer-disease-like pathology in the PDAPP mouse. Nature, 400(6740), 173-177. doi: 10.1038/22124

Schmidt, A. M., Yan, S. D., Yan, S. F., \& Stern, D. M. (2001). The multiligand receptor RAGE as a progression factor amplifying immune and inflammatory responses. J Clin Invest, 108(7), 949-955. doi: 10.1172/JCI14002

Serrano-Pozo, A., Gomez-Isla, T., Growdon, J. H., Frosch, M. P., \& Hyman, B. T. (2013). A phenotypic change but not proliferation underlies glial responses in Alzheimer disease. Am J Pathol, 182(6), 2332-2344. doi: 10.1016/j.ajpath.2013.02.031

Sheedy, F. J., Grebe, A., Rayner, K. J., Kalantari, P., Ramkhelawon, B., Carpenter, S. B., . . . Moore, K. J. (2013). CD36 coordinates NLRP3 inflammasome activation by facilitating intracellular nucleation of soluble ligands into particulate ligands in sterile inflammation. Nat Immunol, 14(8), 812-820. doi: 10.1038/ni.2639

Sierra, A., Encinas, J. M., Deudero, J. J., Chancey, J. H., Enikolopov, G., Overstreet-Wadiche, L. S., . . . Maletic-Savatic, M. (2010). Microglia shape adult hippocampal neurogenesis through apoptosis-coupled phagocytosis. Cell Stem Cell, 7(4), 483-495. doi: 10.1016/j.stem.2010.08.014

Song, M., Jin, J., Lim, J. E., Kou, J., Pattanayak, A., Rehman, J. A., . . . Fukuchi, K. (2011). TLR4 mutation reduces microglial activation, increases Abeta deposits and exacerbates cognitive deficits in a mouse model of Alzheimer's disease. J Neuroinflammation, 8, 92. doi: 10.1186/1742-2094-8-92

Sonkar, V. K., Kulkarni, P. P., \& Dash, D. (2014). Amyloid beta peptide stimulates platelet activation through RhoA-dependent modulation of actomyosin organization. FASEB J, 28(4), 1819-1829. doi: 10.1096/fj.13-243691

Spuch, C., Ortolano, S., \& Navarro, C. (2012). New insights in the amyloid-Beta interaction with mitochondria. I Aging Res, 2012, 324968. doi: 10.1155/2012/324968

Tremblay, M. E., Stevens, B., Sierra, A., Wake, H., Bessis, A., \& Nimmerjahn, A. (2011). The role of microglia in the healthy brain. J Neurosci, 31(45), 16064-16069. doi: 10.1523/JNEUROSCI.4158-11.2011

Varnum, M. M., \& Ikezu, T. (2012). The classification of microglial activation phenotypes on neurodegeneration and regeneration in Alzheimer's disease brain. Arch Immunol Ther Exp (Warsq), 60(4), 251-266. doi: 10.1007/s00005-012-0181-2

Venneti, S., Lopresti, B. J., \& Wiley, C. A. (2006). The peripheral benzodiazepine receptor (Translocator protein 18kDa) in microglia: from pathology to imaging. Prog Neurobiol, 80(6), 308-322. doi: 10.1016/j.pneurobio.2006.10.002

Vina, J., \& Lloret, A. (2010). Why women have more Alzheimer's disease than men: gender and mitochondrial toxicity of amyloid-beta peptide. J Alsheimers Dis, 20 Suppl 2, S527533. doi: 10.3233/JAD-2010-100501

Wake, H., Moorhouse, A. J., Jinno, S., Kohsaka, S., \& Nabekura, J. (2009). Resting microglia directly monitor the functional state of synapses in vivo and determine the fate of ischemic terminals. J Neurosci, 29(13), 3974-3980. doi: 10.1523/JNEUROSCI.436308.2009

Yan, J. J., Cho, J. Y., Kim, H. S., Kim, K. L., Jung, J. S., Huh, S. O., . . Song, D. K. (2001). Protection against beta-amyloid peptide toxicity in vivo with long-term administration of ferulic acid. BrJ Pharmacol, 133(1), 89-96. doi: 10.1038/sj.bjp.0704047 
Yang, Y. M., Shang, D. S., Zhao, W. D., Fang, W. G., \& Chen, Y. H. (2013). Microglial TNFalpha-dependent elevation of MHC class I expression on brain endothelium induced by amyloid-beta promotes $\mathrm{T}$ cell transendothelial migration. Neurochem Res, 38(11), 2295-2304. doi: 10.1007/s11064-013-1138-5

Yankner, B. A., Duffy, L. K., \& Kirschner, D. A. (1990). Neurotrophic and neurotoxic effects of amyloid beta protein: reversal by tachykinin neuropeptides. Science, 250(4978), 279282.

Yao, J., Irwin, R. W., Zhao, L., Nilsen, J., Hamilton, R. T., \& Brinton, R. D. (2009). Mitochondrial bioenergetic deficit precedes Alzheimer's pathology in female mouse model of Alzheimer's disease. Proc Natl Acad Sci US A, 106(34), 14670-14675. doi: 10.1073/pnas.0903563106

Yu, Y., \& Ye, R. D. (2014). Microglial Abeta Receptors in Alzheimer's Disease. Cell Mol Neurobiol. doi: 10.1007/s10571-014-0101-6 